\title{
Inappropriate Sexual Behaviour and Dementia; an Exploration of Staff Experiences
}

\author{
Laura E. Hayward \\ BSc (Hons) \\ Submitted in partial fulfilment of the requirements of the \\ Doctorate in Clinical Psychology \\ University of Leicester \\ April 2009
}


Declaration.......................................................6 6

Acknowledgments................................................ 7

Word Count........................................................ 8

Thesis Abstract.................................................... 9

\section{Literature Review}

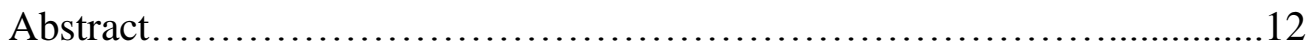

1. Introduction ..................................................... 14

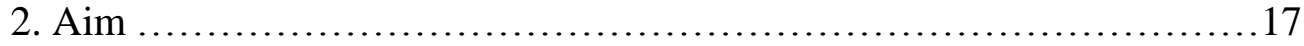

3. Methods......................................................... 17

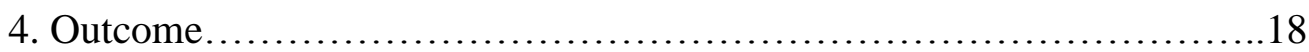

5. Quality Appraisal.................................................. 19

6. Data Abstraction...................................................20

7. Results.......................................................27

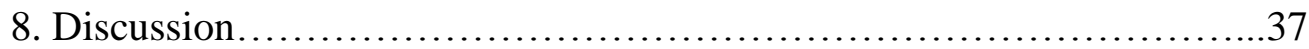

9. Limitations ......................................................... 40

10. Clinical Implications.........................................41

11. Further Research.................................................41

12. Conclusion................................................... 42

References.....................................................43

Appendices.......................................................51

\section{Empirical Paper}

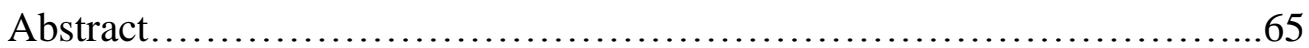

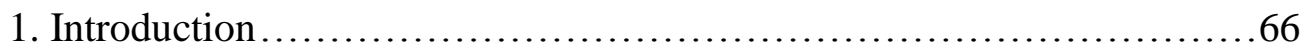

2. Aim ......................................................... 69

3. Context....................................................... 70

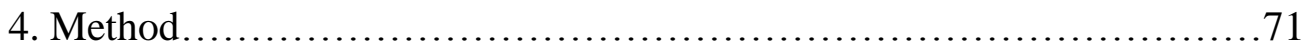

5. Procedure....................................................... 75

6. Analysis.................................................... 81

7. Quality Issues.................................................. 84

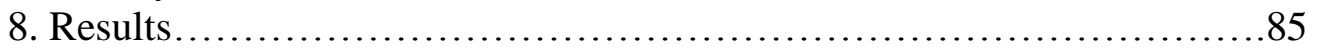

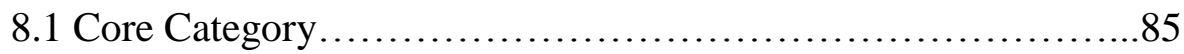

8.2 Process Model.........................................88

8.2.1 Main Category: Beyond My Construing...............88

8.2.2 Main Category: Contextualising.....................92

8.2.3 Main Category: Interpreting........................103

8.2.4 Main Category: "Dealing With"....................111

9. Discussion..................................................... 123

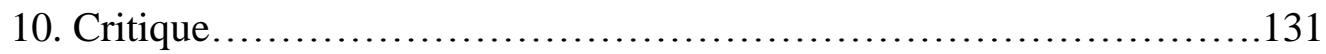

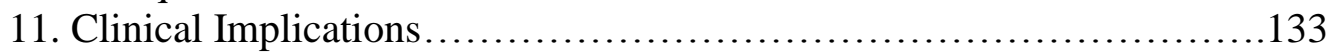

12. Further Research................................................... 134 


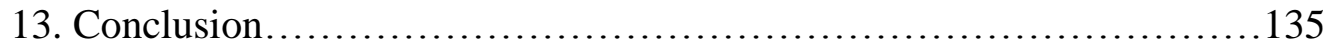

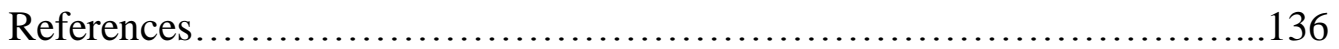

\section{Critical Appraisal}

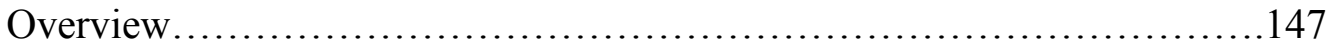

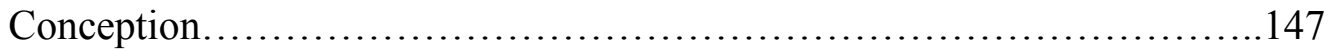

Methodology ......................................................... 148

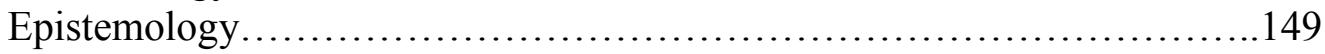

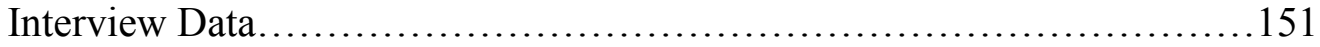

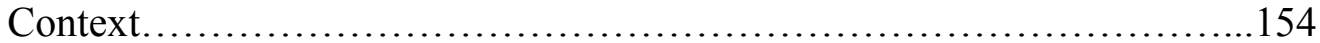

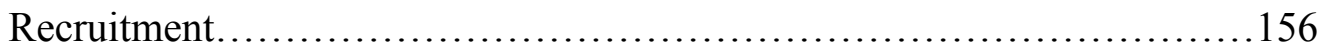

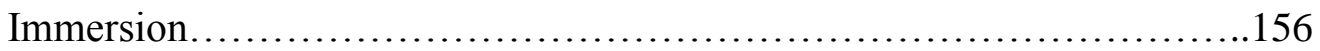

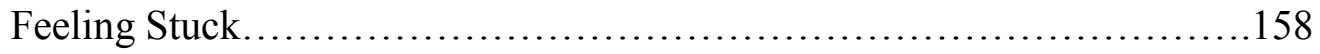

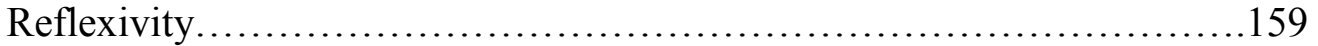

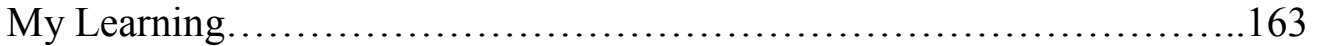

Concluding Thoughts..................................................... 166

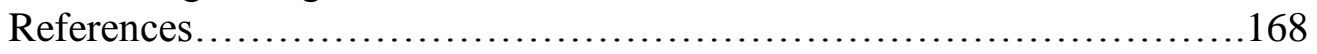

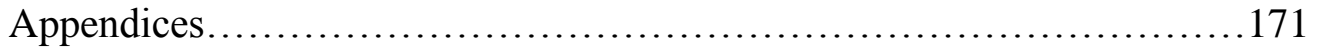




\section{List of Tables}

\section{Literature Review}

Table 1. Aims and themes of the reviewed studies...............................21

Table 2. A Summary of data analysis.......................................... 59

\section{Empirical Paper}

Table 1. Modified transcribing conventions 


\section{List of Figures}

\section{Empirical Paper}

Figure 1. Diagrammatic representation of the data collection process and analysis....78

Figure 2. Core Category: A Question of Attribution........................... 87

Figure 3. Beyond My Construing......................................... 89

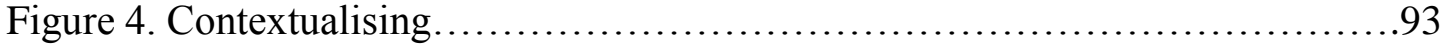

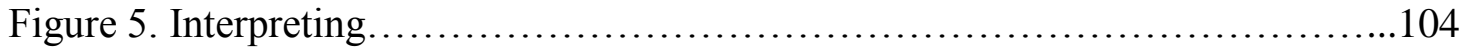

Figure 6. "Dealing With" ................................................. 112 


\section{Declaration}

This thesis has been submitted in partial fulfilment of the degree of Doctorate in Clinical Psychology. It is based on work conducted by the author in the Department of Clinical Psychology at the University of Leicester between October 2006 and April 2009. All of the work recorded in this thesis is original unless otherwise acknowledged in the text or by references. None of the work has been submitted for another degree in this or any other University. 


\section{Acknowledgements}

I am extremely thankful to the fourteen people who agreed to take part in my research. Without you, this would not have been possible.

To Noelle and Caroline for your encouragement, support, inspiration and faith. I have truly appreciated it.

To my entire cohort, especially Becky, Sue and Nicola, for your kind words, curiosity, thoughtfulness and general containment over the last year (and then some).

To my supervisors; Jules, Deb, Tracey, Jo, Maria and Alison. Your genuine interest and understanding were valued.

To Mia; thank you for making me smile when things seemed tough and I could not get out into my garden.

To my family. Your love, belief and pride have taken me far. I am and will always be grateful that I have such wonderful and kind people in my life.

Finally, to My Tom. I have so much to thank you for, especially your belief in me when I had lost mine, your patience and just for being you. Here is to us, Egypt and our Lotus. I love you loads. 


\section{Word Count}

Without References/Tables With References/Tables

$\begin{array}{lcc}\text { Literature Review } & 5821 & 8742 \\ \text { Empirical Paper } & 12878 & 14694 \\ \text { Critical Appraisal } & 4720 & 5147 \\ \text { Total } & \mathbf{2 3 , 4 1 9} & \mathbf{2 8 , 5 8 3}\end{array}$




\title{
Thesis Abstract
}

\section{Inappropriate Sexual Behaviour and Dementia; an Exploration of Staff Experiences}

\author{
Laura E. Hayward
}

\begin{abstract}
Literature Review
Dementia care in acute services is under researched, not least an examination of the emotional impact of the work. This review aimed to explore and synthesise the available literature regarding the experiences of staff in acute care settings. A systematic review was conducted using systematic and transparent methods. Themes, as experienced and described by staff, included environmental inadequacies and insufficient knowledge of dementia. The emotional impact of the work was elicited and areas of enlightened practice were indicated.

Supporting patients with a dementia in the acute care setting appears to be complicated by a range of influences including case complexity, insufficient resources and staff constructions of the patient. The review highlighted areas of need as identified by staff.
\end{abstract}

\section{Empirical Paper}

Research assessing the impact of Inappropriate Sexual Behaviour (ISB) on staff working in dementia care is circumscribed. This study explored staff experience of ISB exhibited by older adults with a dementia. Interviews with fourteen staff working within an inpatient setting were undertaken and analysed using a Grounded Theory methodology.

The core category, 'A Question of Attribution' was identified, describing the process experienced when confronted with ISB. Four main categories were inducted representing participants initial experiences, their contextualising of the behaviour, their process of interpretation and pragmatic management of ISB. Staff's feelings about ISB appeared equivocal with some staff reporting indifference, others feeling violated.

Findings imply that the impact of ISB should be more routinely considered in preparing staff for working with patients with a dementia.

\section{Critical Appraisal}

This paper outlined numerous reflections and observations made during the research journey with consideration of the chosen methodology, study limitations and the personal impact of conducting the research, in addition to the learning experience.

\section{Word Count: 298}




\section{Literature Review}

Staff Experiences of Working with Older People with a Dementia in Acute Care; a Qualitative Literature Review 


\section{Note on style}

The following literature review has been written in accordance with the requirements of the Journal of Advanced Nursing ${ }^{*}$. Guidelines for contributors have been adhered to where possible unless they contravene University of Leicester requirements for the thesis submitted in partial fulfilment of the Doctorate in Clinical Psychology.

${ }^{*}$ See Appendix 1 for Notes to Contributors 


\begin{abstract}
Aims

To explore and synthesise the available literature regarding the experiences of staff in acute care settings working with patients who have a dementia.

\section{Background}

Dementia care in acute services is under researched. A systematic exploration of the experiences of staff in this context has been overlooked, not least an examination of the emotional impact of the work. Understanding these experiences may enhance acute care for patients and importantly support staff in enhancing self-care practices.

\section{Data Sources}

Cumulative Index of Nursing and Allied Health Literature, British Nursing Index, Psychinfo, Medline, Scopus, Web of Science plus manual searching.

\section{Method}

A systematic review was conducted between December 2008 and January 2009 yielding eight articles, all qualitative. Systematic and transparent methods were used to analyse the data (Meyrick, 2006) and a synthetic analysis of the themes was undertaken.
\end{abstract}

\title{
Results
}

Most papers were exploratory but whilst providing a rich account of staff experiences did not generate theory. Themes described working environment and management that were regarded as inadequate in meeting the needs of the client group. Difficulties in responding to disruptive/aggressive behaviours were well documented as were limitations in professional resources, including knowledge of dementia. The emotional impact of working with patients with a dementia was elicited by staff as was the staff-patient relationship, with evidence of some enlightened practice. Ethics and ethical care were also considered.

\section{Conclusion}

Staff experiences as reported in the reviewed studies indicate that supporting patients with a dementia in the acute care setting is complicated by a range of influences including perceived case complexity, inappropriate environment and insufficient resources. This review has highlighted staff needs as identified and described by them.

\section{Keywords}

Qualitative review, Dementia, acute medical ward, general medical setting, nurs*, staff, experience*

\section{Word count: 286}


"The World Health Organization (WHO) embraces a definition of health as "physical, mental, and social well-being". Of these elements, mental well-being historically has been misunderstood and often forgotten"

(WHO, 2005, pIV).

"Good nursing practice is more than caring for machinery; it includes the ability to make people feel valued, no matter their age or disorder"

(McLafferty \& Morrison, 2004, p453).

"If you're diagnosed with early onset Alzheimer's, you feel as though you're standing on a beach and the tide has gone out and so has everybody else. There's no one there."

Sir Terry Pratchett (2008) 


\section{Introduction}

The human cost of dementia, "a collection of symptoms, including a decline in memory, reasoning and communication skills, and a gradual loss of skills needed to carry out daily activities" (Alzheimer's Society, 2007, p.12) is profound. There are an estimated 24.3 million people with a dementia worldwide, 700,000 of whom live in the UK (Department of Health, DoH, 2009). As people live longer the predicted prevalence in the UK is expected to rise to $1,735,087$, by 2051, an increase of $154 \%$ (Alzheimer's Society, 2007) with the cost of responding to dementia more than the total expenditure relating to stroke, cancer and heart disease combined in England alone (Care Services Improvement Partnership, 2005). Responding to those affected by dementia will require significantly more resources and such demands are shaping evolving international policy, especially with regards to early detection (DoH, 2009; Department of Health and Ageing, 2006; National Institute of Health and Clinical Excellence, NICE, 2006).

\section{Acute Care}

Dementia care in acute settings is a focus of burgeoning research (Birrer, Singh \& Kumar, 1999; Dewing, 2001; McCloskey, 2004; Moyle, Olorenshaw, Wallis \& Borbasi, 2008; O’Connell et al, 2007; Pritchard \& Dewing, 2001) with approximately two thirds of acute beds occupied by people over 65 and between $18 \%$ and $41 \%$ of Accident and Emergency (A \& E) admissions attributed to older adults (Cunningham \& McWilliam, 2006; Downing \& Wilson, 2005). A clinically significant proportion of these people will have a dementia (Royal College of Psychiatrists, RCP, 2005), which in acute settings is known to be under recognised, poorly assessed and where identified not necessarily 
linked with appropriate care planning (Birrer et al, 1999; Cunningham \& McWilliam, 2006; DoH, 2009; Park, Delaney, Mass \& Reed, 2004; Tolson, Smith \& Knight, 1999).

Balancing the needs of this patient group with competing organisational demands is complex. People with a dementia tend to suffer from a range of co-morbidities, most commonly hypertension, cardiac dysrythmias, urinary tract infections and delirium (Park et al, 2004; RCP, 2005). Such combinations of acute physical illness and dementia can mean deferred discharge (Park et al, 2004), counter to directives to reduce long-stay care and release patients promptly from acute beds (Cunningham \& Archibald, 2006).

\section{Dementia Care in Acute Settings}

Caring for people with a dementia in what is often an extremely stressful physical environment (McCloskey, 2004) is highly demanding (Tolson et al, 1999). Meeting the needs of this group within a service geared primarily towards physical healthcare is further complicated by the marginalisation and ageist stereotypes of older adults, including those with cognitive impairment, that are perpetuated through staff attitudes (Higgins, Slater, Van Der Riet \& Peek, 2007; Kitwood, 1997; Neville, 2008), service organisation (DoH, 2001; RCP, 2005; Woods, 2003) and society (Townsend 2006).

\section{Impact on Staff}

Providing responsive, person-centred care is fundamental when caring for a person with a dementia (Cunningham, 2006) and can be undermined by strain (Hallberg \& Norberg, 1995). Whilst there exists an extensive literature on the psychological, emotional and physical impact of caring for someone with a dementia regarding informal/familial 
caregivers (Etters, Goodall \& Harrison, 2008; Mayer, 2001; Robertson, Zarit, Duncan, Rovine \& Femia, 2007), comparative research regarding professional caregivers ${ }^{\dagger}$ is in its infancy (Mackenzie \& Peragine, 2003). Studies examining the impact on staff appear focused on specialist settings for older adults, including long-term care contexts (Josefsson, Sonde \& Robins Wahlin, 2007; Pekkarinen et al, 2006). Research investigating older adults within acute settings has indicated that staff experience distress regarding the inadequate care they provide (Higgins et al, 2007). However, the scarce literature focused on older people with a dementia in acute care appears to be defined by addressing knowledge and attitudes (Moyle et al, 2008), the latter of which is generally fraught with inconsistencies and neglects the realities, complexities and subtleties of knowledge production in relation to nursing ageism (Herdman, 2002).

In their review examining best practice principles and models of care regarding people with a dementia, Moyle et al (2008) raised the complexities of dementia care in acute settings. However, a systematic exploration of the experiences and perceptions of staff working in acute settings and encountering patients with a dementia appears to have been neglected in the literature particularly an examination of the emotional impact of the work and support structures. Further, studies such as that of Moyle et al (2008) have not reflected the experiences of other staff, for example allied health professionals, who might have different perspectives. It is hoped that understanding these experiences may strengthen the case for additional resources and development in acute care for the benefit of patients and importantly support staff in enhancing self-care practices.

\footnotetext{
† Professional caregivers will be referred to as 'staff'.
} 


\section{Aim}

The aim of this review was to synthesise the available literature regarding the subjective experiences of staff working with patients who have a dementia in acute care settings using systematic and transparent methods (Meyrick, 2006). Previous studies have understandably focused on nursing staff given the primacy of their continuing care role. Although this author recognised the central status afforded to this particular staff group (Higgins et al, 2007) a decision was made to broaden the review to multi-professionals given that dementia care can involve multi-disciplinary involvement with potential cultural transmissions of attitudes and beliefs.

\section{Methods}

\section{Search Strategy}

An initial search of the literature revealed no pre-existing reviews. Between the $5^{\text {th }}$ December 2008 and the $15^{\text {th }}$ January 2009 the following electronic databases were searched: Cumulative Index of Nursing and Allied Health Literature, British Nursing Index, Psychinfo, Medline, Scopus and Web of Science in addition to manually searching the references of relevant articles for additional papers. Three authors in the field were contacted for further/unpublished work (Bezzant; Meyer, Bridges \& Spilsbury; Norman $^{\ddagger}$ ). No time limit was applied to the search.

\footnotetext{
* Attempts to contact Rachel Norman failed; no valid email address could be found.
} 


\section{Search Terms}

Dementia OR Alzheimer* OR cognitive impairment AND acute medical ward OR general medical setting OR accident and emergency AND nurs* OR staff OR profession* AND experience* OR attitude* OR view* OR emotion* OR affect* OR perception* (an asterisk represents truncation). Peer review and English were stipulated from the outset.

\section{Inclusion criteria}

- Research that explored staff experiences of working with older patients with a dementia in acute care settings.

\section{Exclusion criteria}

- Intervention studies were excluded (e.g., education) as they were judged to be pre-emptive/assumptive.

- Correspondence, brief commentaries and books.

\section{Outcome}

After examining the abstracts generated from searching and removing duplications, 100 articles were identified as potentially relevant and obtained in full. Nine articles appeared to fit the inclusion criteria but after scrutiny, one was rejected due to insufficient detail regarding data collection and analysis (Atkin, Holmes \& Martin, 2005). Cheek and Gibson (2003) explored the perceptions of nurses caring for older adults more generally; however, their paper devoted a substantial part of its content to staff experiences of working with patients with a dementia and was included in this review. Similarly, the 
focus of Norman's (2006) observational study was to “explore what happens to a person with dementia when admitted to a ward in a general hospital" (p. 454). Given that her observations included both patients and staff it was judged to meet the inclusion criteria. Eight studies thus comprise this review and are asterisked in the reference section. To note, one paper (Jones, Borbasi, Nankivell \& Lockwood, 2006) was 'one facet' of a larger study (Borbasi, Jones, Lockwood \& Emden, 2006) and utilised the same data with slightly different focus and analysis. All of the studies were qualitative since no quantitative studies matched the inclusion criteria. The countries of origin comprised Australia $(\mathrm{N}=3)$, the UK $(\mathrm{N}=2)$, Ireland $(\mathrm{N}=1)$, Canada $(\mathrm{N}=1)$ and Sweden $(\mathrm{N}=1)$.

\section{Quality Appraisal}

Meyrick's (2006) pluralistic overview was used to assess the quality of the studies. Transparency and systematicity have been identified as key indicators of rigour and quality (see Appendix 2) and were used in producing this review.

\section{Reflexivity}

Reviews can be complicated by the reviewers own stance (Sandelowski, 2008) as his/her own influences are inevitably brought to bear on a review even if systematic in approach.

This author has seven years clinical experience within the National Health Service, two of which have been spent in older adult services including Intermediate Care for older people with a dementia. This author had a clinical interest in staff experiences of working in mental health and was conducting research regarding staff experiences of 
inappropriate sexual behaviour exhibited by patients with a dementia within a specialist inpatient unit. This author had no experience of working within acute, medical settings.

This author recognised that her interest in staff experiences and in particular her concern regarding the psychological effects of working with this client group had the potential to shape the findings. Furthermore, this author was aware that her optimistic stance might influence the results by unduly highlighting areas of positive practice. Methods to minimise these influences are detailed below.

\section{Data Abstraction}

A data extraction sheet based on Meyrick's (2006) framework was developed in order to facilitate value judgments about the quality and rigour of the studies (Appendix 3).

\section{Synthesis}

Guidance on how to conduct a narrative synthesis was sought (Popay et al, 2006) and an inductive thematic analysis was used to identify, analyse and report themes (see Braun \& Clarke, 2006). This method had the benefit of grounding the themes within the studies and thus minimising potential sources of undue influence, as previously mentioned.

Regarding the process, each paper was read and re-read allowing this author to become familiar with the material. To enable comparison and synthesis of findings the aims and themes of each study were constructed in a table (Table 1). Themes were then extracted, further analysed and grouped accordingly. This was achieved by literally cutting out each theme and manually arranging them on a table in order to identify significant themes and relationships between themes. 
Table 1: Aims, Themes and Conclusions of the Reviewed Studies

\begin{tabular}{ll} 
Reference & Aims \\
\hline 1. Borbasi, & Exploration of healthcare \\
Jones, & professional's experiences of \\
Lockwood \& & managing patients with dementia \\
Emden (2006) & who have acute physical health \\
S. Australia & problems.
\end{tabular}

\section{Cheek \& \\ Gibson \\ (2003) \\ the issues for nurses caring for older people in acute care}

Australia
Themes

1. Environment Unfamiliarity (patients towards environment \& staff towards patients); inability to provide security; challenging behaviour affecting staffing needs; difficulties finding staff to care for patients

2. Organisation System under pressure; no time; patients require more time for basic tasks; inadequate management; lack of assessment and knowledge; primacy of medical model; delayed services; justifying why patient still in hospital 3. Key players - Patient Challenging, complex, requiring more thought and supervision; unable to provide history; dementia specialists getting to the root more quickly; requiring more resources Family - assets, supporting family, conflict protecting patients Staff - Shared perspectives; importance of MDT, nursing staff instrumental; some staff "reasonably tolerant and knowledgeable" stereotyping; judging, occluding the person; surgical teams seen as less sympathetic; staff in aged care more sympathetic

1. Complexity Managing care of people with dementia most challenging aspect; understanding how acute illness impacts on dementia; staff pressures; use of chemical and physical restraints in absence of expertise; lack of support from colleagues; medical staff
Conclusions

1. The physical environment presents a risk

2. Health professionals do not possess adequate skills to deliver dementia care

3 . Best practice principles are required from higher management

4. The needs of patients with a dementia are complex
1. Registered nurses are critical in MDTs caring for older people 2 . Nursing practice is affected by the complex needs of this population, the environment, disparate and insufficient resources 
lacking expertise

2. Problematic environment Layout; structure; patient mix; pace; noise; exposure to

different staff; rigid routines

\section{3. 'Heavy' work Patients with a dementia} contribute to 'heaviness' of caseload

\section{Drayton, Description of how a MDT}

Canter \&

Allen

(2003)

Canada responded to the needs of a patient with a dementia and multiple physical health problems in an acute care setting
1. Medical issues Managing co-morbidities; non-compliance of treatments; readmissions; assessing cognitive status

2. Aggression Extremely stressful setting; staff feeling personally abused; undermined person-centred care; consulting psychiatry

3. Ethical/legal issues Dilemma of promoting patient autonomy whilst responding to family concerns; consulting mission statement; conflict; seeking ethical advice.

4. Team perspective Feeling daunted; repeatedly explaining treatment; verbal abuse; agonizing over interaction with patient; satisfaction from team discussion; avoiding splits; time needed to work with patient; distress hope/relief that patient safe; traumatized; staff stripped of dignity; disrespected; demoralised; unsupported by peers/management; care refusal 5. Interventions Psychiatric advisor enrolled; working in twos fostered feelings of security; contracting turn-taking
3. Tension exists between the 'curative' focus of acute care and the needs of older people.

1. Older adults with a dementia can present with complex needs that need to be appreciated

2. More work and resources are required

3. Addressing the learning needs of the staff enhances the working environment 
Table 1: Summary continued

4. Erikson \& Description of difficulties

Saveman

experienced in relation to caring

Sweden
1. Ethics and abuse Administering medications against patient's will; medication used to manage patients - adverse effects; forgetting to treat patients with dignity; violating integrity because patients cannot express self; 'strong feelings that linger'; acute wards are inappropriate; seeking help or transferring patients to psychiatry

2. Disorderly conduct Feeling powerless; recipient of violence/accusations; unable to do job; lack of co-operation; communication difficulties mean inadequate pain assessments; frustration at patients who have a disturbing influence on ward (other patients see behaviour as threatening); frustrated at patients' inability to navigate around the ward

3. Organisation Multiple transfers; trying to limit number of people present; feeling powerless-

demands to decrease care time; guessing/solving problems or using force or ignorance; demands from family; difficulties providing help to someone who does not want it; adhering to routines disturbs patients; no baseline; frustrated by demands of dementia; inadequacy; failure; ineffective communication between staff; feeling powerless when patient admitted because of social factors rather than acute illness
1. Caring for people with dementia acute wards is 'untenable'

2. Action is needed to improve care 3. Patients are at risk of neglect and abuse 
Table 1: Summary continued

5. Harrison \& Identification of the relevant factors 1. Disruption Major problem; disruption to staff/ Zohhadi in meeting the mental health needs (2005) of older people in acute care

UK

6. Jones,

Borbasi,

Exploration of the issues relating

Nankivell \& behaviour/s

Lockwood

(2006)

Australia ward; intrusive, unpleasant behaviour; increased noise; lack of co-operation; paranoid about staff; wrong setting

2. Role conflict Problems identifying difficulties; physical not mental health; some fatalistic views that patients cannot improve; stress

3. Professional resources Lack of internal resources (skills, time, knowledge) and external resources (training, support, supervision, understanding from management); impact on views of professional/personal self; rationalising behaviours but left with emotions

4. Professional distress Exhaustion; emotionally drained; inadequacy; some staff questioning ability to continue their in role/practice

1. Disruptive behaviour Increased numbers of patients with a dementia in acute care; management is complex; requires more thought and close supervision; being pushed to the limit; staff perceived as not coping well with violence

\section{Constraints to care - environment}

Inappropriate setting leads to restraint; having to justify nurse specialing; using security guards; no family areas; inadequate aids (e.g., wandering alarm)

3. Constraints to care - staff Lack of understanding; feeling ill-equipped; no time to get to know patient or for a thorough needs
1. Nursing needs of older people are complex

2. Psychological/mental health needs are met with ineffective nursing care 3. Services should address personcentred care

4. Nurses regard themselves as lacking relevant competencies

1. Staff are ill-prepared to meet increasing numbers of patients with dementia

2. 'Heavily medically dominated environment' exacerbates patients difficulties

3. Restraint often used to manage challenging behaviour

4. A 'multifactorial approach'

is required 'supported by education' 
assessment; under pressure; feeling let-down by system; enhanced assessment by dementia-care nurse

4. Constraints to care - restraint Not wanting to restrain but having to for patient safety; soft restraints used first; witnessing distress; feeling more confident when patient less ambulant;

inappropriate responses when under pressure; staff on speciality wards use restraints less

7. Nolan Illuminate nurses' experiences (2006) of caring for older persons with Ireland dementia in an acute hospital
1. Ethical way of being Desire to care for patient as 'autonomous being'; challenged by pace of environment; guilt; exculpating patient if aggressive/agitated; knowing the person offers uniqueness and meaning; concern that colleagues would not consider patient as openly; protecting patients from stigmatisation

2. Bonding Bonding fundamental to ethical care and aids caring process; persistence and authenticity required; achievable even with aggressive patient; feelings of worth and professional accomplishment 3. Relative/carers Importance of working with relatives/carers to understand patient and develop influence on ward; caring for grieving relatives/ carers; patient as primary concern
1. Knowing and respecting patient is important

2. Caring occurs via a relationship

3. 'Specific knowledge on which

to base care' is needed 
Table 1: Summary continued

\begin{tabular}{|c|c|c|c|}
\hline $\begin{array}{l}\text { 8. Norman } \\
(2006) \\
\text { UK }\end{array}$ & $\begin{array}{l}\text { Observe the processes and care } \\
\text { that occur during the stay of patients } \\
\text { with dementia and consider the } \\
\text { patients' responses }\end{array}$ & $\begin{array}{l}\text { 1. The person with dementia expressing 'self' } \\
\text { Patients use a variety of ways to express self } \\
\text { (verbal and non-verbal) to control care/treatment } \\
\text { 2. Identifying and acting towards the person } \\
\text { with dementia Viewing patients based on } \\
\text { previous knowledge; experience and emotions in } \\
\text { relation to this client group; understanding } \\
\text { individuals; identifying patients as 'positive and } \\
\text { acceptable' (whole individuals) or 'negative and } \\
\text { unacceptable' (reduced to parts) though not } \\
\text { consistent. } \\
\text { 3. Dynamic process Shared interactions, staff-led } \\
\text { interactions } \\
\text { 4. Nurses role Some nurses worked practically } \\
\text { (minimal collaboration), others worked } \\
\text { emotionally (increased collaboration; prioritising } \\
\text { patient needs), others achieved both } \\
\text { 5. Environment Constructions of environment } \\
\text { seen to influence how care was provided and } \\
\text { received (living environment versus working } \\
\text { environment) }\end{array}$ & $\begin{array}{l}\text { 1. Care that orientates to 'realisation' } \\
\text { of patient (e.g., promoting patient } \\
\text { autonomy) rather than restriction } \\
\text { essential } \\
2 . \text { Recognition of the 'self' will } \\
\text { enhance care practices and } \\
\text { the experience of hospitalisation } \\
\text { for patients }\end{array}$ \\
\hline
\end{tabular}




\section{Results}

A methodological overview of the studies based on Meyrick's (2006) quality criteria is considered before presenting a synthesis of the findings.

\section{Epistemological/Theoretical Stance}

Three studies explicated their epistemological/theoretical stance from the outset (Borbasi et al, 2006; Harrison \& Zohhadi, 2005; Nolan, 2006) whilst the remaining papers merely alluded to a particular standpoint or did not address their stance at all. The majority, with the exception of Norman (2006), were exploratory or interpretative, which provided a richer account of staff experiences but did not generate theory.

Regarding reflexivity, three studies (Harrison \& Zohhadi, 2005; Nolan, 2006; Norman, 2006) made their relationship with the participants and/or setting transparent. Nolan (2006) discussed her 'educational links' with the acute unit, stating that this preexisting relationship facilitated rapport with participants. Issues such as the impact of pre-existing relationships or the emotional investment of the researcher on the findings were not explored and therefore, it is difficult to ascertain how they may have shaped the results.

\section{Methods}

All aims were specified and appeared to correspond to a general lack of literature and awareness relating staff experiences to older adults with a dementia in acute care settings. All methods seemed appropriate to the aims. For example, Harrison and Zohhadi (2005) endeavoured to describe the significant issues perceived by nurses and subsequently 
adopted a qualitative method to explore "the real life experiences of those taking part" ( $p$ 473).

\section{Sampling}

The majority of papers specified their sampling technique (Borbasi et al, 2006; Cheek \& Gibson, 2003; Harrison \& Zohhadi, 2005; Nolan, 2006; Norman, 2006) of which purposeful sampling was the most frequent and arguably to be expected with studies that have an interpretative focus. Borbasi et al (2006)/Jones et al (2006) recruited senior staff on the basis of their 'expertise' in the area. However, no definition of expertise was provided. Eriksson and Saveman (2002) identified professional experience as a key criterion for sampling and as such included two nurses, one with substantial experience and one with limited experience, from each of the six wards/departments sampled. However, the authors provided no theoretical or clinical rationale for doing this and experience was not mentioned in the results or discussion. The majority of interviews were conducted with nursing staff though a minority of studies sampled a range of professional groups (Borbasi et al, 2006; Cheek \& Gibson, 2003; Jones et al, 2006). The contributions of each staff group were not clearly delineated with the exception of Cheek and Gibson (2006), masking any differences between professional groups.

\section{Data Collection}

Generally, papers did not specify whether patients had received a formal diagnosis of a dementia though in one study (Norman, 2006) staff perceptions of the patient as having a dementia were seen as valid. 
With the exception of one observation study (Norman, 2006) and a case study (Drayton et al, 2003) all of the studies used semi-structured interviews and/or focus groups providing varying levels of detail of these processes. Some studies included general questions/interview domains (Cheek \& Gibson, 2003; Eriksson \& Saveman, 2002; Harrison \& Zohhadi, 2005; Jones et al, 2006) but these did not permit any judgments to be made about issues such as forcing the data (Charmaz, 2006). Only one of the studies that used a focus group methodology provided a rationale for its use (Cheek \& Gibson, 2003). No consideration was afforded to the impact of group dynamics, including power/dominance, on the results, nor the advantages such as enhanced recollection (Fontana \& Frey, 2000).

Details regarding context were provided in all of the studies, again with varying levels of information. The majority were conducted in general acute environments, including Accident and Emergency. However, three studies were conducted in acute settings specifically for older adults/tertiary care (Cheek \& Gibson, 2003; Harrison \& Zohhadi, 2005; Nolan, 2006). Norman (2006) included observations from longer-stay units and one study included staff from aged and dementia care, including a Senior Geriatrician (Borbasi et al, 2006/Jones et al, 2006). No study considered potential influences such as increased awareness of older people's health needs, access to training, motivation to work with older people or their personal experiences of dementia.

\section{Analysis}

Differences in transparency and systematicity were evident in analyses, making appraising epistemological consistency difficult. Most studies employed thematic 
content analysis, the details of which were often lacking or vague. Case deviance was generally not addressed with the exception of Nolan (2006) who actively 'searched for rival explanations' to bolster credibility of findings. Attempts to ensure rigour were demonstrated in most studies and utilised methods including reflective journals (Nolan, 2006; Norman, 2006), inter-rater agreement or peer review (Harrison \& Zohhadi, 2005; Nolan, 2006) and reference groups in order to contextualise findings (Cheek \& Gibson, 2003; Borbasi et al, 2006; Jones et al, 2006). Regarding the latter, information pertaining to group composition ${ }^{\S}$, their relationship to the researchers and how they shaped the analysis was not included, though this clearly demonstrates attempts to strengthen findings.

\section{Results and Conclusions}

All of the studies used quotes and/or observation notes to illustrate themes and conclusions, in addition to contextualising findings within the literature. The illustrative use of quotes varied in number and the lack of transparency that characterised some papers meant conclusions were read with caution (Eriksson \& Saveman, 2002). The path from data collection to results varied significantly; whilst some studies provided a comprehensive overview of the process (Cheek \& Gibson, 2003), many others did not.

Most studies addressed issues of transferability, though some seemed to use the concept in a confused and even contradictory way (Borbasi et al, 2006; Eriksson \& Savemen, 2002; Jones et al, 2006). For example, Borbasi et al (2006) stated that due to the qualitative nature of their study, "there was no requirement for generalizability" (p.

\footnotetext{
${ }^{\S}$ Personal communication between this author and Sally Borbasi revealed that the reference group comprised people from Alzheimer's Association, the University and senior health professionals involved in dementia care.
} 
301) yet in summing up they suggest that the findings have applicability to policy and practice in related settings. Many advocated further research in order to assess transferability (Harrison \& Zohhadi, 2005; Nolan, 2006; Norman, 2006).

\section{Quality of the Reviewed Papers}

As indicated in the methodological overview the studies provided varying levels of detail regarding the research processes involved. The lack of transparency, especially in relation to the author's epistemological/theoretical stance and data analysis (see Appendix 3) mean that attempts to transfer the findings should be made with caution albeit efforts were made to ensure that the results were trustworthy (i.e., peer review, reflective journals).

Special note must be made to the case study by Drayton et al (2003). A decision was made to include the paper on the basis that it provided a rich description of staff experiences. However, due to insufficient information regarding data collection ${ }^{* *}$ care must be taken when interpreting the findings.

\section{Findings}

The findings are presented according to common themes as identified within the studies. It should be noted that the groupings are not mutually exclusive.

\section{Environment}

The acute environment was a major theme in four of the studies (Borbasi et al, 2006;

Cheek \& Gibson, 2003; Jones et al, 2006; Norman, 2006) and most referred to

\footnotetext{
${ }^{* *}$ An attempt was made to contact the authors for further details, which was unsuccessful.
} 
environmental inadequacies. The acute setting was generally regarded as unsafe, busy, stressful, inappropriate for people with a dementia (including families) and in some cases was seen to adversely affect the mental wellbeing of patients and exacerbate pre-existing difficulties. Perceived as well as actual environment was privileged; Norman (2006) theorised that it was how staff and patients construed the ward environment that was important and had the potential to influence the caring process. Staff often viewed the ward as a working environment, which was at odds with patients who interpreted the ward as a living space.

\section{Organisation}

Two studies (Borbasi et al, 2006; Eriksson \& Savemen, 2002) identified organisation as a key theme yet this featured in other studies in different guises. For example, Cheek and Gibson (2003) placed 'rigid routines' under environment. The organisation was described as a 'system under pressure' leading to inadequate assessment and care provision including the use of force or ignorance. Other issues included delayed discharge resulting in staff having to justify why patients remained in hospital, multiple patient transfers, the primacy of the medical model and inadequate communications between staff groups magnifying a sense of staff powerlessness.

\section{Managing Care}

Managing the care of people with a dementia was perceived to be extremely complex (Cheek \& Gibson, 2003; Drayton et al, 2003) and undermined by a lack of appropriate resources, understanding, support and time. Staff attempting to care for this client group 
reported having little knowledge about the impact of acute illness upon dementia (Cheek \& Gibson, 2003) and others experienced conflict, perceiving their role as providing physical rather than mental health care (Harrison \& Zohhadi, 2005) or social care (Eriksson \& Saveman, 2002). Drayton et al (2003) reflected the complexity of responding to the needs of patients using their case study that described 'Mrs A', who in addition to dementia had multiple complex physical problems. Caring for patients who present with multiple co-morbidities was further complicated by non-compliance and aggressive behaviours (Drayton et al, 2003; Eriksson \& Saveman, 2002).

\section{Disruptive and Aggressive Behaviours}

Disruptive and aggressive behaviours displayed by patients featured strongly in the majority of studies (Borbasi et al, 2006; Drayton et al, 2003; Eriksson \& Saveman, 2002; Harrison \& Zohhadi, 2005; Jones et al, 2006) and were viewed as negatively affecting patient management, colleagues, other patients, carers and ward atmosphere more generally. Responding effectively to these behaviours seemed to be undermined by the organisation, the environment and a lack of time. There also seemed to be an unsettling trend to use chemical and/or physical restraints in the absence of expertise (Cheek \& Gibson, 2003; Eriksson \& Saveman, 2002) including the use of security guards (Jones et al, 2006). Norman (2006) found that those patients regarded as 'negative and unacceptable' were "reduced to their parts, with needs or actions to be performed for them...did not acknowledge the presence of the person" (p. 454). Themes of staff inability to cope and emotional distress were commonly noted. 


\section{Emotional and Psychological Impact}

In response to aggression staff were reported to feel personally abused, traumatized, demoralised, powerless and frustrated (Drayton et al, 2003; Eriksson \& Saveman, 2002). Attempts to cope with the impact of challenging behaviour included rationalisation (Harrison \& Zohhadi, 2005), seeking specialist advice in psychiatry or dementia care (Drayton et al, 2003; Eriksson \& Saveman, 2002) and team discussion (Drayton et al 2003). However, lack of support from colleagues was noted (Cheek \& Gibson, 2003; Drayton et al, 2003) including a lack of understanding from higher management (Harrison \& Zohhadi, 2005).

Generally patients with a dementia were regarded as 'heavy' (Cheek \& Gibson, 2003) and staff found the caring experience exhausting, burdensome and emotionally draining (Harrison \& Zohhadi, 2005). Some staff reported feeling frustrated by the lack of co-operation, patients' inability to navigate themselves around the ward and by the demands of dementia, which left them feeling inadequate (Eriksson \& Saveman, 2002) with some staff questioning their ability to continue in their role (Harrison \& Zohhadi, 2005). Other studies found that staff refused to care for the patient with a dementia (Drayton et al, 2003). Care also appeared compromised by staff shortage as well as staff avoidance (Borbasi et al, 2006). Staff reported feeling more confident when patients were less ambulant (Jones et al, 2006) and relief that the patient was in a safe place (Drayton et al, 2003). Nolan (2006) reported that staff developed feelings of worth and professional accomplishment through the caring relationship although this appeared to be a much less frequently expressed theme. 


\section{'Professional Resources'}

Although some staff were perceived to be reasonably knowledgeable about dementia (Borbasi et al, 2006), most studies reported the converse. Harrison and Zohhadi (2005) noted deficits as having 'internal' and 'external' sources; staff reported constrained skill, time and knowledge (internal resources) in addition to a lack of appropriate training, support, supervision and understanding from higher management (external resources). For many, a lack of time meant that getting to know patients was difficult resulting in inadequate assessment (Eriksson \& Saveman, 2002; Jones et al, 2006) and inappropriate use of restraint/s.

Where time and resources were available, enhanced practice was noted. For example, dementia care nurses provided more thorough assessment (Jones et al, 2006), which although demanding at times, enhanced a sense of professional accomplishment (Nolan, 2006). Working in pairs within a supportive team fostered feelings of security and satisfaction (Drayton et al, 2003)

\section{Staff-Patient Relationship}

Themes regarding the patient-staff relationship were mixed. Staff reportedly 'agonised' over interactions and some refused to engage (Drayton et al, 2003); staff failed to treat patients with dignity (Eriksson \& Saveman, 2002); patients sometimes refused help (Drayton et al, 2003; Eriksson \& Saveman, 2002) and time constraints hindered understanding patients (Jones et al, 2006). Unlike aged care wards, Borbasi et al (2006) noted that surgical wards were less sympathetic towards patients though the impact on the staff-patient relationship was not clear. Norman (2006) observed that nurse-patient 
interactions varied. Largely, "participants were seen to belong to one of two groups, either 'positive and acceptable patients' or 'negative and unacceptable" (p458). Patients perceived as 'positive' were treated as 'whole' and autonomous whereas those construed as 'negative,' also known as 'the heavies', were seen as dependent and ignored, which was also noted by Borbasi et al (2006). Furthermore, emotional and practical staffpatient interactions were associated with collaboration and non-collaboration, respectively (Norman, 2006). In contrast, Nolan (2006) found staff persisted in understanding patients as individuals, which was demanding at times, especially in relation to patients exhibiting aggression. Regardless, bonding was found to positively facilitate the caring process.

\section{Family/Relatives}

Family/relatives emerged as themes in two of the studies (Borbasi et al, 2006; Nolan, 2006) and were viewed as having a positive effect on the relationship between patients and staff because of their ability to impart valuable information about the patient. However, staff also found themselves having to support grieving family/relatives or responding to demands or concerns expressed regarding their relatives' well-being (Drayton et al; 2003; Eriksson \& Saveman, 2002).

\section{Ethics}

Ethics and ethical practice were explicitly raised in three of the studies (Drayton et al, 2006; Eriksson \& Saveman, 2002; Nolan, 2006) though ethical issues, particularly restraint, emerged covertly in other studies (Cheek \& Gibson, 2003; Jones et al, 2006). 
Ethics related to events in which it was possible to preserve or undermine patient autonomy either through care practices including staff knowledge of dementia or the ward environment. Only Drayton et al (2003) clearly raised the legal dilemmas staff faced regarding capacity issues when 'Mrs A', adamant on returning home, was perceived by most of the clinical team as incapable of making decisions.

\section{Discussion}

Studies reviewed provide a rich account of the complexities related to working with older adults with a dementia in acute care settings and a full description of the demands placed upon staff, in particular nursing staff. Although emphasising the difficulties staff face, this review provides evidence of enhanced practice-based care. For example, pairing up to provide care and a supportive peer environment where staff could openly process their experiences proved beneficial to the integrity of the worker and development of the team (Drayton et al, 2003).

A proactive approach to mental health in general health care is well-established for adults of working age and operational through integrated, consultation-liaison teams but not for older people (British Psychological Society, BPS, 2008; RCP, 2005). The Royal College of Psychiatrists (2005) specified that liaison teams are a minimum requirement, raising mental health awareness, developing staff skill base, advocating for older people and supporting complex cases. Creating specialist dementia services, including linkage to Intermediate Care, within or attached to acute care is an ideal that services are actively working towards and forms part of the National Dementia Strategy (DoH, 2009). Vision must also remain grounded and address staff needs in order for 
positive dementia care to happen. Importantly, responsibility of care to care must not be devolved to the wider system; staff must be seen as partners, "sharing responsibility for learning...focussing on the development of the practice skills and workplace cultures that support person-centred care” (Bezzant, 2008, p. 144).

Themes of the environment, disruptive and/or aggressive behaviour, professional resources and family/relatives are consonant with previous studies (Cunningham, 2006; Dewing, 2001; McCloskey, 2004; Moyles et al, 2008), bolstering the credibility of this review. However, this review also highlights distinctive areas not addressed within existing literature. The emotional and psychological impact of working with patients exhibiting aggressive behaviours in acute care is often overlooked in favour of promoting strategies to manage behaviours (Allison \& Marshall, 1994; Cunningham, 2006; Dewing, 2001; Pritchard \& Dewing, 2001). Addressing deficiencies in ensuring psychological support for staff in acute care may be fulfilled via the proposed hospital consultationliaison teams (RCP, 2005), in which clinical supervision is regarded as essential. This has been strongly indicated in dementia care and has been shown to facilitate patient-staff relations (Edberg et al, 2008; Hallberg \& Norberg, 1995). Supervision may help validate staff experiences and conforms to Kitwood's (1997) person-centred care, in which the needs of caregivers are considered. Interestingly, the word 'supervision' does not appear once in the National Dementia Strategy (DoH, 2009).

Perceived time constraints appeared to undermine patient-staff relations (Jones et al, 2006) yet investing time in getting to know patients as opposed to 'processing' them (Marshall, 1999) was seen to enhance the caregiving experience (Nolan, 2006). Establishing rapport can be fostered through basic curiosities such as learning someone's 
preferred name of address (Allison \& Marshall, 1994) and may demand a degree of 'imagination' by staff. For example, Kontas and Nagile (2007) found that where nonverbal communication was construed as an expression of personhood, time efficiency and general ward atmosphere was enhanced. Responding to the psychological needs of patients should not be a 'low priority' (Pritchard \& Dewing, 2001) and Collier (1998) implies that nurses may benefit from being "more sensitive to their own human responses to a person in distress" (p59).

Wider reflections on communication were articulated by Norman (2006) noting that 'practical' interactions tended to be non-collaborative and potentially pernicious. A recent report led by the Commission of Social Care Inspection (2008) similarly found that 'task-orientated' or 'neutral' communications, not necessarily negative in tone, with persons with dementia negatively effected well-being. Positive communications (e.g., demonstrating warmth) were observed to promote happier environments. These findings highlight the need for basic communication skills, beyond competencies in knowledge and emphasize the importance of developing critical thinking (i.e., open-mindedness, continual inquiry) via education combined with increased knowledge of dementia and older adults (Heffner \& Ruby, 2008). Compromised communication, operationalised as disruptive and aggressive behaviours, was also prominent, however little mention was made of patient withdrawal, which can be equally as problematic and detrimental to patient well-being.

Only one study (Drayton et al, 2003) cited ethics and capacity as an issue for the multi-disciplinary team yet legal, ethical and moral considerations (e.g., informed consent) are an integral part of clinical practice (BPS, 2006; Collier, 1998). It might be 
that issues of capacity, especially in the UK, become more apparent in light of the Mental Capacity Act (2005). Once again, this raises important considerations in relation to training and awareness.

One observation that this author made whilst conducting the review was that the literature was replete with definitions of dementia as an 'organic', 'progressive', 'neurodegenerative', 'psychiatric' and 'mental health' condition/disorder. It is interesting to note the splits between physical and mental health care (RCP, 2005; WHO, 2006) and arguably these tensions may be counter-productive to regarding patients with dementia within acute care as whole beings (Harrison, 2007).

\section{Limitations}

Assessing the clinical utility and transferability of this review requires caution, not least because the studies originated from various countries with different healthcare systems and cultures of training. However, themes did appear to overlap, irrespective of geography, suggesting general factors and processes.

Some studies failed to address potential sources of influence including sampling participants from acute units for older adults (Cheek \& Gibson, 2003; Nolan, 2006) or using participants working in aged care (Borbasi et al, 2006/Jones et al, 2006). Potential influences would be purely speculative therefore this author advises readers to be mindful of extrapolating findings. The majority of studies were interpretative, aiming to increase local understanding and awareness rather than to transfer findings more broadly. However, the findings do encourage questions about current understandings and practice, aspects of which will be applicable to the wider healthcare community. 
This review chose to focus on dementia because of its permanence yet delirium shares many features with dementia (WHO, 1993) and can be misconstrued as dementia (Cole, 2004). Findings from this review may help to elucidate the psychological and social processes related to this usually transient condition. However, it might be that more can be learned about staff experiences of caring for someone with a dementia by drawing on a literature examining delirium. In addition, investigating the literature regarding people with intellectual disabilities and dementia, a group highlighted in the Dementia Strategy (DoH, 2009), may be useful.

\section{Clinical Implications}

This review suggests the need for staff education/training regarding dementia/dementia care and offers particular direction for future training for staff in acute care (i.e., developing communication skills). In addition, this review recognises the emotional demands attached to caring/nursing someone with a dementia within this setting and highlights the need for staff support especially regarding supervision, which disappointingly, has not been explicitly addressed within current government agenda (DoH, 2009).

\section{Further Research}

Limitations associated with the literature have been discussed (i.e., dementia versus delirium; organic and/or functional definitions). A further review could seek to compare 
and contrast staff experiences, which may also include other co-morbidities such as depression.

Given that only three studies emanated from the UK and that cultural differences exist in relation to training, healthcare systems and possibly views regarding older people with a dementia, further research is indicated.

\section{Conclusion}

Supporting patients with a dementia in the acute care setting appears to be complicated by a range of influences including perceived case complexity, inappropriate environment and insufficient resources including a reported deficiency in staff training, further undermined by poor communications with patients. Responding to the needs of people with a dementia has been construed as an international priority, demanding a holistic and humanistic approach. This review has highlighted some areas for consideration as indicated by staff (e.g., supervision), which if addressed, may promote person-centred care and best practice. In addition, this review has identified examples of positive practice experienced by staff, which may provide support and encouragement to staff, teams and services. 


\section{References}

Allison, A., \& Marshall, M. (1994). Dementia in acute units: the issues. Nursing Standard, 21(8), 28-31.

Alzheimer's Society (2007). Dementia UK: The Full Report. Retrieved from the Web $9^{\text {th }}$ March, 2007:

http://www.alzheimers.org.uk/News_and_Campaigns/Campaigning/PDF/Dementia _UK_Full_Report.pdf

Atkin, K., Holmes, J., \& Martin, C. (2005). Provision of care for older people with comorbid mental illness in general hospitals: general nurses' perceptions of their training needs. International Journal of Geriatric Psychiatry, 20, 1081-1083.

Bezzant, K. (2008). Practice development: providing benefits for both managers and older patients with delirium and dementia. Journal of Nursing Management, 16, 141-146.

Birrer, R., Singh, U., \& Kumar, D. N. (1999). Disability and dementia in the emergency department. Emergency Medicine Clinics of North America, 17(2), 505-517

*Borbasi, S., Jones, J., Lockwood, C., \& Emden, C. (2006). Health professionals' perspectives of providing care to people with dementia in the acute setting: towards better practice. Geriatric Nursing, 27, 300-308.

British Psychological Society. (2006). Code of Ethics and Conduct. Retrieved from the Web 29 $9^{\text {th }}$ March 2009 from: http://www.bps.org.uk/downloadfile.cfm?file_uuid=5084A882-1143-DFD0-7E6CF1938A65C242\&ext=pdf 
British Psychological Society. (2008). Response to the Department of Health

Consultation: Transforming the Quality of Dementia Care: Consultation on a National Dementia Strategy. Retrieved from the Web $25^{\text {th }}$ March 2009 from:

\section{http://www.psige.org/psigepdfs/Dementia\% 20Strategy \% 20\% 20BPS \% 20respo} nse_Sept_08.pdff

Braun, V., \& Clarke, V. (2006). Using thematic analysis in psychology. Qualitative Research in Psychology, 3, 77-101.

Care Services Improvement Partnership. (2005). Everybody's Business. Integrated Mental Health Services for Older Adults: a Service Development Guide. Retrieved from the Web $25^{\text {th }}$ March 2009 from:

http://kc.csip.org.uk/upload/factsheetserviceusers.pdf

Charmaz, K. (2006). Constructing Grounded Theory. A Practical Guide through Qualitative Analysis. Sage. London.

*Cheek, J., \& Gibson, T. (2003). Issues impacting on registered nurses providing care to older people in an acute care setting. Nursing Times Research, 8(2), 134-149.

Commission for Social Care Inspection. (2008). See Me, not just the Dementia. Understanding People's Experiences of Living in a Care Home.

Cole, M. G. (2004). Delirium in elderly patients. American Journal of Geriatric Psychiatry, 12(1), 7-21).

Collier, E. H. (1998). The concept of consent and cognitive impairment - nursing issues. Clinical Gerontology, 8, 53-63.

Cunningham, C. (2006). Understanding challenging behaviour in patients with dementia. Nursing Standard, 20(47), 42-45. 
Cunningham, C., \& Archibold, C. (2006). Supporting people with dementia in acute hospital settings. Nursing Standard, 20(43), 51-53.

Cunningham, C., \& McWilliam, K. (2006). Caring for people with dementia in A \& E. Emergency Nurse, 14(6), 12-16.

Department of Health. (2001). National Service Framework for Older People. Retrieved from the Web $29^{\text {th }}$ March 2009 from: http://www.dh.gov.uk/en/Publicationsandstatistics/Publications/PublicationsPolicy AndGuidance/DH_4003066

Department of Health and Ageing. (2006). National Framework for Action on Dementia 2006-2010. Retrieved from the Web $20^{\text {th }}$ January 2009 from: http://www.health.gov.au/internet/main/publishing.nsf/Content/ageing-dementianfad-0610.htm

Department of Health. (2009). Living Well with Dementia: A National Dementia Strategy. Retrieved from the Web $28^{\text {th }}$ March 2009 from: http://www.dh.gov.uk/en/Publicationsandstatistics/Publications/PublicationsPolicy AndGuidance/DH_094058

Dewing, J. (2001). Care for older people with a dementia in acute hospital settings. Nursing Older People, 13(3), 18-20.

Downing, A., \& Wilson, R. (2005). Older people's use of Accident and Emergency services. Age and Ageing, 34, 24-30.

*Drayton, S., Canter, A., \& Allen, C. (2003). Dilemmas in providing patient-focused care. Journal of the Canadian Association of Nephrology Nurses and Technicians, 13(4), 30-33. 
Edberg, A., K., Bird, M., Richards, D. A., Woods. R., Keeley. P., \& Davis-Quarrell, V. (2008). Strain in nursing care of people with dementia: Nurses' experience in Australia, Sweden and United Kingdom. Ageing and Mental Health, 12(2), 236243.

*Eriksson, C., \& Saveman, B-I. (2002). Nurses' experiences of abusive/non-abusive caring for demented patients in acute care settings. Scandinavian Journal of Caring Sciences, 16, 79-85.

Etters, L., Goodall, D., \& Harrison, B. E. (2008). Caregiver burden among dementia patient caregivers: A review of the literature. Journal of the American Academy of Nurse Practitioners, 20, 423-428.

Fontana, A., \& Frey, J. H. (2000). In N. K. Denzin \& Y. S. Lincoln (Eds.) Handbook of Qualitative Research. Second Edition. Sage. London.

Hallberg, I.R., \& Norberg, A. (1995). Nurses' experiences of strain and their reactions in the care of severely demented patients. International Journal of Geriatric Psychiatry, 10, 757-766.

*Harrison, A., \& Zohhadi, S. (2005). Professional influences on the provision of mental health care for older people within a general hospital ward. Journal of Psychiatric and Mental Health Nursing, 12, 472-480.

Harrison, A. (2007). Improving mental health care in general hospitals. Nursing Older People, 19(4), 32-37.

Heffner, S., \& Rudy, S. (2008). Critical thinking. What does it mean in the care of elderly hospitalised patients? Critical Nursing Care Quarterly, 31(1), 73-78. 
Herdman, E. (2002). Challenging the discourses of nursing ageism. International Journal of Nursing Studies, 39, 105-114.

Higgins, I., Slater, L., Van Der Riet, P., \& Peek, C. (2007). The negative attitudes of nurses towards older patients in the acute hospital setting: A qualitative descriptive study. Contemporary Nurse, 26, 225-237.

*Jones, J., Borbasi, S., Nankivell, A., \& Lockwood, C. (2006). Dementia aggression in the acute sector: Is a code black really the answer? Contemporary Nurse, 21, 103115.

Josefsson, K., Sonde, L., \& Robins Wahlin, T-B. (2007). Violence in municipal care of older people in Sweden as perceived by registered nurses. Journal of Clinical Nursing, 16(5), 900-910.

Kitwood, T. (1997). Dementia Reconsidered: The Person Comes First. Open University Press. Buckingham.

Kontos, P. C., \& Nagile, G., (2007). Bridging theory and practice. Imagination, the body, and person-centred care. Dementia, 6(4), 549-569.

Mayer, J., Bridges, J., \& Spilsbury, K. (1999). Caring for older people in acute settings: Lessons learned from an action research study in accident and emergency. Nursing Times Research, 4(5), 327-339.

Mayer, M. (2001). Chronic sorrow in caregiving spouses of patients with Alzheimer's Disease. Journal of Aging and Identity, 6(1), 49-60.

Mackenzie, C. S., \& Peragine, G. (2003). Measuring and enhancing self-efficacy among professional caregivers of individuals with dementia. American Journal of Alzheimer's Disease and Other Dementias, 18(5), 291-299. 
Marshall, M. (1999). "They should not really be here" - people with dementia in the acute sector. Age and Ageing, 28, 9-11.

Meyrick, J. (2006). What is good qualitative research? A first step towards a comprehensive approach to judging rigour/quality. Journal of Health Psychology, 11(5), 799-808.

McCloskey, R. M. (2004). Caring for patients with dementia in an acute care environment. Geriatric Nursing, 25(3), 139-144.

McLafferty, I., \& Morrison, F. (2004). Attitudes towards hospitalized older adults. Journal of Advanced Nursing, 47(4), 446-453.

Mental Capacity Act (2005). Retrieved from the Web 25 ${ }^{\text {th }}$ March 2009 from: http://www.opsi.gov.uk/acts/acts2005/ukpga_20050009_en_1

Moyle, W., Olorenshaw, R., Wallis, M., \& Borbasi, S. (2008). Best practice for the management of older people with dementia in the acute care setting: a review of the literature. International Journal of Older People Nursing, 3(2),121-130.

Neville, S. (2008). Older people with delirium: worthless and childlike. International Journal of Nursing Practice, 14, 463-469.

National Institute for Health and Clinical Excellence. (2006). Dementia. Supporting People, with Dementia and their Carers in Health and Social Care. Retrieved from the Web $15^{\text {th }}$ March 2009 from: http://www.scie.org.uk/publications/misc/dementia/dementia-qrg.pdf

*Nolan, L. (2006). Caring connections with older persons with dementia in an acute hospital setting - a hermeneutic interpretation of the staff nurse's experience. International Journal of Nursing Older People Nursing, 1, 208-215. 
*Norman, R. Observations of the experiences of people with dementia on general hospital wards. (2006). Journal of Research in Nursing, 11(5), 453-465.

O’Connell, B., Gardner, A., Takase, M., Hawkins, M. T., Ostaszkiewicz, J., Ski, C., \& Josipovic, P. (2007). Clinical usefulness and feasibility of using reality orientation with patients who have dementia in acute care settings. International Journal of Nursing Practice, 13, 182-192.

Park, M., Delaney, C., Mass, M., \& Reed, D. (2004). Using a nursing minimum data set with older patients with dementia in an acute care setting. Journal of Advanced Nursing, 47(3), 329-339.

Pekkarinen, L., Sinervo, T., Elovainio, M., Noro, A., Finne-Soveri, H., \& Leskinen, E. (2006). Resident care needs and work stressors in special care units versus nonspecialized long-term care units. Research in Nursing and Health, 29, 465-497.

Popay, J., Roberts, H., Sowdon, A., Petticrew, M., Arai, L., Rodgers, M., Britten, N., Roen, K., \& Duffy, S. (2006). Guidance on the Conduct of Narrative Synthesis in Systematic Reviews. ERSC Methods Programme.

Pratchett, T. (2008). Terry Pratchett: Living with Alzheimer's for BBC TWO. Retrieved from the Web 25 ${ }^{\text {th }}$ March 2009 from:

http://www.terrypratchett.co.uk/news/Terry\%20Pratchett\%20documentary.doc

Pritchard, E., \& Dewing, J. (2001). Older people with dementia in acute settings. Nursing Older People, 12(10), 21-25.

Robertson, S. M., Zarit, S. H., Duncan, L. G., Rovine, M. J., \& Femia, E. E. (2007). Family caregiver's patterns of positive and negative affect. Family Relations, 56, 12-23. 
Royal College of Psychiatrists. (2005). Who Cares Wins. Improving the Outcome for Older People Admitted to the General Hospital: Guidelines for the Development of Liaison Mental Health Services for Older People. Retrieved from the Web $25^{\text {th }}$ March 2009 from: http://www.bgs.org.uk/PDF\%20Downloads/WhoCaresWins.pdf

Sandelowski, M. (2008). Reading, writing and systemic review. Journal of Advanced Nursing, 64(10), 104-110.

Tolson, D., Smith. M., \& Knight, P. (1999). An investigation of the components of best nursing practice in the care of acutely ill hospitalized older patients with coincidental dementia: a multi-method design. Journal of Advanced Nursing, $30(5), 1127-1136$.

Townsend, P. (2006). Policies for the aged in the 21st century: more 'structured dependency' or the realisation of human rights? Ageing and Society, 26, 161-179.

Woods, B. (2003). So what's so different about older people? Clinical Psychology and Psychotherapy, 10, 129-132.

World Health Organisation (1993) ICD-10. Classification of Mental and Behavioural Disorders. Diagnostic Criteria for Research. Geneva.

World Health Organization. (2005). Promoting Mental Health. Concepts. Emerging Evidence. Practice. Retrieved from the Web $27^{\text {th }}$ March 2009 from: http://www.who.int/mental_health/evidence/MH_Promotion_Book.pdf 
Appendix 1

Notes to Contributors for the Journal of Advanced Nursing 


\section{Review Papers ${ }^{\dagger \dagger}$}

Journal of Advanced Nursing publishes high quality traditional literature reviews, aggregative and interpretive reviews, qualitative, quantitative and mixed method systematic reviews, meta-analyses, meta-summaries and meta-syntheses.

Review papers should not exceed 5000 words for the main text, excluding the abstract, summary statement, tables and references.

The following headings should be used:

- Title

Should end with a descriptor that best describes the type of review, such as: literature review, qualitative, quantitative or mixed method systematic review, meta-summary, meta-synthesis or meta-analysis.

- Abstract The 250 word abstract should use the following headings: Aims (of the paper), Background, Data Sources, Review Methods, Results, Conclusion.

- Summary Statement Please see the Summary Statement guidelines for further information.

- Keywords Should include 'literature review' and other MeSH headings appropriate for the specific review, such as 'systematic review', as well as subject-specific keywords.

\section{Introduction}

As for empirical papers - should include rationale, conceptual or theoretical context, international relevance of topic.

\section{The Review}

\section{$\operatorname{Aim} / \mathbf{s}$}

- Of the review

- Include research topic/ objectives / questions / hypothesis(es) For example, "The aim of the (type) review was to..."

\section{Design}

Should identify type of review, methods used and sources of reference, such as the Cochrane Handbook, Centre for Reviews and Dissemination Handbook, EPPI approach, Joanna Briggs Institute approach, or other rigorous systematic review methodological approach.

\footnotetext{
${ }^{\dagger}$ Retrieved from http://www.journalofadvancednursing.com/default.asp?file=guidereview
} 
Should identify and adhere to relevant gold standards for the reporting and conduct of systematic reviews such as the QUOROM statement for meta-analyses of RCTs (see http://www.consort-statement.org/?0=1065 ) or, for example, ESRC guidance on Narrative Synthesis.

\section{Search methods}

Should include: search strategy, inclusion/exclusion criteria, databases searched, keywords, languages and inclusive dates of the literature searched.

\section{Search outcome}

Search outcome and audit trail if appropriate - application of inclusion/exclusion criteria, retrieval and selection of references and handling. Summarise included and, if appropriate, excluded studies in separate tables.

\section{Quality appraisal}

Should include approaches used and audit of discarded studies. For qualitative and traditional reviews, include a statement as to whether included studies were quality appraised or not and a supporting rationale.

\section{Data abstraction}

Systematic reviews should include a description of the process(es).

\section{Synthesis}

Should include description of process(es) used.

\section{Results}

With appropriate subheadings and should adhere to the relevant standard(s) of reporting (eg QUOROM statement for systematic review of RCTs).

Where appropriate, identify the conceptual or theoretical context of each definition or discussion of the concept found in the literature.

\section{Discussion}

Start with limitations and strength of the evidence.

Draw out the applicability, theoretical and practical implications of the findings. 


\section{Conclusion}

Real conclusions, not just a summary/repetition of the findings.

Recommendations for practice/research/education/management as appropriate, and consistent with the limitations.

Where appropriate, consider whether one or more nursing conceptual or theoretical frameworks could guide future research about the topic of the review. 
Appendix 2

Summary of Meyrick's (2006) Framework for Assessing Qualitative Research 
Meyrick's (2006) guide to assessing the quality of qualitative research encourages the reader to consider the principles of systematicity and transparency, both of which commonly prevail as key criteria when assessing for quality and rigour in qualitative research. Transparency refers to the "disclosure of all relevant research processes (Yardley, 2000, p.222), and systematicity, the use of regular or set data collection and analytic process, and deviation in which are described and justified" (Meyrick, 2006, p.803). Assessing for transparency and systematicity is achieved within the context of six domains that are; researcher epistemology and theoretical stance, methods, sampling, data collection, analysis and results and conclusions. Points of good practice in relation to each domain are presented. For a more detailed account please refer to Meyrick (2006).

\section{Researcher Epistemological and Theoretical Stance}

- Epistemological and theoretical stance clearly stated

\section{Methods}

- Aims are explicit enabling judgements to be made regarding the appropriateness of the methodology

- Methods appropriately referenced

\section{Sampling}

- Sampling technique specified and justified (e.g., if sample selected to represent themes then participants will be collected until saturation; for representation, demographic data should be included) 


\section{Data Collection}

- Context specified

- Explicit analytic framework identified

- Process of data collection should be made clear to reader

\section{Analysis}

- Details that enable the reader to map the research process should be made available

- All data should be accounted for, including deviancy

- Details of interview technique may be explicated

- Potential influences associated with participant, researcher and/or situation explored

- Could use objective measures such as triangulation

\section{Results and Conclusions}

- Use of quotes/conclusions grounded in data

- Respondent validation

- Issues of transferability addressed 
Appendix 3

Summary of Data Analysis 
Table 2. A Summary of data analysis $*$

Reference Epistemological/

$\begin{array}{ll}\text { Methods } & \text { Sampling } \\ & \sqrt{ }\end{array}$

Analysis

Results/Conclusions

1. Borbasi, Jones,

Lockwood \&

Emden (2006)

Constructivist

in keeping with

interpretative

realism saturation

\section{V V}

Purposive; Critical incident

Thematic analysis

\section{VI}

Issues of transferability 24 nurses \& technique interviews, No acknowledgment noted - contradiction others health 4 focus groups, 9 of deviancy professionals; nominal groups recruit for 'information rich'- saturation not mentioned

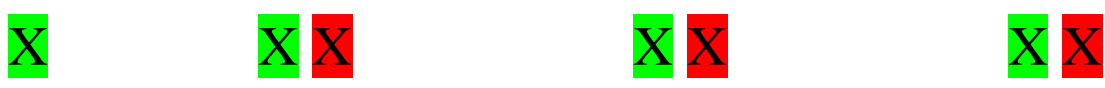

3. Drayton, Canter X X \& Allen (2003) use of advisory panel but not explicit

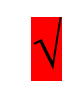

\footnotetext{
Key: A $\sqrt{ }$ or $X$ denote that the criteria has been judged as met; the colours green and red relate to the principles of transparency and systematicity respectively.
} 
Table A continued

\begin{tabular}{|c|c|c|c|c|c|}
\hline 4. Eriksson \& & & $X$ & $\sqrt{x}$ & & $\sqrt{ } \sqrt{ }$ \\
\hline Saveman (2002) & $\begin{array}{l}\text { Alludes to } \\
\text { phenomenological- } \\
\text { hermeneutic but not } \\
\text { explicit }\end{array}$ & $\begin{array}{l}12 \text { nurses; } \\
\text { not clear why } \\
\text { experience is } \\
\text { important; } \\
\text { not mentioned } \\
\text { in results }\end{array}$ & $\begin{array}{l}\text { Semi structured } \\
\text { interviews }\end{array}$ & $\begin{array}{l}\text { Thematic content } \\
\text { analysis, } \\
\text { systematicity \& } \\
\text { transparency noted } \\
\text { but lacking detail }\end{array}$ & $\begin{array}{l}\text { Grounded in quotes } \\
\text { \& literature }\end{array}$ \\
\hline
\end{tabular}

\section{Harrison \& Zohhadi (2005)

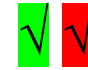 \\ Phenomenological perspective}

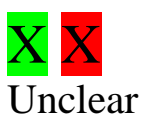

Nankivell \&

Lockwood (2006)

7. Nolan (2006)

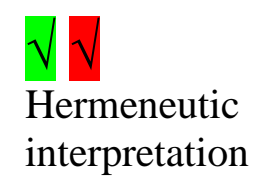

\section{V}

In-depth, non-

directive interviews; search for rival explanations
Convenience; Focus groups eight nursing staff \& one ward manager

$\begin{array}{ll}\mathrm{X} & \mathrm{XX} \\ 25 \text { healthcare } & \text { Interviews; } \\ \text { professionals } & \text { not clear how data } \\ \text { Indicates } & \text { extracted from main } \\ \text { sampling for } & \text { study; use of } \\ \text { themes but } & \text { research assistant } \\ \text { not explicit } & \text { mentioned }\end{array}$

\section{$\sqrt{ } \sqrt{ }$}

\section{$\mathrm{X}$}

Thematic content analysis, deviance not mentioned; no indication of how interpersonal factors may have impacted on findings

\section{X \\ 'Recognised \\ $\sqrt{ }$} qualitative techniques' Issues of transferability Different analysis to noted - contradictions first paper; unsure details of project reference group

Purposive; seven nurses

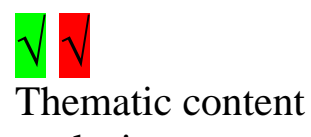

analysis

\section{VI}

Illustrated/quotes +++ Issues of transferability noted 
8. Norman (2006) $\sqrt{ } X$

Unclear $\sqrt{ } \sqrt{ }$

Convenience; Observations eight patients

$\&$ ward nurse
X X

Grounded theory $\sqrt{ } \sqrt{ }$

Illustrated 


\section{Empirical Paper}

Inappropriate Sexual Behaviour and Dementia; an Exploration of Staff Experiences 


\section{Note on style}

This paper has been written according to the requirements of the Journal of Aging and Mental Health ${ }^{\S \S}$. Guidelines for contributors have been adhered to where possible unless

they contravene University of Leicester requirements for the thesis submitted in partial fulfilment of the Doctorate in Clinical Psychology

\footnotetext{
${ }_{\S}^{\S}$ See Appendix 1 for Notes to Contributors
} 
"What we refer to as the 'self' is a product of biological and social forces arising from the interaction of individual, isolated, brains. There is no spark in a single stone but, struck together, two stones can start a blaze"

(Paul Broks, 2003, p102) 


\section{Abstract \\ Inappropriate Sexual Behaviour and Dementia; an Exploration of Staff Experiences \\ Laura Hayward}

Aim: To explore staff experience of Inappropriate Sexual Behaviour (ISB) exhibited by older adults with a dementia.

Background: Research assessing the impact of ISB on staff working in dementia care is circumscribed yet studies from forensic and brain injury settings indicate that staff regard ISB as uniquely challenging requiring acknowledgement and management of personal and cultural values.

Method: Interviews with fourteen staff working within an inpatient setting were undertaken and recorded, with transcripts analysed verbatim using a social constructivist Grounded Theory methodology (Charmaz, 2006).

Results: The core category, 'A Question of Attribution' was identified, describing the process experienced when confronted with ISB. Four main categories were inducted representing participant's initial experiences, their contextualising of the behaviour, their process of interpretation and pragmatic management of ISB.

Conclusion: Complex social and psychological processes appeared to underpin participant's experiences of ISB. Feelings of shock, embarrassment and incomprehension were prominent when ISB was initially encountered, precipitating a loosening of expectations about the patient group. Knowledge of dementia, knowing patients and social norms were important in contextualising ISB and staff often minimised the impact of ISB by construing a lack of capacity. Staff's feelings about ISB appeared equivocal with some staff reporting indifference, others feeling violated.

Clinical Implications: Findings imply that the impact of ISB should be more routinely considered in preparing staff for working with patients with a dementia.

Keywords: Qualitative, older adults, inpatient setting

\section{Word count: 244.}




\section{Introduction}

Over $80 \%$ of people with a dementia exhibit behaviours that are perceived as challenging (Lonergan, Luxenberg, Colford \& Birks, 2002; Scott et al., 2002). Challenging behaviours have been described as "unsafe and disruptive and that interfere with the care of the patient in any given environment" (Black, Muralee \& Tampi, 2005, p.155).

Challenging behaviours may include verbal and physical aggression, wandering and selfinjury. Managing challenging behaviour is demanding and associated with inappropriate interventions, staff burnout and can compromise community living (Feeney, Ylvisaker, Rosen \& Greene, 2001; Hallberg \& Norberg, 1994; Souder \& O’Sullivan, 2003). As the population increases and prevalence of dementia grows, challenging behaviour will become familiar to more caregivers worldwide. It is therefore important that care providers appreciate how individuals, families and staff are affected by these behaviours so that sensitive and effective interventions can be developed and implemented where appropriate.

\section{Inappropriate Sexual Behaviour}

"Sexuality is with us from the moment of birth to the moment of death" (Zilbergeld, 2004, p 15) and is therefore a fundamental part of being human. When a person's sexual expression is affected, as can occur with dementia, confusion, distress and embarrassment may ensue, leading to social isolation for familial caregivers and reluctance to accept social support (Robinson, 2003). The National Institute of Clinical Excellence (NICE, 2006) in advocating a person and relationship-centred care approach, recognised 
Inappropriate Sexual Behaviour (ISB) as a challenging behaviour associated with the dementias.

\section{Prevalence}

The prevalence of ISB exhibited by people with a dementia is reported to be between $1.8 \%$ and $17.5 \%$ (Alagiakrishnan et al, 2005; Johnson, Knight \& Alderman, 2006) though this is likely to be an underestimate as literature is scarce and definitions have been obscure (Johnson et al, 2006). Johnson and colleagues (2006), and Knight et al (2008) provided comprehensive reviews of the variable definitions associated with ISB, which will not be duplicated in this paper. However, to highlight the range and inherent subjectivity of the terms employed, definitions include 'sexual advances' (Souder \& O’Sullivan, 2003), 'hypersexuality', 'propositioning' (Nagaratnam \& Garagay, 2002), 'sexually intrusive behaviour' and 'inappropriate commentary' (Bezeau, Bogod \& Mateer, 2004). Inappropriate Sexual Behaviour was more recently defined as "a verbal or physical act of an explicit, or perceived, sexual nature, which is unacceptable within the social context in which it is carried out" (p688, Johnson et al, 2006).

Inappropriate sexual behaviour is less frequent than other challenging behaviours, for example aggression, but is still clinically significant (Brodaty \& Low, 2003). Sixty-three percent of staff working in aged care facilities ( $N=259)$ reported ISB occurring once a week or more with 9\% experiencing it more than once a day (Cubit, Farrell, Robinson \& Myhill, 2007). The St Andrew's Sexual Behaviour Assessment, or SASBA (Knight et al, 2008) was developed to provide a standardised way of identifying and assessing ISB exhibited by people with neurological impairment within inpatient 
settings. Modelled upon the Overt Aggression Scale - Modified for Neurorehabilitation

(OAS-MRS; Alderman, Knight \& Morgan, 1997) and cultivated from staff examples, the SASBA was developed as an objective, continuous observational tool capturing data including antecedent, contributing factors and ISB type. It demonstrated good construct validity, content validity and inter-rater reliability.

\section{Aetiology}

Precise aetiology has not been defined; rather, neurobiological, psychological and environmental explanations have been offered to understand ISB exhibited by people with a dementia (Guay, 2008; Johnson et al, 2006). Frontal cortex and hypothalamic pathology have been advanced in addition to social factors, such as being attended to by opposite-sex caregivers (Black et al., 2005). Psychological factors have been constructed as loss of self-esteem and/or control plus a need for intimacy (Robinson, 2003).

\section{Impact on staff}

Literature investigating the effects of ISB is restricted to forensic and Traumatic Brain Injury populations. However, findings raise important clinical questions regarding staff and client wellbeing. Brown and Barrett (1994, as cited in Hughes \& Hebb, 2005) suggested that sexual behaviour is particularly challenging for staff as it requires objectivity and "to view the behaviour from outside their own religious and cultural beliefs; thus, challenging their own attitudes and thinking" (p97). Research also indicates that staff feel uncomfortable with issues around sexuality, burnout is common and relevant training is infrequent (Hughes \& Hebb, 2005; Robinson, 2003; Wittig, 1999, as 
cited in Bezeau, Bogod, \& Mateer, 2004). Bezeau et al (2004) described behaviours as "emotionally charged" for informal and formal caregivers. Ninety-seven percent of rehabilitation professionals surveyed reported that ISB moderately impacted on rehabilitation practices.

Matsuoka, Mityamoto, Ito and Kurita (2003) who defined ISB as 'sexual behaviour that annoys other people' found a prevalence rate of 5\% and hypothesised that the relatively low rate of ISB was due to the "caregiver's subjective feeling toward the sexual-like behaviour" (p573). They suggested that staff do not regard ISB as problematic compared to other behavioural disturbances such as psychosis and aggression and therefore do not report it. However, it may equally be that a nebulous definition of ISB rendered identification and subsequent reporting difficult. Alternatively, it is possible that transcultural differences exist in how ISB is construed.

The lack of literature regarding staff experiences of ISB exhibited by older people with a dementia, and until recently the poor and variable operationalisation of the phenomenon, means there is insufficient awareness of the potential clinical impact on staff and clients (Johnson et al, 2006; Knight et al, 2008). Understanding the phenomenon is likely to have implications for staff development (e.g., training, supervision) in addition to enhancing the quality of care both for people with a diagnosis of a dementia who exhibit ISB and their families, as specified within national guidance (NICE, 2006).

\section{Aim}

To provide a detailed exploration of how staff experience and interpret ISB exhibited by older people with a diagnosis of a dementia within an inpatient setting. 


\section{Context}

The Hospital ${ }^{* * *}$ where the research was conducted offered a range of services for older people and adults, including secure services, specialist dementia and challenging behaviour services and palliative care. The majority of patients were male (76 males and 21 females). Patients were situated on wards that best enhanced their care pathway. For example, it was possible that a patient with a dementia exhibiting persistent and severe challenging behaviour might be transferred to the secure service for better management.

Training was provided during the mandatory induction covering challenging behaviour, person-centred care and use of recording tools. The Hospital also offered dedicated training regarding challenging behaviour (e.g., emphasising reinforcement principles) and sexuality though this was accessed voluntarily.

During the recruitment stage of this research significant changes were progressing within the Hospital including transition to gender-specific wards in line with the Department of Health guidance (2005). In addition, the specialist dementia unit moved accommodation. It is hard to know exactly what effect this had on the research but it was noted that recruitment of permanent nursing staff from this ward occurred in the latter stages.

\section{Relationship with the Hospital}

This author ${ }^{\dagger \dagger \dagger}$ had not worked at the Hospital in a clinical capacity. However, she had

\footnotetext{
${ }^{* * * *}$ Details regarding the Hospital have been removed/edited to protect participant confidentiality.

${ }^{i t \dagger}$ The author and principal researcher of this study will be referred to as 'this author'.
} 
conducted a service evaluation there in May 2008. This involved no patient ${ }^{\mathrm{t} t}$ or staff contact, except with the Psychology department. This author received regular research supervision at the Hospital. Additionally she observed one multi-disciplinary team meeting in August 2008.

\section{Method}

The following questions underpinned the method:

- How do staff make sense of ISB exhibited by older adults with a dementia?

- How does ISB exhibited by this patient group affect staff?

- Is ISB experienced and perceived differently compared to other inappropriate behaviours (e.g., aggression), and if so, how?

- How able do staff feel in managing ISB?

- How do staff feel about the support they receive in relation to ISB?

\section{Design}

Questionnaire designs were initially examined including scales such as the Controllability Beliefs Scale (Dagnan, Grant \& McDonnell, 2004). However, given the absence of a detailed exploration of staff experiences within dementia care this was regarded as presumptive with potential undermining of clinical applicability (Brantlinger, 1987, as cited in Yool, Langdon \& Garner, 2003). In order to generate knowledge of the area from the area, semi-structured interviews were used to elicit data and Grounded Theory

\footnotetext{
Ht 'Patient' was the term used by most participants to describe all people receiving care. This term will be adopted throughout the paper.
} 
(GT) was identified as the most appropriate methodology (Charmaz, 2006). An overview of qualitative methods, GT and this author's epistemology is provided in Appendix 2. A critique of interview methods will be discussed in the Critical Appraisal.

\section{Reflexivity}

It is essential that researchers expound any preconceptions, experiences and views regarding their area of interest (Cutliffe, 2000; Henwood \& Pidgeon, 2003; Meyrick, 2006). After all, 'everything is data' (Glaser, 1978, as cited in Cutliffe, 2000). This section will detail this author's experience, orientation and relationship with the research question.

\section{Background}

At the time of writing, this author had seven years clinical experience within the National Health Service, two of which were spent in older adult services including Intermediate Care for older people with a dementia. This author had experienced two incidents of ISB exhibited by this client group; one whilst working in Intermediate Care services as an Assistant Psychologist and one during her second year of training for the DClinPsy. Subsequently she developed an awareness and appreciation of the difficulties and dilemmas associated with ISB, which included protecting residents and staff as well as grappling with issues around sexuality and dementia. 


\section{Orientation}

Clinically, this author had cultivated her interest in George Kelly's (1955) Personal

Construct Psychology (PCP) to practitioner level and was halfway though a two yearlong specialist psychodynamic psychotherapy placement. She also had interests in community psychology, which had developed throughout training.

\section{Reflective diary}

To keep sight of the aforementioned issues and for purposes of transparency, a hallmark of quality in qualitative design (Meyrick, 2006), a reflective diary was kept, including process notes taken post-interview. The diary was also used to log tentative ideas, early memos and formulations about the data (Box 1). Additionally, this author requested to be interviewed using the interview schedule, which was facilitated by her academic supervisor and subsequently transcribed (see Critical Appraisal). The aim of the diary and interview encouraged this author to remain alert to the process of decision-making, to create an audit trail and to enhance reflexivity. 
Box 1. Extracts from the reflective diary

$26^{\text {th }}$ August 2008 - Process notes; Helen

Completed my third interview today. It felt very different from my other conversations; perhaps it was something to do with Helen's role on the ward - she gave me an 'insider's perspective'... I wondered if her resilience and way in which she talked about her experiences shocked me or went against my assumptions...It was interesting how she did not think ISB was problematic. Indeed, my opening thoughts when I first embarked on this research was 'is it a problem'? I confess, maybe my own assumption deep down is that it is...

$23^{\text {rd }}$ September 2008 - Process notes; Mike

Managed to get through the entire schedule today. Some really interesting and disturbing data emerged regarding a couple of incidents Mike was on the receiving end of. Straight away I was faced with feeling of being unsettled, violated and needing to wash. It felt quite traumatising in a way and I did draw on my therapy skills to check that things were okay. Mike seemed fine but I worry about his and other staff's sense of isolation...

$5^{\text {th }}$ October 2008 - Coding Grace

“...things worked out for the best and it was all about risk management obviously, um, which was-which was fine..." [Grace, 440-442] ... 'obviously'. Quite an interesting word. Almost a hint of sarcasm. Is this because Grace did not feel protected or that the situation did not feel particularly managed until she...instigated it? What is the function of risk management anyhow? To protect who? To manage what?....Must have been a very difficult situation to be in.

$11^{\text {th }}$ December 2008 - Sorting

I am now moving my elements/codes around on the dining room table to look for meaningful chunks, patterns, different ways of seeing my data. There is a lot... What I am starting to see are new relationships...it occurred to me that 'separating patient and behaviour' and 'seeing behaviour as part of care role' relate to coping... separate to integrate. How does that interact with the relationship?... 


\section{Procedure P§§ $^{\S}$}

\section{Ethical Approval}

The research proposal was ratified both by the Leicestershire, Northamptonshire and Rutland Ethics Committee and the Research and Development Departments for the sponsoring NHS Trust and the Hospital where the study took place (Appendix 4).

\section{Confidentiality}

Given the conduct of research in a closed system, additional measures were taken to protect participant and patient confidentiality; anonymising transcripts, modifying potentially identifiable information and gathering basic demographic information.

\section{Pilot Interviews}

In addition to piloting the interview schedule with both academic and field supervisors, a local Clinical Psychologist in the NHS and an Assistant Psychologist at the Hospital volunteered to take part in pilot interviews, which were conducted in June 2008. Both had experience of ISB exhibited by older adults with a dementia. The purpose of the pilot was threefold; it enabled this author to practice the schedule, gaining confidence in its delivery; it allowed the interview questions to be assessed in respect of their clarity and appropriate prompts to be created and finally, the author wished to monitor participant response. Ensuring that the interview was framed as sensitively as possible was paramount. Both pilot interviewees indicated that the interview felt safe. Prompts were developed following the pilot interviews and integrated into the semi-structured

\footnotetext{
${ }^{\S \S}$ A chronology of the research process can be found in Appendix 3
} 
interview schedule. Prompts included questions such as, "what were your thoughts, feelings and reactions to ISB" and "what would have made your experience of ISB more/less challenging?". The interviews were not audio recorded; process notes were taken immediately afterwards. One criticism of conducting pilot interviews includes contamination/priming of themes. For transparency, themes from both interviews are included in Appendix 5.

\section{Recruitment}

Two hundred participant information packs were distributed to senior clinicians/ward managers during a clinical governance meeting to forward to staff at ward level. Packs contained an introduction letter (Appendix 6) plus an information sheet (Appendix 7). Signed, informed consent to be approached and to participate was required prior to interview (Appendix 8 \& 9).

\section{Inclusion criteria}

Participants were required to have experienced at least one memorable incident of ISB exhibited by an older adult with a dementia. A provisional definition of 'ISB' (as used by the Hospital) and 'older adult' was provided within the participant information pack. This author was aware of the potential for alternative constructions and in line with her chosen epistemology (social constructivist GT) was prepared to embrace and explore this. 


\section{Exclusion criteria}

Participants were excluded in the absence of at least one memorable experience of ISB exhibited by an older adult with a dementia.

\section{Participants}

Fourteen participants were interviewed. Nine were female and five were male. Thirteen were White British, one was White European. Six staff were qualified and eight were unqualified. Participants comprised nine nursing staff and five allied health professionals. Ages ranged between eighteen and sixty-five years. All participants had at least one year experience of working with older adults with a dementia; a minority had over fifteen years (three people). Participants' experiences of ISB varied; for some it occurred regularly, for others it was encountered infrequently.

Of note, two participants worked in 'less traditional' dementia care settings. Neil's experience was restricted to the secure ward, where patients with a dementia without an offending history did reside, but were in a minority. Beth had experience of working with patients with Huntington's Disease. As both felt they had the necessary experience they were interviewed as part of this study.

\section{Data Collection}

Interviews, which took place at the Hospital, lasted between 30 and 90 minutes and were conducted between July 2008 and February 2009. A diagrammatic representation of the data collection process and analysis is presented in Figure 1. 
Figure 1. Diagrammatic representation of the data collection process and analysis

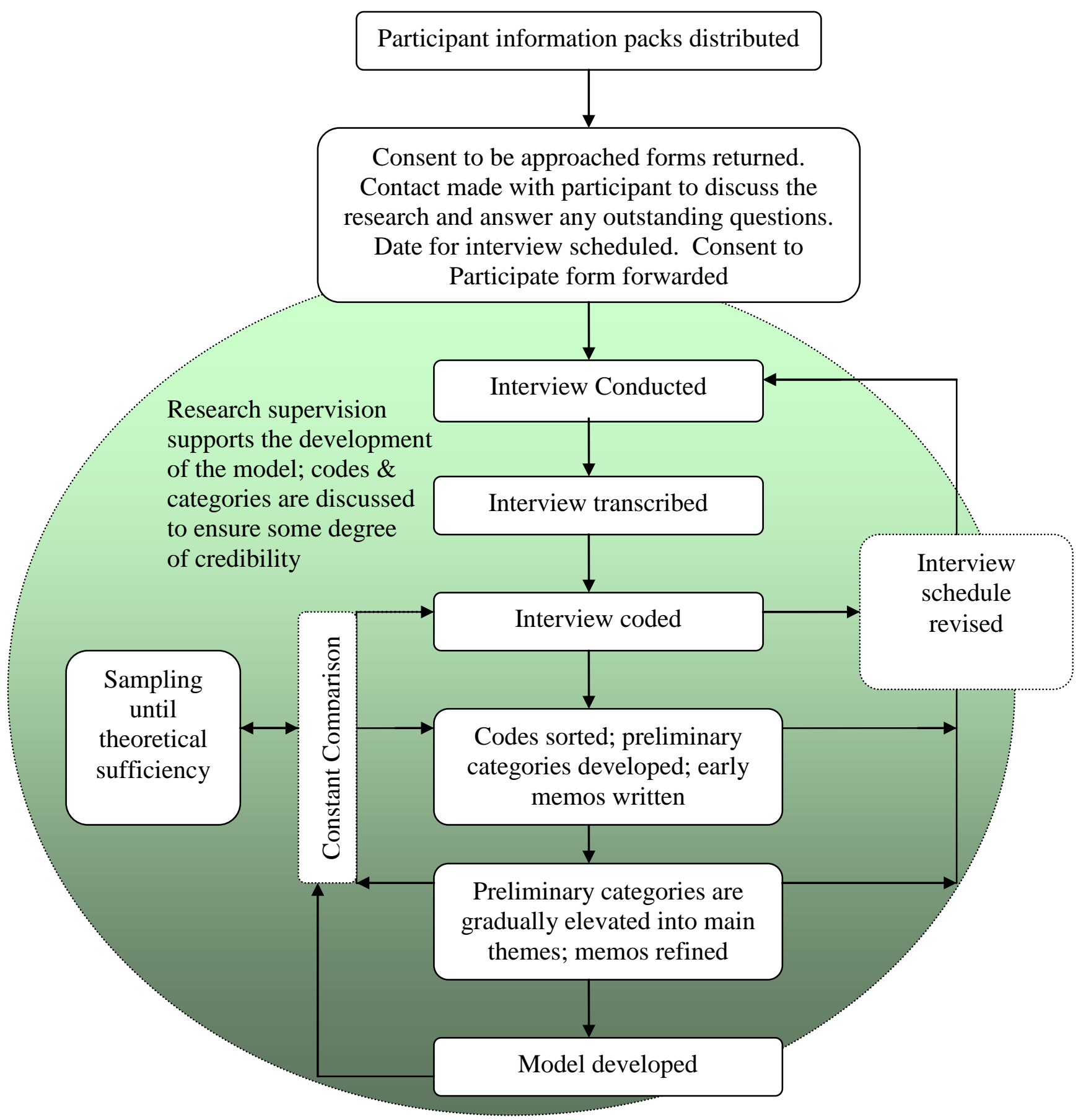




\section{Transcription}

Interviews were digitally recorded and transcribed verbatim by this author, demonstrating commitment to and a prolonged engagement with the data (Yardley, 2000) ${ }^{* * * *}$.

Participants were ascribed a pseudonym. To assist location of relevant quotations each line of each transcript was numbered. Transcribing conventions were adopted from Bailey (2008) and modified for the purposes of this research (Table 1).

Table 1: Modified transcribing conventions

Key Indicated

\begin{tabular}{ll}
\hline$(?)$ & Too obscure; unable to transcribe \\
Hhhhh & Audible out-breath \\
.hhh & Audible in-breath \\
{[} & Overlapping talk begins \\
] & Overlapping talk ends \\
$()$. & Noticeable pause; more than one second but less than two \\
$(.)$. & Noticeable pause; more than two seconds but less than three \\
$(\ldots)$ & Noticeable pause; over three seconds \\
(number) & Pauses over ten seconds are specified \\
Wantin- & Cut off/interrupted \\
I said it & Emphasis \\
[comments] &
\end{tabular}

\section{Interview Schedule}

The initial interview schedule followed the structure proposed by Charmaz (2006)

(Appendix 10). Open-ended questions were asked first, followed by intermediate questions accompanied by probes. The interview concluded with questions aimed at bringing the interaction back to general conversation. The schedule was not static; new

\footnotetext{
${ }^{* * * *}$ Interview transcripts are bound separately as an addendum.
} 
questions were added as interviews progressed, integrating domains raised by participants (i.e., theoretical sampling). Additional questions included patient sexuality, ISB experienced by a patient of the same sex, patient gender, personal space and the perceived differences between stages of dementia. As codes developed and memos were elaborated, questions designed to test out hypotheses were asked. For example:

“...something that I, I've heard said is the perceived differences between somebody in an earlier stage of a dementia, an older adult in the earlier stage... and somebody who is maybe in the later stages of, of their illness. Um, do you think that makes a difference and if so how?" (Interviewer, Rachel, p22, 535-542).

"Yeah it, it feels like the relationship with the patient is very important, um, when making sense of inappropriate sexual behaviour...I wonder what your thoughts were?" (Interviewer, Sam, p60, 1460-1465).

This author encouraged participants to explore areas of concern or significance, which sometimes meant that the schedule was not asked in full, adhering to the ethos of a social constructivist GT aimed at reflective co-creation, not interrogation (Charmaz, 2006). 


\section{Analysis}

\section{Coding}

Initial interviews were coded line-by-line permitting a detailed and open exploration of the text, initiating further questions and thought, culminating in the development of theoretical categories (Charmaz, 2006). Coding this way ensures that the researcher remains firmly grounded in the data (Charmaz, 2003), enhancing credibility. The process of sorting initial codes began after the first two interviews. This was achieved by literally cutting out each code with its accompanying line/sentence and allocating it to a plastic wallet.

Once several 'strong analytic directions' (Charmaz, 2006) had been generated from line-by-line coding and sorting, focused coding was used to elaborate codes and explicate relationships between them (see Appendix 11 for an example of coding). The constant comparative method was used throughout the analysis to compare data within codes, across codes, within and between interviews and across time (Charmaz, 2006; Glaser \& Strauss, 1967). Thoughts and ideas generated from this process formed memos.

\section{Memo-Writing}

"Memo-writing is the intermediate step between coding and the first draft of the complete analysis" (Charmaz, 2000, p517, as cited in Denzin \& Lincoln, 2000). Memos supported category development and conceptualisation by defining emerging codes, encouraging further questions, identifying gaps and motivating new directions (also known as inductive and deductive reasoning). This was achieved using the constant comparative method and was bolstered by exploiting diagrams that depicted and refined connections 
between emerging categories. Additionally, adopting active rather than inactive codes (e.g., habituating not habituate) ensured sensitivity to underlying processes within the data and ultimately elevated the analysis to theory rather than description (Charmaz, 2006). An example of a memo can be seen in Box 2.

Box 2. Example of an early memo

Acknowledging Patient Sexuality - There is acknowledgment that older people do still have sexual lives. For example, Helen talks about her example and considers if the behaviour was to prove the patient's sexual prowess. However, this does seem to clash with *the dementia diagnosis - level of illness and * patient awareness behaviours are not seen as sexual.

Links to Patient Intentionality

Links to Patient Vulnerability

Cannot hold onto vulnerable patient and sexual being at the same time. Perhaps this relates to palliation?

\section{Raising Codes to Theory}

The iterative process of coding, memo-writing, constantly comparing and sampling theoretically culminated in the emergence of several categories viewed as possessing significance to the surfacing theory, which were elevated accordingly.

\section{Theoretical Sampling}

Glaser and Strauss (1967) define theoretical sampling as;

"the process of data collection for generating theory whereby the analyst jointly collects, codes, and analyzes his data and decides what data to 
collect next and where to find them, in order to develop his theory as it emerges"(p45).

Charmaz (2006) distinguishes between 'initial sampling', which forms the starting point of the analysis and theoretical sampling. For this research, the requirement for the initial sample was that the participants had to have experienced at least one memorable incident of inappropriate sexual behaviour. Only after analysing and comparing the data from two initial interviews were 'points of departure' (Charmaz, 2006) identified and pursued (see extract from reflective diary, Box 3).

Box 3: Extract from reflective diary

19.08 .08

... When I asked her (Grace) about females on the wards I was referring to women exhibiting ISB. My intention at the time was to follow up Christopher's comments regarding behaviours seen as acceptable from a woman (verbal comments) but not a man...she interpreted my question as 'what would it be like to be the recipient of these behaviours'. Grace indicated that she would be more disturbed by this. Perhaps I need to meet a member of staff who this has happened to...

\section{Theoretical Sufficiency}

Once this author felt that theoretical sufficiency had been achieved in relation to the core and main categories (Dey, 1999, as cited in Charmaz, 2006) interviews were discontinued. Theoretical sufficiency was used as an alternative to theoretical saturation, which occurs when "gathering fresh data no longer sparks new theoretical insights, nor reveals new properties of your core theoretical categories" (Charmaz, 2006, p113). This 
author felt that reaching true saturation after fourteen interviews was probably unlikely given the expansive topic area.

Negative cases

Where participants deviated from the emerging theory, analysis was re-scrutinised and refined. Examples of negative cases will be included in the results section.

\section{Quality Issues}

Meyrick’s (2006) pluralistic overview guided this study, in which transparency and sytematicity are considered core features of rigour and quality. Transparency refers to the "disclosure of all relevant research processes (Yardley, 2000, p.222), and systematicity, "the use of regular or set data collection and analytic process, and deviation in which are described and justified" (Meyrick, 2006, p.803).

A social constructivist approach would argue that measures such as triangulation and member checks are unnecessary as there is an implicit assumption that data production is co-constructed and inherently interpretative (Yardley, 2000). However, as this was the first time this author had used GT additional measures were taken. Independent coding of transcript excerpts by supervisors occurred in addition to debriefing with peers to ensure that there was sufficient agreement regarding the emerging codes and model. 


\section{Results}

This section describes the analysis and inducted model, beginning with an overview of the core category and its relation to the four main categories. The four main categories and associated major and lower-order categories will then be explored in detail. Diagrams will be used to aid conceptualisation. Quotes are presented throughout to ground all components. Quotes are accompanied by pseudonyms, page and line numbers to facilitate location. Bold italics denote the Interviewer.

\subsection{Core Category}

The core category, 'A Question of Attribution', characterised all fourteen accounts. The term was used to reflect the way in which participants circumnavigated and explored causality in relation to ISB exhibited by older adults with a dementia (Figure 2).

Initial encounters with ISB were 'beyond participants' system of construing' and were received with shock and incomprehension. Once experienced, a process of 'Contextualising' the ISB occurred. Participants described having access to several contexts including the behaviour itself, dementia and knowledge of the patient. Contexts were highly varied between participants and influenced by, for example, the frequency with which ISB was experienced, when the incident(s) last occurred and the degree of relatedness between participant and patient (e.g., knowing patients generally supported interpretations).

Participants utilised context to 'Interpret' the ISB, which demanded several complex psychological and social processes (e.g., assessing capacity and reflecting), whilst holding the whole patient in mind. 
'Dealing With' was an in vivo term that referred to participants' responding to the behaviour by minimising it, being risk aware, managing boundaries and doing their best. Despite representing 'Dealing With' as an outcome, it could precede 'Contextualising' and 'Interpreting' and has been represented by a bi-directional arrow:

“...my instant reaction is, $i$-i-is internalised. Have I done what I should do? Mm Am I doing what I should be doing? Um (.) more so then, then afterwards you can become a bit more reflective..." (Neil, p17, 406412). 
Figure 2. Core Category: A Question of Attribution

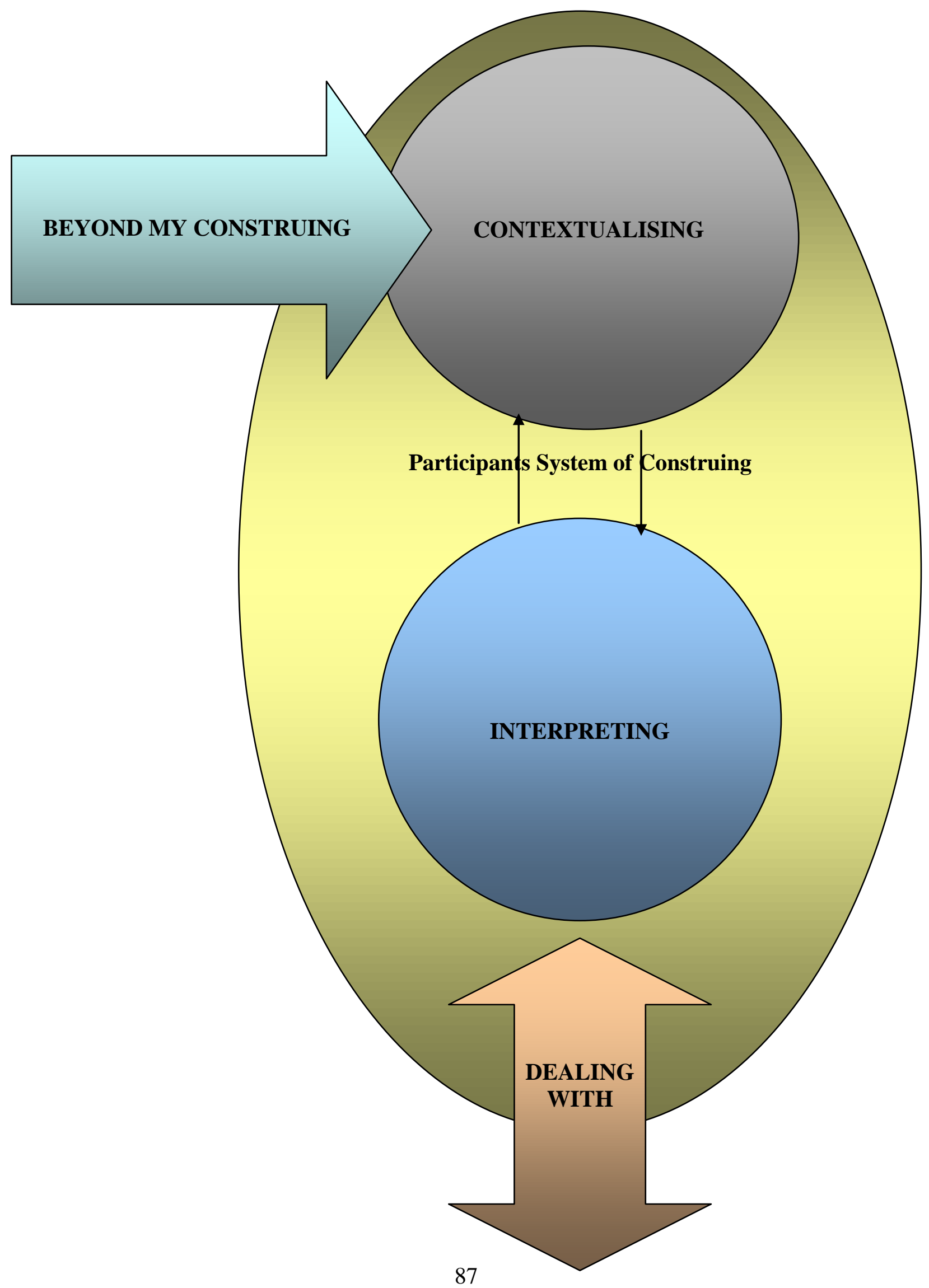




\subsection{Process Model}

The process model comprised four main categories; 'Beyond My Construing', 'Contextualising', 'Interpreting' and 'Dealing With'. Linearity was imposed on the model for structural purposes to benefit write up and comprehension. Movement between categories was fluid.

To note, wider/distal influences, which appear in relation to the main categories 'Contextualising' and 'Dealing With' are represented in the diagrams by circles that feature in the background. This is to suggest that they are less explicit/conscious influences compared to those categories that appear in the foreground.

\subsubsection{Main Category: Beyond My Construing}

'Beyond My Construing' (Figure 3) represented participants' initial experience(s) of ISB exhibited by older adults with a dementia, though was not confined to first encounters alone. This process was activated when staff met new patients, worked on new wards, depended on the behaviour type and occurred when ISB was experienced infrequently. Participants described three stages, reflected by the major categories below. 
Figure 3. Beyond My Construing

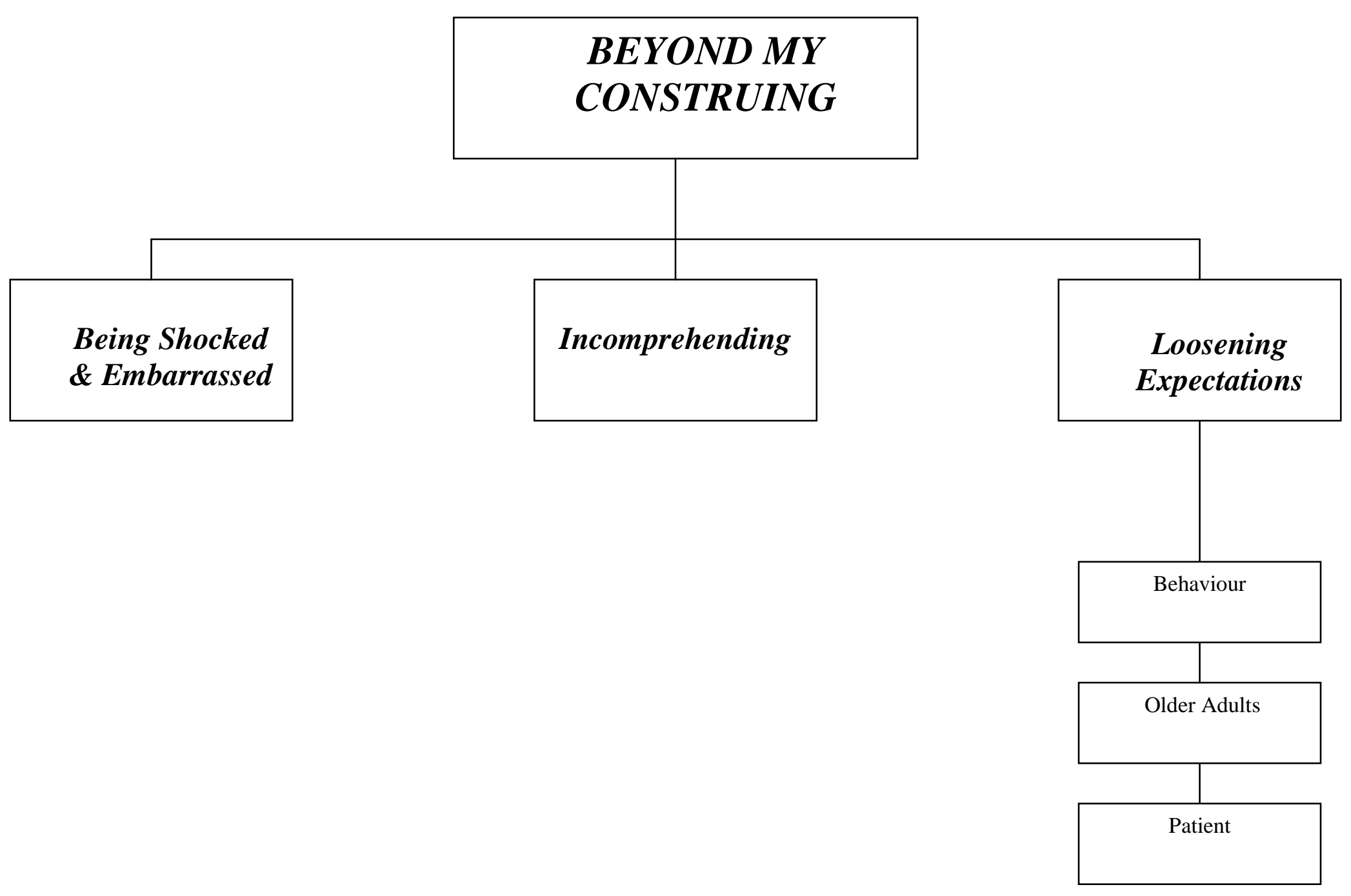




\section{Major Category: Being Shocked and Embarrassed}

“...I'll be completely honest, I was embarrassed, um took myself off for

a few minutes, didn't quite know how to respond..." (Kate, p9, 205-208).

Feelings of shock and embarrassment were initially experienced by participants. A minority felt that the shock was not synonymous with not expecting ISB, rather it related to a belief that it would not be personally experienced.

“...you don't think it's going to happen to you and when it does happen it is a massive shock and you do feel very, you know, very vulnerable..." (Anna, p62, 1533-1536).

However, Helen recounted amusement, which she attributed to being older.

"I found it quite funny. I mean, there again, probably my age." (Helen, p21, 505-506).

\section{Major Category: Incomprehending}

Incomprehending reflected the general sense of bewilderment, incapacity and disorientation in knowing how to respond to ISB $(* 1)^{\dagger \dagger \dagger \dagger}$, which changed over time with repeated experience.

${ }^{\dagger+1}$ Additional supporting quotes can be found in Appendix 12. 
“...I was quite young as well, probably quite embarrassed... maybe a bit embarrassed, not expecting it... and not really knowing what to do I suppose is the other thing. Do you $\mathbf{m m}$ do you say, 'don't say that' or do you say.hhh 'ignore it' or...” (Rachel, p11-12, 263-272).

\section{Major Category: Loosening Expectations}

This concerned participants loosening and revising their expectations regarding anticipated behaviours, the patient group and patients. Generally, participants expected to experience challenging behaviour although many, like Grace, felt unprepared for ISB $(* 2)$.

“...I didn't expect it [ISB], I guess. Um, I kind of understood and expected that there'd be challenging behaviour in terms of aggression, um, because I knew that that could be the case. I knew that that would be likely why part of the reason they were here..." (Grace, p6-7, 144-149).

Some participants had never equated ISB with the client group $(* 3)$. Two participants described their initial stereotypes of older people as benign $(* 4)$. For others, ISB was juxtaposed with younger patients because it was regarded as more in context and for a minority related to previous experience $(* 5)$. 
"You know, you'd expect, well I would expect, a younger person, maybe. Hormones going mad when you're young, yeah?" (Dennis, p40, 967-969).

Loosening expectations was a process that was also described in relation to patients who had never exhibited ISB before $(* 6)$ and related to 'Knowing Patients'.

\subsubsection{Main Category: Contextualising}

Contextualising related to the ways in which participants used different contexts to understand their experiences. Participants' achieved this by attending to the behaviour itself, using their knowledge of dementia and of the individual patient. Some described wider contextual influences, which were termed 'Upholding Social Norms' and 'Holding the Whole Person in Mind' (Figure 4). 


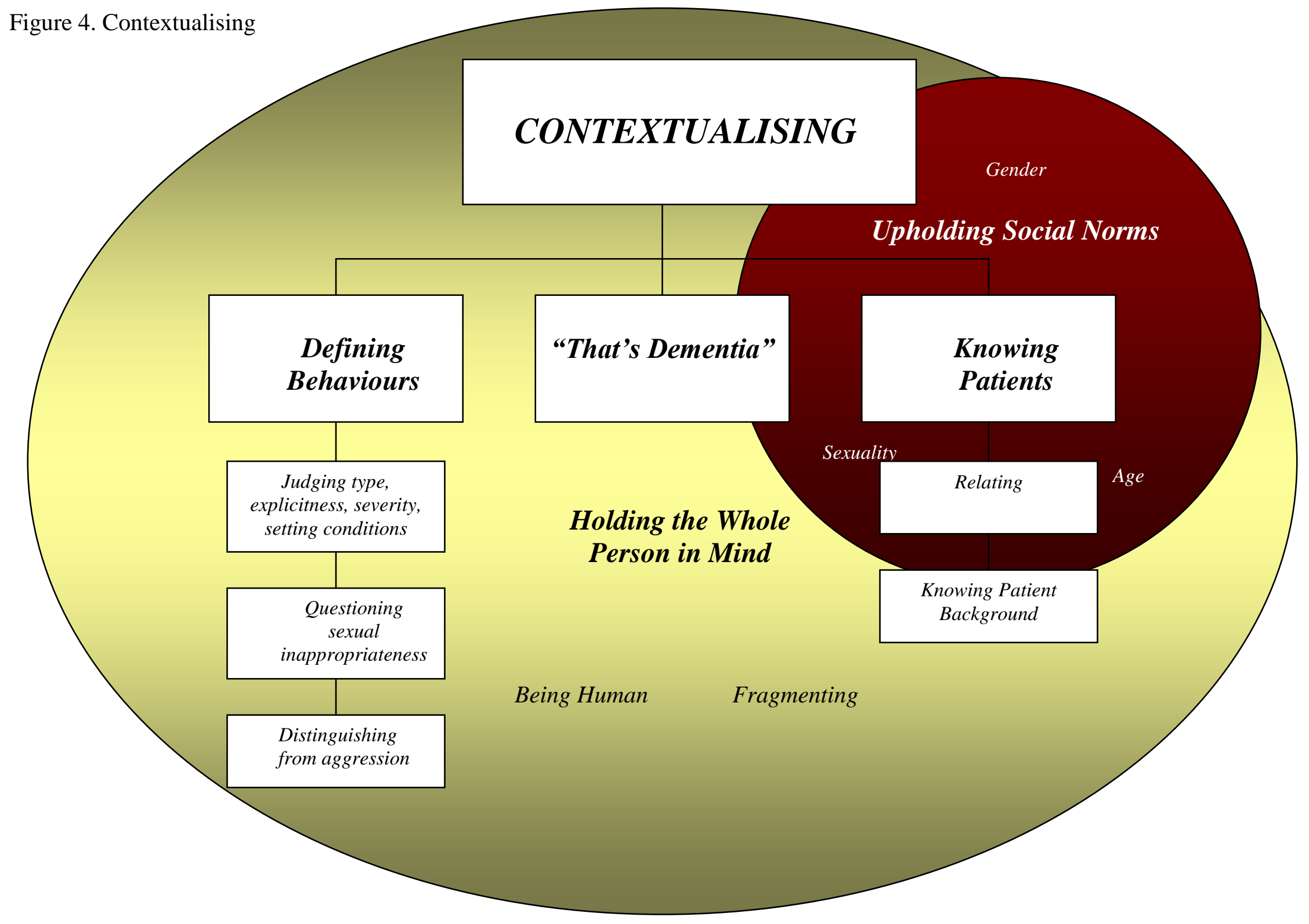




\section{Major Category: Defining Behaviours}

Participants had perceived and experienced a range of ISB from subtle innuendoes to overt behaviours such as groping, though it was noted that defined behaviours seemed more synonymous with explicit acts. Defining behaviours was an active process requiring judgements to be made using a range of external and internal sources including the type, severity and frequency of the ISB. Environment appeared vital during this process and participants questioned inappropriateness, especially in relation to personal care routines.

"I'm not saying what they are doing is right but sometimes you can (..) excuse what they're because sometimes you are putting them in a situation where they are exposed" (Anna, p22, 532-536).

Participants conveyed the importance of assessing the possible function of ISB rather than assuming arousal. For instance, participants hypothesised that disrobing related to temperature control. ISB was also construed as patients communicating need.

"...she came in the dining room and took her clothes (.) all down cause she wanted a tissue out of the holder" (Beth, p28, 671-673)

Perceptions were mediated by how staff felt towards behaviours (*7), which was subjective as different participants had different tolerance for certain behaviours: 
“... a verbal comment to me might seem very trivial but to somebody else

it, you know obviously it, it, it can differ immensely" (Kate, p7, 155-

158).

There were some interesting differences in how participants experienced ISB compared to aggression, which was frequently encountered at the Hospital. Aggression was regarded as more tangible, acceptable to others and less personal. Some participants also described feeling more uncomfortable, unsettled and exposed in relation to ISB. Grace and Sam summarised this in the following quotes.

"I'd feel more comfortable going to the ward manager and going 'oh my God I've been punched in the face' with my face bleeding than going to the manager [laughs] and saying 'I've just had my crotch (..) squeezed...the aggression's almost more, I don't know (.) obvious and blatant and in your face..." (Grace, p46-47, 1133-1142).

“...when it's actually (.) sexualised it's almost, you feel a bit like it's more direct and... I don't know what it is but I find it much more unnerving than (.) being, being called a, a nasty name" (Sam, p19-20, 468-479). 
In contrast, some participants felt that aggression was a threat to physical safety $(* 8)$ and further compromised patients by the use of restraint, which was less evident in relation to ISB.

Major Category: "That's Dementia”

'That's Dementia' (in vivo code) related to the process of contextualising the ISB within and as a consequence of the illness. This was facilitated by having knowledge of dementia through training, self-education and experience and strengthened with time and exposure. Having knowledge helped participants to rationalise their experiences, creating a sufficient enough distance for people to interpret the behaviour and deal with it (*9).

“...I weigh up the sort of pathology of the patients to sort of help me $\mathbf{m m}$ um to sort of rationalise it and, you know, not try and let it get too personal... you're able to rationalise it and see that it's a, an (.) an evident part of their illness, their disinhibition” (Mike, p32, 762-766).

\section{Major Category: Knowing Patients}

Relating with and knowing about the past lives of patients supported definition $(* 10)$, attribution $(* 11)$ and anticipation of behaviours $(* 12)$ (fundamental to risk awareness) plus assisted intervention.

"People will have, er, misinterpreted who I am in the past, have mistook me for their wife and therefore tried to kiss me, for example, um, so it's 
about for me, it's about looking into a person's history, about whether they were married, you know, what sort of life did they have before..." (Kate, p20-21, 494-500).

Knowing patients was not always possible, however, due to insufficient and inconsistent recording (e.g., staff construing behaviours as safety-seeking and failing to document) or simply not having access to information (e.g., patient history of sexual abuse that might account for their behaviour). Communication difficulties and lack of reciprocity with those patients perceived as 'more advanced' were also cited, which affected intervention.

“...the ones that I build up more of a, er, er, like a relationship with it's (.) m-it's, I think it's easier to, to deal with, you know...the ones that are less responsive...it's difficult to get a response oth-and, you have to do more for them." (Dennis, p37-38, 899-918).

Patients with a forensic history were not the focus of this study. However, some participants had experience of working with this patient group and therefore it warranted comment. Participants felt that ISB was less likely to be tolerated and internal attributions were more common compared to patients without an offending history $(* 13)$. Despite this difference, treatment was reportedly similar. 


\section{Major Category: Holding the Whole Person in Mind}

This category referred to the way in which staff attempted to keep the whole person in mind whilst contextualising ISB, a process that was characterised by narratives of integration and fragmentation. 'Being human' related to participants trying to maintain the humanity, dignity and sexuality of patients through a process of empathy, sympathy and for some an awareness of their own mortality $(* 14)$.

“..I think I just try to look at the whole person. Try and keep their dignity intact..." (Kate, p40, 987-989).

"...at the end of the day they are human, the same as us and they do have needs and I think sometimes, you know, maybe that is forgotten about..." (Anna, p47, 1154-1157).

“...these are people who, who's, um, who don't have the inhibitions upon us that, you know (..) we do and there but for the grace [Julie taps the table] of God go all of us really in a way..." (Julie, p8, 177-180).

Keeping the whole patient in mind was impacted upon, at times, by perceived capacity; the less aware patients were perceived to be, the more fragmented they were regarded $(* 15)$. Separating the ISB from the patient occurred through a process of desexualising and diminishing and when exhibited by patients without awareness was generally regarded as a 'misfiring of the brain' as opposed to sexual. 
“...you felt sorry for him because you thought 'oh God love him, you know, he doesn't know what he's saying...He's not being sexual. Well, he is, the words are but his intention isn't there, not really..." (Helen, $\mathrm{p} 25,605-610)$.

Desexualisation was also viewed as a wider organisational issue.

....I personally think that (..) if, if patients have been in (.) in hospital

for quite a long time they tend to become asexual (.) in my

experience..." (Steve, p9, 214-217).

\section{Major Category: Upholding Social Norms}

This category concerned the way in which social constructions, namely gender and sexuality, permeated the Hospital. Generally, ISB was associated with male patients. Female staff, especially young females, seemed more likely to be the recipient of ISB compared to male colleagues. However, there appeared to be a qualitative difference in the way ISB exhibited by male and female patients was perceived, especially when patients were regarded as 'early stage'.

“...usually if it's a man it's always seen as sexual, if it's woman it isn't... if it happens from a patient male, a male patient, staff will usually see that as sexual but if it's a wo-a female patient they tend not 
to because it's, they give like an allowance of what's expected or what's not" (Christopher, p18-19, 446-461).

This 'allowance' seemed to relate to behaviours being seen as 'flirtatious' or 'friendly' rather than being sexually inappropriate $(* 16)$.

“...I'm not saying that's how I think but she's a woman, she's harmless, she's not going to do anything...it's just flirting, I think. Where do you think that comes from? I think that's just social norms, to be honest. I think if a woman flirts it's harmless, if a man flirts he [laughs]...he's up to something, you know, he's not just flirting..." (Sam, p47-48, 1151-1164).

Interestingly, observations suggested that the type of ISB exhibited differed between the sexes; women were more likely to disrobe and men were more likely to publicly masturbate $(* 17)$, possibly contributing to perception.

These differences also resonated with participants' own gender. Male participants tended not to see themselves as a target compared to females $(* 18)$ possibly reflecting patient composition at the Hospital (i.e., predominantly male). Females were sensitised to/anticipated ISB exhibited by male patients and somewhat desensitised to ISB exhibited by female patients $(* 19)$. 
"I'm thinking of another patient at the moment that I go and see now who's (.) who has this very penetrating look... it has sort of those sexual overtones...I mean as a woman you are aware of things like that" (Julie, p9, 207-216).

Dennis' experience of being groped by a female patient caused uncharacteristic disturbance. This was not related to the behaviour per se but stemmed from how he believed others would construe a potential allegation.

“...it's (.) maybe (.) something to do with what you think other people think...you know, being (.) a, a male that's married and, you know...the likelihood of me (.) touching a male patient [laughs]..." (Dennis, p50, 1211-1219).

Assuming heterosexuality was reported by some participants to pervade the Hospital, which radiated beyond interpretations of ISB into realms of patient sexuality, sexuality and older adults and participant sexuality.

“... people tend to think everybody's sort of, um (.) heterosexual, I think, um, and obviously, you know, we have same sex relationships and with older people I think people find that a little bit um (.) unusual [laughs] shall we say" (Kate, p51, 1241-1245). 
This seemed to account for Mike's unsettling experience of ISB exhibited by a patient of the same sex.

“...I just think from another male, um, it's just (.) different, er, a male displaying some sexually inappropriate behaviour. It was quite (.) sort of difficult to deal with. I'm not a homophobic in the slightest but there was just something more uncomfortable” (Mike, p44-45, 1074-1081).

Largely participants did not think that the age of the patient was relevant in experiencing and interpreting ISB.

“...do you think age is a relevant factor in inappropriate sexual

behaviour?...No because at the end of the day dementia can strike anyone as I've just said"' (Helen, p38, 930-937).

However, a small minority of participants indicated that 'old-fashioned' views existed including disbelief that older adults were sexually active, possibly relating to social context as many older patients were widowed and without a sexual partner.

“...it's happened quite a bit and people have 'oh my God. I didn't think they-they'd still do that'. You know what I mean? And you're thinking well hang on. They're still sexual beings. They might be a bit older..." (Steve, p14, 320-325). 
For one participant who had an elderly relative with a dementia, 'ISB and older people' seemed incomprehensible highlighting the personal significance staff bring to their work.

\subsubsection{Main Category: Interpreting}

Participants described attempting to make sense of ISB, which involved cognitive, emotional and socially-driven processes and are represented in the diagram (Figure 5). 
Figure 5: Interpreting

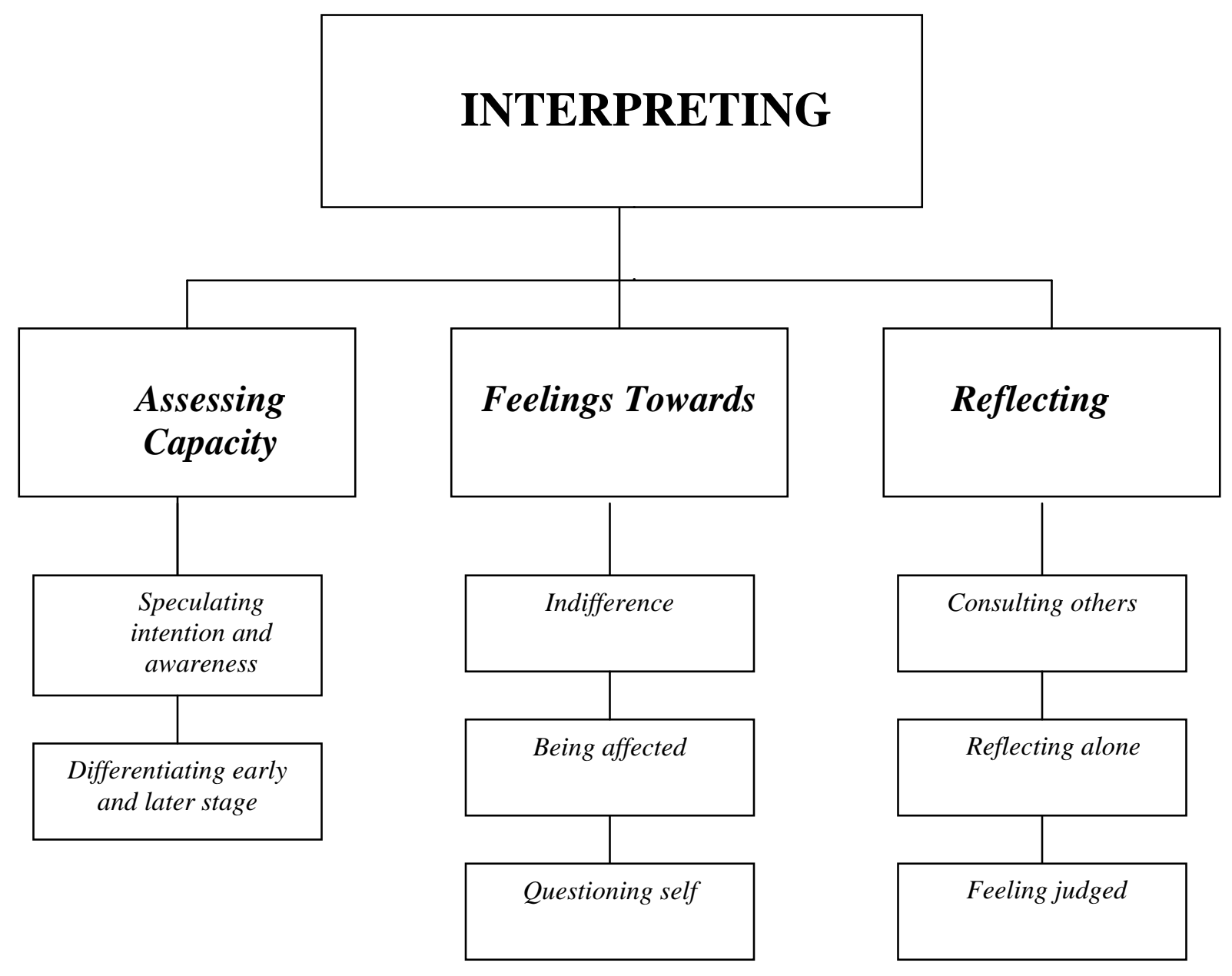




\section{Major Category: Assessing Capacity}

Many participants speculated about patient intention and awareness, shaped by their knowledge of the individual and dementia. For many there appeared to be a clear differentiation between early and later stage dementia. Inappropriate sexual behaviour exhibited by 'patients in the earlier stages' was considered sexual, intentional and within control whereas ISB exhibited by 'patients in the later stages' was desexualised because patients were generally seen as unaware $(* 20)$. Explorations of how early and later stage dementia was identified revealed that participants predominantly used physical indicators, such as mobility and continence control.

"He knew exactly what he was doing, which, which I find difficult to get my head round because he's got (.) dementia...people with really bad dementia and Alzheimer's, they're incontinent, they can't feed themselves. I mean he does all that, he walks around, takes himself to the shower, goes to the toilet, feeds himself, has a conversation with you. So he must be (.) very early stages I would assume else he wouldn't be doing all this for himself, would he?" (Helen, p24, 576-589)

Patients construed as lacking capacity were generally exculpated. When patients were seen to have intention it often co-existed with a belief that they had capacity to extinguish behaviours. This had the potential to generate feelings of anger and a lack of sympathy within participants and staff teams. 
"What sort of, um, feelings, emotions did that sort of behaviour create on the ward (.) do you think? Er, there was a lot of anger at the time because um (...) a lot of staff thought that er (.) this particular patient was just doing it for attention..." (Rachel, p18, 418-424).

This was not unanimous, however. Kate described one patient who was considered to have capacity yet his behaviours were met with good-humour and reluctance to record, possibly relating to 'knowing patients' and 'defining behaviours'.

“...we've had a chap who does, you know, like to touch a bottom and pat and it's all done very jovial..." (Kate, p23, 557-559).

Not all participants felt that assessing capacity was relevant in interpreting ISB. Patient history $(* 21)$, the diagnosis and the behaviour $(* 22)$ seemed more important.

Major Category: Feelings Towards

"What sort of emotions would be attached for you? Indifference really. Indifference. Because first of all they can't help it, if they've (.) dementia." (Helen, p19, 452-457).

Feelings towards ISB appeared equivocal with some participants reporting indifference, others feeling exposed and violated. Those who reported apathy towards ISB 
contextualised it in the dementia diagnosis $(* 23)$ though on exploration all participants reported discomfort at some point, especially regarding earlier experiences. Explanations for why participants remained relatively neutral included a greater concern for the dignity of the patient or colleagues, the type of ISB, having a 'thick skin' and limited experience $(* 24)$.

“...how does inappropriate sexual behaviour exhibited by an older adult with a dementia affect you? If at all. To be honest I just worry about the dignity of the person. That sounds really bizarre but I guess it will depend on the severity of it...I've never sort of been in a, a potentially an unsafe environment where somebody's actually, you know, for example pinned me against the wall and made it a little bit more...disturbing” (Kate, p39-40, 960-973).

In contrast to indifference, feelings of awkwardness, disturbance and upset were experienced by some participants $(* 25-* 26)$ with a minority experiencing anger $(* 27$ *28).

“...I just felt like a, you know, just [laughs] a bit sort of dirty really.

Mm. You know and I felt like I must [gently laughs to the next five words] go and have a shower but. Yeah. You know, just really felt quite unsettling I, yeah I must admit that one was really (.) really difficult to deal with and I've certainly been a lot more careful with that particular patient since” (Mike, p7, 160-171). 
None of the participants shared any personal history of abuse but this was raised as a potential factor regarding staff distress:

“...some people can be quite distraught...you know especially if they've had a bad past before or something, it triggers something off..." (Anna, $\mathrm{p} 7,170-173)$.

A minority of participants, including those generally indifferent towards ISB, questioned themselves. Specifically, they grappled with the question of whether or not they had 'led the patient on'.

“...I've got a fairly thick skin. But it made me question whether I'd done something to encourage it (..) I think in a way, cause I suddenly sort of looked back and thought, well I did used to, you know, go up to him and, and talk to him perhaps more than other patients... so I suddenly thought oh God I hope that I haven't done anything to make him think that I'm having a relationship with him" (Grace, p16, 380-392).

For Kate, this process dissipated over time but had the potential to reoccur depending on the context.

\footnotetext{
"Have your reactions to inappropriate sexual behaviour changed over time and if so what are your reactions now? Yeah, I don't feel
} 
embarrassed anymore. I don't feel that it's my fault. I don't question whether I'm being too friendly (.) although on saying that I did on one occasion. I did on one occasion recently because a patient sort of became a little bit almost fixated on me..." (Kate, p13, 310-318).

Despite most participants reportedly feeling comfortable discussing ISB and issues around sexuality, this felt questionable. The use of laugher and whispering responses suggested possible unease/embarrassment.

"He was sitting facing me (..) and he started exposing himself and masturbating in the lounge [Beth says 'masturbating in the lounge' quietly]" (Beth, p9, 200-203).

\section{Major Category: Reflecting}

'Reflecting' captured the way in which participants processed their experience(s) of ISB. This could be a shared process and/or undertaken alone. Consulting others, in particular peers who knew the patient, was described as adequate, supportive and utilised though for a minority ISB remained a taboo $(* 29)$. Sharing experiences assisted formulation and intervention, remaining mindful of potential prejudices, validating experiences, gaining perspective and reducing isolation $(* 30-* 31)$.

“We make judgements all the time. We're, it's what humans do...but it's being conscious of that and saying well, you know, ok but is that 
effecting (.) you're, you're ability to be effective?...You have to be honest which is kind of what I think of with the MDT, coming back to the ward round, we're able to do that, in a way" (Neil, p74, 1811-1824).

“... knowing about it, talking about it, being open about it, being $\underline{\text { aware }}$ of the risk, talking about the best way to deal with it...I feel much (.) um, safer and um, much more positive about engaging that person which ultimately promotes their quality of life..." (Grace, p62-63, 1533-1540)

A minority of participants felt less able to seek support and reflected alone, apparently a consequence of lack of opportunity and understanding in conjunction with the infrequency of ISB (*32). Furthermore, very few people reported having regular access to clinical supervision. For some, anticipating a negative response from colleagues impeded participants from sharing their experiences, which had the potential to exacerbate distress.

"I didn't want to really discuss it with her (colleague) cause I knew she'd be like 'oh, so what?... so, um, I did sort of, ruminated on it myself. And how did that feel for you, Mike? Just again, I just felt pretty violated, really and just a sense of being (.) you know like I wanted to go and have a wash." (Mike, p11, 251-259) 
Personal reflection for Sam allowed her to carry on with the task at hand.

"I might just (.) have a bit of quiet time just, just on my own. Not, not do anything but (.) and within five minutes, so we're up and about, just that little bit of reflection." (Sam, p10, 241-245).

\subsubsection{Main Category: "Dealing with"}

'Dealing with' was an in vivo term used by all participants to denote how they responded to ISB.

"You know we just deal with it” (Beth, p34, 815).

The word 'deal' is quite interesting. Participants did 'deal with' ISB as agreed by their teams (e.g., care planning, risk assessment) though at times interventions appeared reactive and ad hoc.

'Dealing with' was also adopted to convey the general tone with which participants talked about responding to ISB that was often blunt and unemotional. 'Dealing with' ISB was a source of concern for some participants and will be outlined below. See Figure 6 for a diagrammatic representation of this category. 
Figure 6. Dealing With

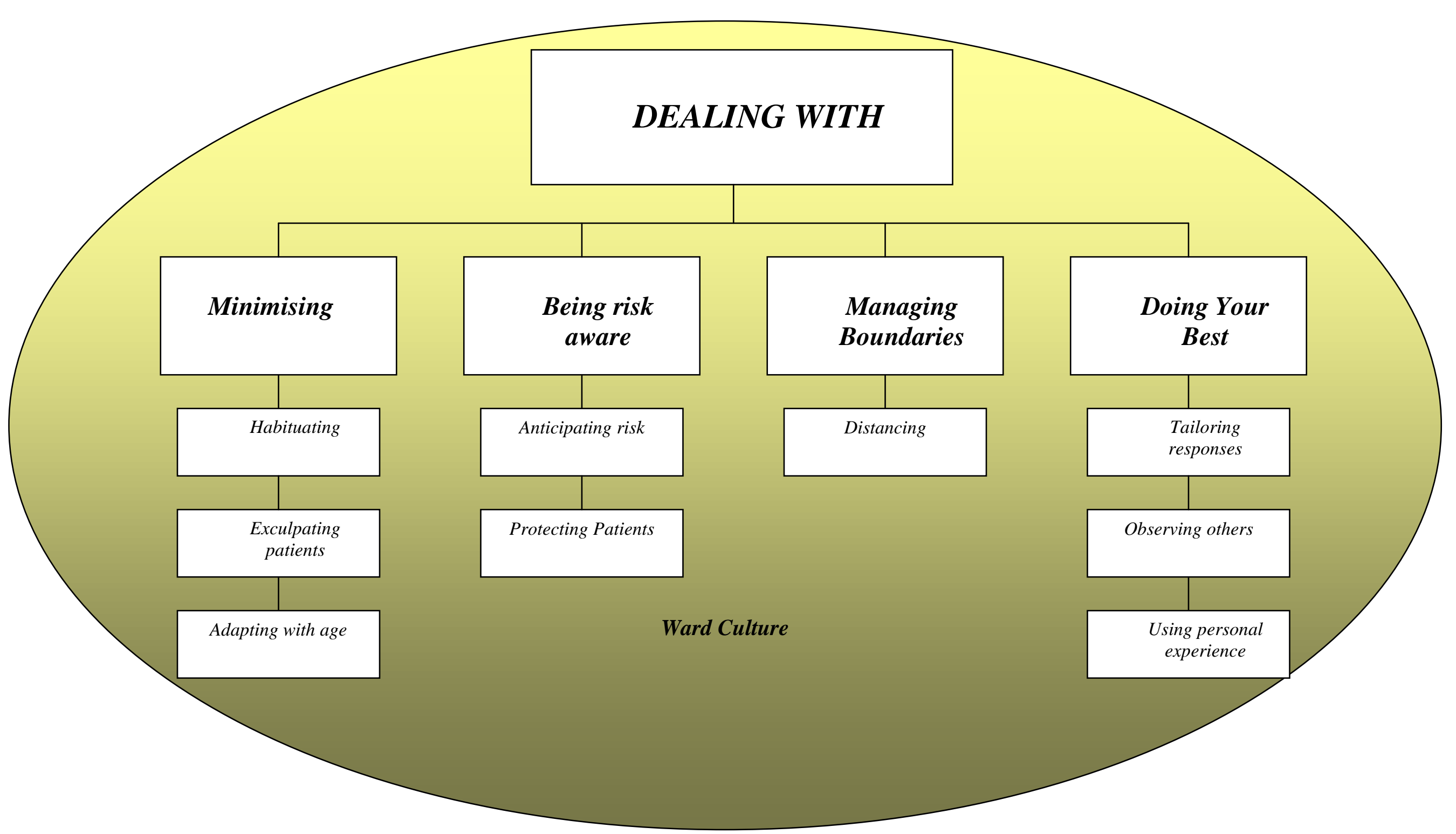




\section{Major Category: Minimising}

The process of minimising ISB developed over time and related to the categories 'knowing patients', 'assessing capacity' and 'indifference'. Minimising occurred in three foremost ways; 'habituating', 'exculpating patients' and 'adapting with age'.

With repeated exposure, participants described 'getting used to' and 'immune' to ISB $(* 33)$.

“...you can just get used to it really. You know, a lot different patients $\mathbf{m m}$ over the years and a lot of it's cause of their illness more than anything else" (Eileen, p2, 32-36).

“...you sort of get immune to it after a bit so you forget that, not that you, you don't forget, you see it and it's just a natural thing" (Dennis, p3, 65-68).

As Rachel noted, this process protected staff.

“...you can't (.) react every single time otherwise you would be exhausted" (Rachel, p46, 1128-1129)

Some participants reported concern that habituating could foster a 'blasé attitude', endangering both staff and patients, linking to 'being risk aware' (*34). 
Exculpating patients predominately occurred when ISB was perceived as uncontrollable, and seemed to develop over time with experience.

"I think again as, as, as (.) as patients decline (.) staff (..) think, 'oh well they can't help it' whereas...to begin with it's like (.) almost like a personal.... think people take it very personally" (Rachel, p23, 558-564)

Exculpating did not mean the behaviour was seen as acceptable, though many acknowledged that it could be an aspect of a patient's presentation (*35). For Anna, despite 'overruling' ISB and construing patients as unwell, she still could not entirely free patients from fault.

“... it's not right and we are not here to be abused in either sexually or, you know, mentally..." (Anna, p7, 159-161)

'Adapting with age' emerged from conversations with female participants who defined themselves as 'older'. Due to time restrictions, and because all of the males were recruited earlier in the study, no attempt was made to sample for potential gender differences, although transcripts from all male participants were re-analysed.

Female participants felt that dealing with ISB evolved with age. In addition to having more transferable life experiences, participants viewed themselves as more accepting of life in general, more self-aware, more willing to talk about sex and 
possessing enhanced coping mechanisms that supported their response to ISB compared to younger colleagues, although this was not unanimous $(* 36)$.

“...I suppose being older as well we get more comfortable in our own skin and more confident...” (Beth, p20, 467-469).

"...you get the jokes and the jests and the innuendos and over the years and the older you get you just take no notice. And I think I've brought that with me...maybe you sort of get a bit immune and you think, 'oh yeah', you know 'here we go again, another comment'. Whereas the younger ones..." (Helen, p16, 377-388).

Participants said they were less likely to regard themselves and be regarded as sexual objects, which possibly enabled a greater degree of indifference towards behaviours.

"I think you feel you're getting older and you're no longer perhaps a ...sexual object. I don't quite mean that Mm But, you (.) you know, you see your wrinkles on your face every morning and you, you know, do a Germaine Greer. You know, Germaine Greer said something about becoming a, a, um, invisible” (Julie, p11-12, 266-276).

Commentaries from younger participants appeared to fit with reports from older colleagues, in particular participants reported more discomfort and less acceptance of 
ISB. However, this did not necessarily relate to assertiveness. Younger participants compared the rapport between themselves and older patients to relationships with older male relatives.

"I feel uncomfortable (.) in the fact that, you know, it's (.) um, the patients you work with and I suppose (..) um, because their age and you kind of look at it that they're old enough as your father and stuff..." (Anna, p42, 1033-1038)

Interestingly, this was not exclusive to younger participants. Eileen used the daughterfather relationship to highlight the inappropriateness of patient behaviour when other interventions failed (*37) possibly linking with 'Loosening Expectations' and 'Upholding Social Norms'.

\section{Major Category: Being Risk Aware}

'Being Risk Aware' was a predominant discourse within the Hospital and mediated by knowing patients, assessing capacity and ward culture. Knowing which patients would exhibit ISB and having a context alerted participants to the possibility and associated risk of ISB, a process also applicable to aggression. At ward level it ensured measures were introduced to protect staff and patients from harm, offence and accusation. 
"I'm certainly, um a lot more cautious with particular patients, er with that patient I'm, I'm more sort of risk aware..." (Mike, p12-13, 299$302)$.

“...if there's a patient um (..) that would be quite forceful, not that we've really got any but if there was then you would go in (.) you wouldn't go into the room by yourself. You'd go in with other members of staff..." (Eileen, p40, 965-970).

Protecting staff/patients also demanded consideration of patient wellbeing. For example, a minority of participants described the importance of male patients having access to female company:

“...you've got to balance out if the patient, um, gets a lot from just female company...it's a difficult one because obviously you've got to protect you, your staff but you've got to look out for the welfare of the patient so $\quad$ mm it's a difficult one” (Steve, $\mathrm{p} 30,727-735)$.

In terms of anticipating risk, some participants believed that older adults, especially those construed as having an advanced dementia, were less risky. This contrasted with experience of other patient groups, especially younger patients and for some had shaped their decision to enter into dementia care $(* 38)$. 
“...I don't see older adults with dementia as a threat... I feel quite safe

(.) in being in between all the adults with dementia as far as sexual

behaviour is concerned..." (Christopher, $\mathrm{p} 42,1028-1038)$.

“...when they're younger (..) I think they would be more forceful anyway

$\mathbf{m m}$ where as with the elderly they're a bit more gentle" (Eileen, p22,

524-528).

\section{Major Category: Managing Boundaries}

The use of touch was viewed as permissible in dementia care because it enabled participants to engage with patients who might otherwise be 'lost' and disconnected. Some participants reported ambivalence within staff teams with some colleagues regarding touch as unsuitable. When patients became disinhibited this was not always deemed appropriate and a minority of participants raised their discomfort regarding 'different boundaries for different patients', which was felt to confuse patients.

"...one thing that is very uncomfortable for me is go to a ward where on hand-over they tell me (.) that patient likes to touch, no allow (..) but then on the same ward they've got another patient who is allowed to touch and that patient is going to see it but he doesn't know why or if he knows he forgets..." (Christopher, p62, 1524-1530) 
This was particularly poignant for Christopher whose transition into English culture and into the Hospital environment challenged his very way of relating.

“...progressing throughout the years and coming to $X$ [Hospital] with the training we get...I would rather not shake someone's hand than (.) or, or not, um hugging someone than...I've become more, um, distant, more cold to those situations..." (Christopher, p28-29, 684702).

This category also referred to staff highlighting boundaries to patients $(* 39)$ and was particularly difficult for some participants when patients mistook them for loved ones.

“...it was very uncomfortable for me and I did feel, you know, really horrible, um (.) but also the patient must feel really awkward when you explain to them no, you're not that person who you think I am" (Anna, p63, 1557-1561).

Physical distancing was used by participants who had been affected by their experience of ISB and could be relatively transient. Anna, for example, used physical distancing when her capacity to tolerate ISB and other challenging behaviours was limited.

“...if I felt okay and I was having an okay day and, and (.) sexually inappropriate, you know, someone was sexually inappropriate, um, I'd 
deal with it...if I was very stressed and (.) sexually inappropriate happened I think I would kind of like (.) maybe not deal with that patient for the rest of the day and that's maybe not a good way on how you deal with the situation ..."(Anna, p30, 727-738)

For Sam, however, the process of detachment was longer-term.

“...I had to separate myself from him yeah so it had an impact on our relationship...It was easier to detach myself and hear it from him than yes than (.) being very friendly with him and just having that rapport and then hearing it"' (Sam, p64, 1556-1564).

Psychological distancing occurred either through construction of an emotional barrier or through self-reflection and rationalisation, which made the ISB feel less personally directed and easier to deal with.

“...you do put up a bit of a barrier ...” (Sam, p66, 1607-1608).

“...in order to function or, or cope that there has to be a degree of detachment” (Neil, p98, 2401-2403). 


\section{Major Category: Doing Your Best}

Despite care planning, dealing with ISB was generally approached heuristically. Staff appreciated that a 'one size fits all' method was impossible, nor person-centred.

However, this caused frustration compounded by a perceived lack of dedicated training on management of ISB.

“...we react to the patient but then there's no follow-up there, there's no teaching, there's no explaining...staff are left to their own devices to decide what to do in those situations. People come with their own knowledge, their own experiences, they come to a place where there's training for everything (..) but for that (ISB), and you see a patient kissing or try to kiss you, you react to (.) to who you are, you $\mathbf{m m}$ you know, you, you do your best..." (Christopher, p64-65, 1575-1589)

Tailored interventions were designed for patients exhibiting severe and persistent ISB. For patients without formalised care plans, participants developed ways of dealing with ISB based on their knowledge of the patient and was facilitated by observing others, especially at the beginning of their careers.

“...I think as you become more, um (..) knowledgeable about your patient group and individuals mm you, you kind of know how to deal with each situation as it arises with each patient" (Rachel, p14, 322327) 
“...I don't think I've had any formal training as such but you learn from other people and when they talk about things" (Julie, p19, 452-455).

Participants drew on previous experiences of responding to ISB in order to deal with it and to judge its inappropriateness (i.e., 'Defining Behaviours'). Previous experience included that with the same patient, experiencing similar behaviours within the Hospital context and in other work settings and personal experiences beyond work, such as experiencing ISB 'out on a Friday night'.

"You get more experience after d-Hhhhh, after it happening every shift after a while" (Dennis, p17, 405-407).

"You've got more life experience, more experience in general and as I say reverting back (.) that stood me in good stead when I worked with a lot of males..." (Helen, p61, 1491-1494).

\section{Major Category: Ward Culture}

Inappropriate sexual behaviour occurred within a culture including that of the ward, the Hospital, mental health care, the professional, personal, wider and changing cultures. Given the enormity of 'culture' this category did not reach theoretical sufficiency with the exception of ward culture. 
ISB seemed to be construed and dealt with differently depending on ward ethos (*40) and related to 'Defining Behaviours', 'Assessing Capacity' and 'Being Risk Aware'. On the specialist dementia ward, ISB was more likely to be minimised $(* 41)$ and clinical leadership was implicated as being influential.

“...the staff on $X$ [specialist dementia ward] unless it's really explicit and sometimes it is, would see it more as (.) just part of the care role. It's much more a residential kind of feeling to it" (Grace, p28, 688-692).

\section{Discussion}

This section will now discuss the findings in relation to relevant literature and existing theory, specifically attribution theory, personal construct psychology and gender. A critique will be presented in addition to considering clinical applicability and further research.

\subsection{Core Category}

A 'Question of Attribution' conceptualised all fourteen interviews and referred to the way participants accounted for ISB exhibited by patients with a dementia. Attribution theory is essentially a learning theory that seeks to understand how people experience, comprehend and predict the world by ascribing causation (Munton, Silvester, Stratton \& Hanks, 1999). Attribution theory has been applied to the learning disability field (Noone, Jones \& Hastings, 2006; Weigel, Langdon, Collins \& O’ Brien, 2006) and other health related care settings (Mackay \& Barrowclough, 2005) to understand the relationship 
between staff attributions and interventions. The model predicts that the more internal (dispositional), controllable and stable (permanent) attributions are the less sympathy and help are elicited (Weiner, 1986, as cited in Weigel et al, 2006).

Controllability was a key characteristic in the major category 'Assessing Capacity'. Rudolph, Roesch, Greitemeyer and Weiner (2004) conducted two metaanalytic reviews of help-giving and aggression that supported a sequential cognitionemotion-behaviour model; judgements regarding controllability (cognition) produced sympathy or anger (emotion) that mediated helping or not helping (behaviour).

Participants in this study described a myriad of intrapersonal, interpersonal (i.e., 'Reflecting'), conscious and less conscious processes (i.e., 'Upholding Gender Norms') whilst attributing ISB. Participants largely attributed ISB to external factors (i.e., 'That's Dementia'), assuming uncontrollability, which according to the model should generate sympathy and help-giving behaviours (Rudolph et al, 2004). However, this was not necessarily the case and despite making attributions of uncontrollability some staff reported upset, distress and even anger, which for some undermined subsequent support/interventions. Furthermore, where attributions of control were stipulated emotional response varied between anger and conviviality.

Rudolph et al (2004) acknowledged the potential for further permutations to their model. The findings from this study extend it and contribute a richness and complexity particularly developing a previously absent temporal dimension. During early encounters with ISB ('Beyond My Construing') participants described less of a sequence of experiences ('shock and embarrassment') rather an inability to understand ('incomprehension' ). With repeated exposure and increased context, participants 
gradually ascribed causation. Arguably, their Rudolph et al did not investigate ISB. In this study ISB was regarded by participants as qualitatively different from aggression, possibly accounting for these findings.

Interestingly, Todd and Watts (2005) discovered limited support for the role of attributions in their study examining helping behaviour of staff working with older adults with dementia who exhibited challenging behaviour. They suggested that the care role supersedes beliefs about causation; internal and controllable attributions could "be cognitively dissonant with core beliefs about professional role and helping” (p.79). This appears to be supported by the literature (Fopma-Loy \& Austin, 1997; Werner, CohenMansfield \& Newman, 1999) and may explain the propensity for participants to 'Minimise' and 'Deal With' ISB.

\subsubsection{Beyond My Construing}

This category was influenced by George Kelly’s Personal Construct Psychology (1955, as cited in Fransella, 2005). According to Kelly's fundamental postulate, “a person’s processes are psychologically channelized by the way in which he anticipates events" (Fransella, 2005, p253). The term was used to capture the way in which participants' constructs were reorganised in light of their experience of ISB (Kelly would call this 'dilation') leading to looser constructs, enabling various predications to be made. The alternative to dilation is 'constriction', whereby perception is narrowed "in order to minimise apparent incompatibilities (Fransella, 2005, p 255). Examples of this included Sam's efforts to distance herself from a patient because ISB in the context of their relationship was irreconcilable. 


\subsubsection{Contextualising}

The power of attributions to shape staff response diminishes with increasing contextual information (Todd \& Watts, 2005), resonating with these findings. Participants utilised various contexts to understand their experiences including the behaviour itself, their knowledge of dementia and of the patient. Some participants also described wider contextual influences, for example, gender. Contextualising challenging behaviour exhibited by patients with dementia is known to facilitate understanding and supports patient-staff relationships (Edberg et al, 2008; Kovach, Noonan, Schlidt \& Wells, 2005), which has been linked to job retention (Sung, Chang \& Tsai, 2005).

Factors such as type, frequency, severity and environment, subjectively construed, seemed to define behaviour as appropriately or inappropriately sexual. Judgement was problematic, not least because "the lack of clear demarcation lines of sexually appropriate and inappropriate behaviour in the wider community emphasizes the difficulties in setting such boundaries within a rehabilitation setting" (Johnson et al, 2006), which seemed qualitatively different from aggression.

There are clearer discourses, structures and dedicated research regarding violence and aggression within health care services (Unite, 2007; Evers, Tomic \& Brouwers, 2001; McKenna, Poole, Smith, Coverdale \& Gale, 2003; National Health Service Security Management Services, 2005). Attempts to bring clarity to ISB are in their infancy (Johnson et al, 2006; Knight et al, 2008) and appear to be complicated by wider and ambiguous social and political contexts regarding what is sexually inappropriate. This may also explain the distinction participants made between training for managing aggression and the lack of training for managing ISB. Although the Hospital viewed the 
principles underpinning aggression training as transferable, participants generally felt that ISB and its impact on staff was qualitatively different, necessitating specialised training.

Tom Kitwood (1997) referred to care practices that objectify patients with a dementia as 'malignant social psychology'. This undermines patient dignity, humanity and respect. Participants in this study did objectify patients to some degree whilst contextualising and interpreting ISB, highlighted by the assumption that people with advanced dementia lacked awareness and intentionality, or loss of selfhood. However, the process of fragmentation, whereby participants separated the behaviour from the patient seemed to relate to staff reconciling the ISB. Participants held onto the whole person by maintaining their humanity, dignity and sexuality through a process of contextualisation, empathy, sympathy and, for some, recognition of their own mortality and sexuality, processes implicated as being particularly important for patients with significant communication impairments (Kontos \& Nagile, 2007). How this oscillation between separation and integration affected rehabilitation in this study, often compromised by fragmentary rhetoric (Dewing, 2003), was unknown, although attempts to distance the self from patients after experiencing an incident were negatively construed.

Patient gender was believed to shape staff perceptions of ISB; behaviours were more likely to be construed as ISB if exhibited by a male rather than a female. Underreporting inappropriate behaviour exhibited by female psychiatric patients has been noted regarding violence (Skeem et al, 2005) and female sexual expression is often overlooked with women repeatedly construed as vulnerable (Hughes \& Hebb, 2005; Ward, Vaas, Aggarwal, Garfield \& Cybyk, 2005). Skeem et al (2005) suggested that 
underreporting occurred because males are generally more overtly violent. Regarding ISB, data from the Hospital suggested that the majority of ISB recordings were malerelated, supporting Skeem et al (2005). However, the findings from this study suggest that mere frequency is not a complete explanation.

'Pathologising' male sexual behaviour whilst rendering female sexuality 'invisible' through constructions of vulnerability is consistent with the literature (Ward et al, 2005). Differences in gender constructions can be traced back to the ancients. The Greek nouns 'aphrodisiazein' and 'aphrodisiasthenai' correspond to the active (masculine) and passive (feminine) roles in sexual intercourse (Aristotle, cited in Foucault, 1984). Each have their distinct functions, "the one who performs the activity and the one on whom it is performed" (Foucault, 1984, p47), which may also be underpinned by the overt versus inverted sexual anatomy of males and females, respectively. These 'poles' are extremely interesting and seem to correspond to the findings from this study. Ward et al (2005) termed this a 'gendered dichotomy', which they suggested is also influenced by environment. It is of note that the majority of staff at the Hospital were female and most of the patients male.

Liberal attitudes towards sexuality in older age were evident in this study. Yool et al (2003) found similar perceptions held by staff in a medium-secure unit for adults with intellectual disabilities. However, they detected difficulties in facilitating same-sex relationships. In this study, there was also recognition that homosexuality regarding patients with dementia was overlooked, consistent with the literature (Ward et al, 2005). Despite participants addressing the sexuality of people with a dementia there was some indication that this was not a view shared by all. 


\subsubsection{Interpreting}

Making sense of ISB involved cognitive, emotional and socially-driven processes, none of which have been adequately captured in the current literature (Knight et al, 2008).

Many participants felt that patients with earlier stage dementia were more aware and in control of their actions, although research suggests that this period of the illness can generate disablement and fear (Steeman, Dierckx de Casterle, Godderis \& Grypdonck, 2005), which was not referred to with the exception of recognising potential embarrassment. Participants who differentiated between earlier and later stage dementia used physical indicators, such as immobility and incontinence. No participant discussed formal capacity assessment but most did communicate behaviour to the wider team, which may have included formal appraisal, though decisions were not made transparent during interviews.

Generally participants felt that ISB did not affect them and this was consistent with other findings (Cubit et al, 2007; Matsuoka et al, 2003). However, all participants at some point experienced discomfort and for some, feelings of distress were concerning. Cubit et al (2007) noted a 'tension' in their study investigating the frequency, disruption and distress caused by 'behaviours of concern'. They described participants reporting distress yet they simultaneously demonstrated 'empathic acceptance'. Cubit et al (2007) subsequently reasoned that this communicated a sufficient knowledge base of dementia or that staff 'objectified' behaviours that essentially stopped staff from formulating problematic behaviours. Similarly, participants in this study who experienced distress contextualised and minimised ISB. However, most participants did not describe disengagement from the process of understanding. Hypotheses regarding sexual 
urge/expression, temperature and communication amongst others were actively

considered. Furthermore, most participants did not experience ISB as acceptable, rather

they accepted it as part of patient presentation. Rather than the dichotomising articulated by Cubit et al (2007), these findings suggest that minimisation is an integrated means of protecting staff, allowing them to fulfil their duties, though concern was expressed regarding the potential for complacency, which could endanger staff and patients.

It is important to recognise the emotional response to behaviours exhibited by patients of the same sex, which has been identified as a major issue for men (Ainscough \& Toon, 1993). The psychological impact of sexual assault on males is often underestimated and services can be ignorant to male victims (Davies, 2002). Although ISB experienced by staff within the context of this research is different to sexual assault that, for example, occurs during dating (Davies, 2002), the effect on staff could be overlooked because of heterosexist assumptions. Despite contextualising his experience in the dementia, Mike recounted feeling 'violated' and 'feeling a need to shower'. His explanation for not seeking support was that colleagues would think him over-reactive. An alternative and possibly less conscious reason may be that he assumed that his voice would not be heard.

\subsubsection{Dealing With}

Participants reported 'Dealing With' ISB by minimising, being risk aware, managing boundaries and doing their best. Habituating to challenging behaviour has been indicated in relation to aggression, especially for staff with over five years' experience (Cubit et al, 2007). Minimising developed over time with repeated exposure and protected 
participants from exhaustion. However, Robinson and Cubit (2007) highlight difficulties associated with this including inadvertently placing students in risky situations without prior knowledge which was raised as a potential issue for staff in this study (i.e., blasé attitudes).

It also is worth noting that minimising was a common strategy encouraged by the Hospital training to deal with ISB (i.e., 'ignoring' challenging behaviour and reinforcing appropriate social interaction). Interestingly during the pilot interviews the staff member who worked at the Hospital felt that ignoring ISB was regularly used because people generally did not know what to do.

Female participants felt that their methods of dealing with ISB evolved with age, relating to cumulative transferable life experiences, an acceptance of life in general and increased self-awareness. The influence of age on response has been noted in relation to aggression and sexual expression and linked with experience (Bouman, Arlecus \& Benbow, 2007; Cubit et al, 2007; Nakahira, Moyle, Creedy \& Hitomi, 2008; Ward et al, 2005). However, studies fail to adequately comment about age and furthermore, do not provide clear information regarding gender.

The women in this study seemed to suggest that being regarded as a sexual being diminished with age. Subsequently ISB was construed less threateningly and exculpated, possibly underpinned by societal attitudes towards female sexuality and aging (Ward et al, 2005).

\section{Critique}

This next section outlines the main strengths and limitations of this study. 
The findings provide a valuable account of the complex psychological and social processes associated with staff experiences of ISB exhibited by older people with a dementia and will help to enrich a growing body of literature regarding ISB exhibited by persons with neurological impairment (Guay, 2008; Johnson et al, 2006; Knight et al, 2008). Quality checks (e.g., prolonged engagement with the material, peer debriefing) and a systematic and transparent approach to write-up further ensure that the resultant model is credible, trustworthy and grounded (Meyrick, 2006).

Fourteen participants were deemed viable for 'theoretical sufficiency' (Dey, 1999, as cited in Charmaz, 2006). Further interviews may have yielded new data/new interpretations of data that would have extended and refined the model. Attempts were made early on to sample domestic staff as they were seen to possess little context of dementia and/or the individual patient and therefore were regarded as having different experiences of ISB. However, these attempts were unsuccessful and due to constrained time no further efforts were made to recruit additional people or re-interview participants. Specifically, questioning males regarding the lower-order category 'adapting with age' and pursuing 'wider culture' could have consolidated or extended the model.

The participants in this study were all self-selecting and therefore it can be reasonably assumed that all were motivated and felt confident enough to discuss their experiences. Other Grounded Theories created with a different sample may produce an alternative or extended model. Given the sensitive nature of ISB an alternative methodology, such as a diary study, might encourage other people to share their experiences that would develop this account. 
Participants primarily drew from their experiences working within a specialist inpatient setting, which was a context familiar with ISB and the Hospital had relatively recently adopted a recording tool to capture it. Inappropriate sexual behaviour therefore could be seen as an artefact of the environment and a major criticism of this research is that the findings are context-specific. Nevertheless, it is important to keep in mind that despite specialist dementia training at the Hospital, ISB remained a source of concern for a significant number of staff with clear and negative ramifications for their wellbeing and the wellbeing of patients (i.e., distancing). The advantage of conducting this research at the Hospital was that ISB was a phenomenon more amenable for discussion, making accessing participants possibly easier than if, for example, a private residential home was approached. Furthermore, recruiting staff from care/residential homes may have been difficult because of reported low prevalence (Algaiakrishnan et al, 2005).

Although not necessarily generalisable, these findings create questions, understandings and an appreciation of some of the complexities related to ISB in dementia-care. Moreover, some staff at the Hospital had worked with other patient groups (e.g., forensic, brain injury) that enabled comparisons to be made, which in terms of theory generation, was beneficial.

\section{Clinical Implications}

The findings from this study have numerous clinical implications, which include:

- Preparing new staff for ISB. Amplifying challenging behaviours to new employees can be unsettling (Robinson \& Cubit, 2007). Gauging extent and type of information for sufficient induction could be achieved via service evaluation. 
- Delivering training regarding ISB to all staff. Training needs to be repeated and ongoing in order to be effective (Cohen-Mansfield, 2001) and meaningfully embedded in work contexts.

- Ensuring adequate support structures for staff through supervision, peer support and more ad hoc provision. Trainees/students, who have less long-term investment in working with older adults, may also profit as research has shown this group are particularly vulnerable (Robinson \& Cubit, 2007).

- Providing adequate context to staff less familiar to dementia care and/or individual patients should be given as this appears instrumental to understanding and managing ISB (Todd \& Watts, 2005).

- Appropriate staff attributions may be enabled by increased awareness of psychological impact of earlier and later stage dementia.

\section{Further Research}

With an increasing focus on maintaining people with a dementia at home for as long as possible, it is essential that services appreciate the experiences of family caregivers. Inappropriate sexual behaviours are known to cause embarrassment leading to isolation and reluctance to accept social support (Robinson, 2003). The impact of ISB on family caregivers has not been explored in depth, which further research could address.

Despite some participants indicating significant variation in how ISB was perceived within cultures others than White British, the category 'Culture' lacked theoretical sufficiency. Studies from anthropology have illuminated cultural variations in perceptions of aging and mental health, including dementia (Dein \& Huline-Dickens, 
1997). Research has shown that there are cultural differences towards sex and intimacy, with potential to affect patient care (Boggatz \& Dassen, 2006). For example, Chinese nurses associate male genital-related care with sex, and given the Chinese culture of 'sexual conservativeness' some nurses were averse to carrying out personal hygiene duties, thus, neglecting care (Zang, Chung \& Wong, 2008). Further research could sample minority groups to explicate this.

The impact of ISB upon other patients was less of a focus in this study yet research has shown that inpatients are not passive observers. Inpatients engage various strategies, such as de-escalation, when feeling under threat (Quirk, Lelliott \& Seale, 2005). A future study might explore the impact of ISB on fellow patients/residents.

Canvassing responses using a questionnaire design based on this research could be developed to recruit a broader audience (i.e., family caregivers and residential). This may utilise additional forms of data collection such as diaries or focus groups.

\section{Conclusion}

Whilst previous research has focused on defining ISB and ascertaining prevalence in patients with neuropsychological impairments (Guay, 2008; Knight et al 2008), an exploration of the psycho-social processes involved whilst working in dementia care and in particular, a fuller understanding of the psychological and emotional impact ISB has on staff has been overlooked. This research responded to that need and uncovered a range and complexity of experience that provides a framework for understanding staff experiences of ISB within inpatients settings. 


\section{References}

Ainscough, C., \& Toon, K. (1993). Breaking Free. Help for Survivors of Child Sexual Abuse. Sheldon Press. London.

Alderman, N., Knight, C., \& Morgan, C. (1997). Use of a modified version of the Overt Aggression Scale in the measurement and assessment of aggressive behaviours following brain injury. Brain Injury, 11, 503-523.

Algaiakrishnan, D. L., Brahim, A., Wong, A., Wood, A., Senthilselvan, A., Chimich, W.T., \& Kagan, L. (2005). Sexually inappropriate behaviour in demented elderly people. Postgraduate Medical Journal, 81, 463-466.

Bailey, J. (2008). First steps in qualitative data analysis: transcribing. Family Practice, 25(2), 127-131.

Bezeau, S. C., Bogod, N. M., \& Mateer, C. A. (2004). Sexually intrusive behaviour following brain injury: approaches to assessment and rehabilitation. Brain Injury, 18, 299-313.

Black, B., Muralee, S., \& Tampi, R. R. (2005). Inappropriate sexual behaviors in dementia. Journal of Geriatric Psychiatry and Neurology, 18, 155-162.

Boggatz, T., \& Dassen, T. (2006). Learning the meaning of care: A case study in a geriatric home in upper Egypt. Journal of Transcultural Nursing, 17(2), 155-163. 
Bouman, W. P., Arcelus, J., \& Benbow, S. M. (2007). Nottingham study of sexuality and ageing (NoSSA II). Attitudes of care staff regarding sexuality and residents: A study in residential and nursing homes. Sexual and Relationship Therapy, 22(1), $45-61$.

Brodaty, H., \& Low, L. (2003). Aggression in the elderly. Journal of Clinical Psychiatry, 64, 36-43).

Broks, P. (2003). Into the Silent Land. Atlantic Books. London.

Charmaz, K. (2003). In N. K. Denzin \& Y. S. Lincoln (Eds). Strategies of Qualitative Inquiry. Sage. London.

Charmaz, K. (2006). Constructing Grounded Theory. A Practical Guide through Qualitative Analysis. Sage. London.

Cohen-Mansfield, J. (2001). Nonpharmacological interventions for inappropriate behaviors in dementia. A review, summary and critique. American Journal of Geriatric Psychiatry, 9(4), 361-381.

Cubit, K., Farrell, G., Robinson, A., \& Myhill, M. (2007). A survey of the frequency and impact of Behaviours of Concern in Dementia on residential aged care staff. Australasian Journal of Ageing, 26(2), 64-70.

Cutliffe, J. R. (2000). Methodological issues in grounded theory. Journal of Advanced Nursing, 31(6), 1476-1484.

Dagnan, D., Grant, F., \& McDonnell, A. (2004). Understanding challenging behaviour in older people; the development of the Controllability Beliefs Scale. Behavioural and Cognitive Psychotherapy, 32, 501-506. 
Davies, M. (2002). Male sexual assault victims: a selective review of the literature and implications for support services. Aggression and Violent Behaviour, 7, 203-214.

Dein, S., \& Huline-Dickens, S. (1997). Cultural aspects of aging and psychopathology. Aging and Mental Health, 1(2), 112-120.

Denzin, N. K., \& Lincoln, Y. S. (2000). Handbook of Qualitative Research. $2^{\text {nd }}$ Ed. Sage. London.

Department of Health. (2005). Elimination of Mixed-Sex Hospital Accommodation. Retrieved from the Web $26^{\text {th }}$ February 2009 from: http://www.dh.gov.uk/en/Publicationsandstatistics/Publications/PublicationsStatisti cs/DH_4112140

Dewing, J. (2003). Rehabilitation for older people with dementia. Nursing Standard, $18(6), 42-52$.

Edberg, A., K., Bird, M., Richards, D. A., Woods. R., Keeley. P., \& Davis-Quarrell, V. (2008). Strain in nursing care of people with dementia: Nurses' experience in Australia, Sweden and United Kingdom. Ageing and Mental Health, 12(2), 236243.

Evers, W., Tomic, W., \& Brouwers, A. (2001). Effects of aggressive behaviour and perceived self-efficacy on burnout among staff of homes for the elderly. Issues in Mental Health Nursing, 22, $439-454$. 
Feeney, T.J., Ylvisaker, M., Rosen, B. H., \& Greene, P. (2001). Community supports for individuals with challenging behaviour after brain injury: An analysis of the New York State behavioral project. Journal of Head Trauma Rehabilitation, 16(1), 6175.

Fopma-Loy, J., \& Austin, J. K. (1997). Application of an attribution-affect-action model of caregiving behavior. Archives of Psychiatric Nursing, 11(4), 210-217.

Foucault, M. (1984). The Use of Pleasure. The History of Sexuality. Volume 2. Penguin Books Ltd. London.

Fransella, F. (2005). The Essential Practitioner's Handbook of Personal Construct Psychology. Wiley. West Sussex.

Glaser, B. G., \& Strauss, A. L. (1967). The Discovery of Grounded Theory; Strategies for Qualitative Research. Aldine Transaction. London.

Grbich, C. (1999). Qualitative Research in Health - an Introduction. Sage. London.

Guay, D. R. P. (2008). Inappropriate sexual behaviors in cognitively impaired older individuals. The American Journal of Geriatric Pharmacotherapy, 6(5), 269-288.

Hallberg, I.R., \& Norberg, A. (1995). Nurses' experiences of strain and their reactions in the care of severely demented patients. International Journal of Geriatric Psychiatry, 10, 757-766.

Henwood, K., \& Pidgeon, N. (2003). In P. M. Camic., J. E. Rhodes., \& L. Yardley (Eds). Qualitative Research in Psychology. Expanding Perspectives in Methodology and Design. American Psychological Association. Washington. 
Heath, H., \& Cowley, S. (2004). Developing a grounded theory approach: a comparison of Glaser and Strauss. International Journal of Nursing Studies, 41, 141-150.

Holstein, J. A., \& Gubrium, J. F. (1995). The Active Interview. Qualitative Research Methods Series, 37. Sage. London.

Hughes, G. V., \& Hebb, J. (2005). Problematic sexual behaviour in a secure psychiatric setting: challenges and developing solutions. Journal of Sexual Aggression, 11, 95102.

Johnson, C., Knight, C., \& Alderman, N. (2006). Challenges associated with the definition and assessment of inappropriate sexual behaviour amongst individuals with an acquired neurological impairment. Brain Injury, 20, $687-693$.

Kitwood, T. (1997). Dementia Reconsidered: The Person Comes First. Open University Press. Buckingham.

Knight, C., Alderman, N., Johnson, C., Green, S., Birkett-Swan, L., \& Yorstan, G. (2008). The St Andrews Sexual Behaviour Assessment (SASBA): Development of a standardised recording instrument for the measurement and assessment of challenging sexual behaviour in people with progressive and acquired neurological impairment. Neuropsychological Rehabilitation, 18, 129-159.

Kontos, P. C., \& Nagile, G. (2007). Bridging theory and practice. Imagination, the body, and person-centred care. Dementia, 6(4), 549-569.

Kovac, C. R., Noonan, P. E., Schlidt, A. M., \& Wells, T. (2005). A model of consequences of need-driven, dementia-compromised behavior. Journal of Nursing Scholarship, 2, 134-140. 
Lonergan, E., Luxenberg, J., Colford, J., \& Birks, J. (2002). Haloperidol for agitation in dementia. Cochrane Database of Systematic Reviews, 2, Art No: CD002852. DOI: 10.1002/14651858. CD002852.

Mackay, N., \& Barrowclough, C. (2005). Accident and emergency staff's perceptions of deliberate self-harm: Attributions, emotions and willingness to help. British Journal of Clinical Psychology, 44, 255-267.

Matsuoka, K., Miyamoto, Y., Ito, H., \& Kurita, H. (2003). Relationship between behavioural disturbances and characteristics of patients in special units for dementia. Psychiatry and Clinical Neurosciences, 57, $569-574$.

McKenna, B. G., Poole, S. J., Smith, N. A., Coverdale, J. H., \& Gale, C. K. (2003). A survey of threats and violent behaviour by patients against registered nurses in their first year of practice. International Journal of Mental Health Nursing, 12, 56-63.

Meyrick, J. (2006). What is good qualitative research? A first step towards a comprehensive approach to judging rigour/quality. Journal of Health Psychology, 11(5), 799-808.

Munton, A. G., Silvester, J., Stratton, P., \& Hanks, H. (1999). Attributions in Action. A Practical Approach to Coding Qualitative Data. Wiley. Chichetser.

Nagaratnam, N., \& Gayagay, G. (2002). Hypersexuality in nursing care facilities - a descriptive study. Archives of Gerontology and Geriatrics, 35, 195-203.

Nakahira, M., Moyle, W., Creedy, D., \& Hitomi, H. (2008). Attitudes towards dementiarelated aggression among staff in Japanese aged care settings. Journal of Clinical Nursing, 18, 807-816. 
National Health Service Security Management Service (2005). Promoting safer and Therapeutic Services. Implementing the National Syllabus in Mental Health and Learning Disability Services. Retrieved from the Web $26^{\text {th }}$ February, 2007: http://62.164.179.2/SecurityManagement/Documents/psts_implementing_syllabus.p df

National Institute for Clinical Excellence \& Social Care Institute for Excellence. (2006) Dementia: Supporting People with Dementia and their Carers in Health and Social Care. Retrieved from the Web $26^{\text {th }}$ February, 2007: http://guidance.nice.org.uk/cg42/niceguidance/pdf/English

Noone, S. J., Jones, R. S., \& Hastings, R. P. (2006). Care staff attributions about challenging behaviors in adults with intellectual disabilities. Research in Developmental Disabilities, 27(2), 109-120.

Parker, I. (1994). In P. Banister, E. Burnam; I. Parker; M. Taylor \& C. Tindall (Eds). Qualitative Methods in Psychology; a Research Guide. Open University Press. Buckingham.

Quirk, A., Lelliott, P., \& Seale, C. (2005). Risk management by patients on psychiatric wards in London: An ethnographic study. Health, Risk \& Society, 7(1), 85-95.

Rudolph, U., Roesch, S.C., Greitmeyer, T., \& Weiner, B. (2004). A meta-analytic review of help-giving and aggression from an attributional perspective: Contributions to a general theory of motivation. Cognition and Emotion, 18(6), 815-848. 
Robinson, K. M. Understanding hypersexuality. (2003). A behavioural disorder of dementia. Home Healthcare Nurse, 21(1), 43-47.

Robinson, A., \& Cubit, K. (2007). Caring for older people with dementia in residential care: nursing students experiences. Journal of Advanced Nursing, 59(3) 255-263.

Scott, K., Lawrence, M., Duggel, A., Darwin, C., Brooks, E., \& Christodoulou, G. (2002). Prescribing patterns for psychotic and behavioural symptoms in dementia: A national survey. Psychiatric Bulletin, 26, 288-290.

Skeem, J., Schubert, C., Stowman, S., Beeson, S., Mulvey, E., Gardner, W., \& Lidz, C. (2005). Gender and risk assessment accuracy: Underestimating women's violence potential. Law and Human Behavior, 29(2), 173-186.

Souder, E., \& O’Sullivan, P. (2003). Disruptive behaviors of older adults in an institutional setting. Journal of Gerontological Nursing, 29, 31 - 36.

Steeman, E., Dierckx de Casterle, B., Godderis, J., \& Grypdonck, M. (2005). Living with early stage dementia: a review of qualitative studies. Journal of Advanced Nursing, 56(6), 722-738.

Strauss, A. L., \& Corbin, J. (1998). Basics of Qualitative Research: Techniques and Procedures for Developing Grounded Theory. $2^{\text {nd }}$ Ed. Sage. London.

Sung, H., Chang, S., \& Tsai, C. (2005). Working in long-term care settings for older people with dementia: nurse's aides. Journal of Clinical Nursing, 14, 587-593. 
Todd, S.J., \& Watts, S. C. (2005). Staff responses to challenging behaviour shown by people with dementia: An application of an attributional-emotional model of helping behaviour. Ageing and Mental Health, 9(1), 71-81.

Unite (2007). Staying safe at work. Amicus Section Hospital Health; the Union Magazine for Health Professionals, 8, 26 - 27.

Ward, R., Vaas, A. A., Aggarwal, N., Garfield. C., \& Cybyk, B. (2005). A kiss is still a kiss? The construction of sexuality in dementia care. Dementia, 4(1), 49-72.

Weigel, L., Langdon, P. E., Collins, S., \& O'Brien, Y. (2006). Challenging behaviour and learning disabilities: The relationship between expressed emotion and staff attributions. British Journal of Clinical Psychology, 45(2), 205-216.

Werner, P., Cohen-Mansfield, J., \& Newman, J. D. (1999). Auditory perceptions of vocalizations manifested by verbally agitated nursing home residents. Aging \& Mental Health, 3(1), 50-53.

Yardley, L. (2000). Dilemmas in qualitative health research. Psychology and Health, 15, 215-228.

Yool, L., Langdon, P. E., \& Garner, K. (2003). The attitudes of medium-secure unit staff toward the sexuality of adults with learning disabilities. Sexuality and Disability, $21,137-150$.

Zang, Y., Chung, L. Y. F., \& Wong, K. S. (2008). Chinese female nurses' perceptions of male genitalia-related care - Part 1. Journal of Clinical Nursing, 18, 817-825. 
Zilbergeld, B. (2004). Better Than Ever. Crown House Publishing. Cromwell Press, Trowbridge, Wiltshire. 


\section{Critical Appraisal}




\section{Overview}

This paper will outline numerous reflections and observations that I made during my research journey and is informed by the research diary. Diary excerpts will be used to illuminate my thinking. This section will pay special attention to the chosen methodology with consideration of the study limitations. This appraisal will begin with a discussion regarding research conception and culminate with the personal impact of conducting the research in addition to my learning.

\section{Conception}

As an Assistant Psychologist (halftime Intermediate Care for people with a dementia) I experienced Inappropriate Sexual Behaviour (ISB) exhibited by an older adult male with a dementia. The ISB, primarily directed at touching female breasts, caused anxiety for some of my colleagues. Subsequently I developed an awareness and appreciation of the difficulties and dilemmas associated with ISB, which included protecting residents and staff as well as grappling with issues around sexuality and dementia. When I met my field supervisor at the research fair in December 2006 and she expressed her interest in the area I was keen to pursue possible research opportunities.

At that time a recent publication had highlighted the inconsistency in definition and operationalisation of ISB within the area of progressive neurological conditions (Johnson, Knight \& Alderman, 2006) that possibly undermined prevalence statistics. Initially the aim of this research was to conduct a mixed design by investigating the prevalence of ISB using a new continuous recording tool, the St Andrews Sexual Behaviour Assessment (Knight et al, 2008) plus explicating staff perceptions through 
questionnaires. However, it became apparent whilst scoping the literature that an adequate exploration of staff experiences of ISB exhibited by people with progressive neurological conditions had been overlooked. Therefore, importing constructs into the research design, including attributions and/or optimism/pessimism scales seemed preemptive. After careful consideration with both my academic and field supervisors I decided to focus the research on a general exploration of staff experiences of ISB exhibited by older adults with a dementia using qualitative methods.

\section{Methodology}

As my interests focused on inducting new data rather than examining it through an existing framework Interpretative Phenomenological Analysis (Smith \& Osborn, 2008) and Grounded Theory, or GT (Charmaz, 2006; Glaser \& Strauss, 1979), neither of which I had used before, were examined. I became more certain that GT was the most appropriate method because my aim was to identify social and psychological patterns/processes and I hoped to generalise from the findings, neither of which IPA sought to do.

My growing certainty about using GT was challenged during a research presentation to my cohort and the academic team in June 2008 where it was commented that my research 'could be IPA'. Subsequently I revisited my proposal, produced an advantages-disadvantages list and contacted both Jonathan Smith and Kathy Charmaz (proponents of IPA and GT respectively), who read my proposal.

Interestingly, Jonathan Smith thought that IPA was the most appropriate method whilst Kathy Charmaz felt that GT was suitable. Jonathan Smith felt that I was 
interested in the nuances of individual accounts rather than general processes, which IPA is geared towards whilst Kathy Charmaz was interested in what ISB meant to participants, thus, neither provided me with a definitive answer but both provoked further questions.

Practically, IPA was advantageous as it required a smaller sample (Jonathan Smith proposed five to six participants) compared to GT. However, my motivation to provide a comprehensible and comprehensive framework for understanding staff experiences superseded participant numbers. A further consultation with the literature (Charmaz, 2006; Denzin \& Lincoln, 2000; Smith \& Osborn, 2008) and support from my advantages-disadvantages list indicated GT, confirming my original proposal. Grounded Theory also had the benefit of providing me with a rigorous and systematic framework, which as a novice qualitative researcher, was useful.

\section{Epistemology}

One of the biggest learning experiences I encountered was debating my epistemological stance. Grbich (1999) suggested that methodologies can be chosen on the basis of 'technique to gain better access' or because of the researcher's beliefs about reality. My clinical interest in George Kelly and his Personal Construct Psychology (Fransella, 2006) led me to believe that there was a reality 'out there' and that people construed that reality differently. This initially led me to think of myself as a critical realist, which would align with a positivist GT method (Charmaz, 2006). However, the second year of university teaching with its emphasis on community psychology precipitated me to readdress to my initial assumptions about the world. I began to read about the debates and alternative 
paradigms within the realm of qualitative research (Madill, Jordan \& Shirley, 2000) and finally discovered Charmaz's constructivist GT, which:

“...places priority on the phenomena of study and sees both data and analysis as created from shared experiences and relationships with participants and other sources of data" (Charmaz, 2006, p 130).

Ultimately, the questions that are asked and the answers that are given are interpreted within the context of a relationship and subsequently form one analysis. As Charmaz (2006) states, "theory depends on the researcher's view" (p130) and other researchers may co-create alternative accounts. In addition, I was also mindful of the potential for my context, as a young female, to affect the findings. Would the model have been different if, for example, the interview had been conducted by a 45 -year old man?

"I wonder how easy it is for my 'more mature' ladies to talk about age and expand the category ('Adapting with Age') when I am a young, less experienced female. My very presence may be shaping and occluding the data” (Diary Entry, 30 ${ }^{\text {th }}$ January 2009).

One definition of ISB was provided in the participant information packs, as utilised by the Hospital. However, I was aware that participants would bring their own experiences and interpretations of ISB to interview and in line with a social constructivist 
GT methodology I embraced and explored that. For example, the code 'questioning inappropriateness' was a process many participants discussed. Whilst this process was commonly experienced, what constituted 'appropriate' and 'inappropriate' varied between individuals.

I felt surer of my social constructivist position as interviews progressed given that many participants commented that they were reviewing material they had never considered before, indicating that their thinking was not a preformed objective truth awaiting discovery (Holstein \& Gubrium, 1995) but rather the beginnings of a coconstruction with me:

“...I think out of everything I've got loads of things going in my head that I have to think about now, which I've never thought about before..." (Dennis, p61, 1480-1483).

\section{Interview Data}

"Intensive interviewing permits an in-depth exploration of a particular topic or experience..." and therefore provides rich data (Charmaz, 2006, p 25). Consideration was applied to other means of accruing rich data, such as analysing nursing notes or incident forms. However, this was discounted because of ethical constraints (i.e., patient consent, confidentiality) and issues of skew (e.g., written notes might restrict data to ISB considered risky). Interview data would overcome these challenges by allowing me to co-create and elaborate an account. Done respectfully interviews foster rapport with participants and allow the researcher to return to earlier ideas (Charmaz, 2006). 
Furthermore, anecdotal evidence from the Hospital indicated that some staff wanted to discuss their experiences of ISB, therefore, the use of interview was regarded as a vehicle for validating peoples' experiences.

Despite its richness, interview data is a 'reconstruction' (Grbich, 1999) and vulnerable to retrospective bias. However, bias "is a meaningful concept only if the subject is seen to possess a preformed, pure informational commodity that the interview process might somehow contaminate" (Holstein \& Gubrium, 1995, p 18). In line with a social constructivist GT methodology (Charmaz, 2006; Strauss \& Corbin, 1998) my aim was to co-create meaning with participants in order to elicit one general understanding of staff experiences of ISB exhibited by older adults with a dementia. Rather than 'contamination' the method acknowledges that researchers do not approach their research as a blank slate; the research process is inherently interpretative. In order to assess credibility of findings I was transparent during write up and maintained a reflective diary, also leaving an audit trail.

I was pleased with the choice of data collection as I felt that the interview space gave the participant and me adequate flexibility to explore issues of concern or experience that may have been restricted, for example, in a group setting. This seemed especially important for participants like Mike, whose experience of ISB left him feeling violated, which was further compounded by feeling judged by colleagues. Furthermore, focus groups are susceptible, for example, to social desirability effects and/or opinionated members (Edberg et al, 2008). 
As highlighted in my diary entry below there are limitations in relying on interview data alone and the process of interviewing did provoke me to think about alternative methodologies, also inspired by a study being undertaken in my cohort.

"I'm transcribing my interview with Helen. It is really fascinating how she positions herself in relation to some of the questions. I feel as though she is avoiding something. Answers are viewed from a colleague's point of view, a wife's, other patients' etc... I am thinking about a research study being conducted by someone in my cohort; they are using observation as a way to triangulate a study that used interview methods. I wonder if this is a structure we could use" (28 ${ }^{\text {th }}$ August 2008).

Observations may not be appropriate given the irregularly of ISB in some settings, although ISB occurred regularly in the Hospital. Furthermore, observing people who may lack the capacity to consent may be unethical.

\section{Alternative methodologies}

Several participants referred to colleagues who experienced ISB 'on a daily basis', yet only a minority of the participants interviewed reported ISB as a regular occurrence, leading me to speculate why more members of staff had not come forward to take part in the research. It may be that staff who reportedly experience ISB daily do not perceive behaviours as ISB or that ISB remains a 
taboo for some people (raised during interviews) and/or exploring these experiences is too difficult, awkward or even painful.

A diary study could be used to elicit further experiences and understandings of ISB to compliment and extend the findings from this study. Alternatively, based on the inducted model, a questionnaire could be designed and administered across the Hospital and other settings including residential and nursing homes in addition to seeking the experiences, views and perspectives of familial carers who may also require recognition and support.

\section{Context}

“... any analysis is contextually situated in time, place, culture, and situation" (Charmaz, 2006, p131).

Residential staff were initially considered as forming part of my sample in addition to more specialist dementia care staff who worked at the Hospital where the research took place. However, because ISB has been found to have low prevalence in long-term care settings (Alagiakrishnan et al, 2005) it was felt that recruitment within residential and nursing homes would be potentially problematic. Restricting sampling to a specialist inpatient environment could be regarded as a limitation of this study. However, this 'limitation' conflicts with my chosen epistemology that acknowledges that research is contextual. Documenting my concerns regarding transferability of findings in my research diary allowed me to explore and resolve my anxieties, which I concluded were 
produced by my positivist research background. Up until training I had been taught that research findings should be reliable, valid and generalisable, constructs that are less applicable to qualitative research. Although not necessarily generalisable, the findings from my study will generate questions, understandings and an appreciation of some of the complexities related to ISB in dementia-care within the Hospital and beyond.

\section{Hospital Reorganisation}

I was made aware in June 2008 that the Hospital was about to undergo reorganisation; specifically wards were accommodating Government legislation to abolish mixed gender wards (Department of Health, 2005). In addition, the specialist dementia ward moved accommodation. At that time there was an indication that staff morale was 'low' and 'negative'. It was unclear how these transitions affected the findings but I noted that permanent staff from the specialist dementia ward participated towards the end of data collection. Participants did not discuss the changes though some did refer to having been mixed-gender wards.

\section{"Patients"}

Using the term 'patients' to describe clients at the Hospital initially felt difficult because of the connotations with the medical model, incongruous to my training as a Trainee Clinical Psychologist and the Hospital's philosophy of person-centred care. Indeed, organisationally the Hospital advocated the term 'service-user'. However, in line with my methodology and influenced by my training in Personal Construct Psychology that advocates adopting participant's/client's own language I remained grounded. 


\section{Recruitment}

Theoretical sampling was achieved by explicating categories using the participants who had volunteered. Where new experiences or perspectives were indicated (e.g., bank staff/new staff experience) my field supervisor was instrumental in supporting recruitment. I also took the initiative and when interviewing domestic staff was suggested as an avenue for exploration (i.e., those staff without any specific training regarding dementia and who were exposed to patients regularly) I instigated contact with managers. Unfortunately no one from the domestic services participated and consequently, the developing model and analysis could not be tested out and/or elaborated.

Due to time restrictions I was also unable to return to earlier participants to ask new questions and to clarify developing codes that, for instance, would have helped to elucidate the code 'Adapting with Age'.

\section{Immersion}

"I have a terrible habit of trying to complete one job before moving onto the next. As I have discovered I need to be immersed in it all!" (Diary Entry, $19^{\text {th }}$ October 2008).

Commitment to and immersion in the data is a hallmark of quality (Yardley, 2000). Analysis began as soon as I asked my first question. The constant comparative method ensured that I moved back and forth between data to verify codes, identify gaps and 
consider connections, which was completely exhausting at times. Self-care was routinely required for my benefit and for the benefit of analysis as my attention became diffused when tired. Coding early data and sorting it into numerous grounded, preliminary categories (which was achieved by literally cutting out every line of text and allocating it a plastic wallet) was overwhelming and compounded by my meticulousness that prompted me to double check the early codes before proceeding. Debriefing with peers/colleagues experienced in GT and who had experienced immersion was hugely validating.

\section{'Flip-Flop'}

Bulmer (1979, as cited in Henwood \& Pidgeon, 2003) described the process of theory generation as a 'flip-flop' between the data and the researcher. Moving within and between transcripts in addition to my own ideas about the data (as captured in the research diary) was a fascinating and validating experience. However, reducing transcripts into codes and then comparing codes with codes felt decontextualised at times, which has been criticised as fracturing the data, compromising complexity (Madill, Jordan \& Shirley, 2000). To aid 'flip-flopping' I worked up an outline for each participant which I compared with other outlines and with the developing model (see Box 1 for a partial example).

Box 1. Partial example of a participant outline

\section{Grace}

Variable experience; understanding that when inhibition compromised patients might be inappropriate during personal care; seeing patients as responding during intimate and personal care; experiencing ISB exhibited by older adults as strange; not expecting ISB; ISB can be difficult; not finding ISB as difficult as some; knowing patients who will and will not exhibited ISB..... 
I also presented a 'work-in-progress' model to Kate and Anna who confirmed the main categories 'Beyond My Construing', 'Contextualising' and 'Interpreting', which was encouraging.

Approaching my analysis using a variety of methods (including diagramming) reassured me that I had remained grounded and true to participants, it facilitated new ways of construing the data and it kept the analysis interesting.

\section{Feeling Stuck}

The reflective diary was an effective way of capturing my thoughts about the data in addition to leaving an audit trail. On reading back through my diary it was stimulating to recall my earlier decision-making and attempts to capture underlying processes and patterns. The diary was especially useful when aspects of the model/analysis did not feel quite right or seem to fit, which left me feeling stuck.

The category 'Holding the Whole Person in Mind' exemplified this. I initially termed this 'Dissonance' and placed it under the main category 'Interpreting'. 'Dissonance' attempted to reflect the tension staff described whilst interpreting ISB. Querying the function of this tension enabled me to see that although on the one hand participants reduced patients to basic physiological responses (e.g., “...they might get an erection but $\mathbf{m m}$ you know that person and you know that really, part of that body is sort of (..) Hhhh not part of the rest of-it wouldn't follow through...", Beth, p3, 57-62) there was also an attempt to preserve their humanity. During supervision the word 'dissonance' was discounted because it was too cognitive and failed to reflect the relational quality of the process. In addition, the category was moved from within 
'Interpreting' and placed under 'Contextualising'. Despite these main categories overlapping the way in which 'Holding the Whole Person in Mind' was described by participants suggested it was a process that underpinned interpretation and therefore it was regarded as a form of contextualisation and placed accordingly.

Similarly, the major codes 'Assessing Capacity' and 'That's Dementia' felt quite similar. Whilst sorting the data I wondered whether these related to similar processes and could be merged but after revisiting the memos and re-reading the transcripts I became more aware of the active cognitive processes related to 'Assessing Capacity' as opposed to 'That's Dementia', which suggested that they should remain separate.

\section{Reflexivity}

Before and throughout the research I attempted to be aware of and transparent about my preconceptions, experiences and views in relation to ISB exhibited by older adults with a dementia that may have, consciously or otherwise, shaped my interpretations of the data. Ironically in August 2009 during data collection I experienced a second incident of ISB (verbal), exhibited by a client who had recently been given a diagnosis of dementia, whilst videoing myself for a university assignment. My immediate reaction to the comment and that of other people was laughter. What was really interesting was my anxiety about submitting the clip for assessment because my assessors had no context of this client or of the group and could construe me negatively. I used my diary to capture these thought processes (e.g., I laughed because I was not sure how else to respond) and remained mindful that these were $m y$ thoughts and interpretations. 


\title{
Reflective interview
}

According to Charmaz (2006) 'memos rely on spontaneity'. I attempted to be spontaneous and free flowing using my reflective dairy. Whilst I found this method useful, at times I felt as though something was lost in translation. My occasional frustration combined with Charmaz's (2006) encouragement to 'do whatever works for you' inspired me to approach my academic supervisor who I requested to interview me using the interview schedule. This took place in December 2008.

Arguably, using the interview to encapsulate my own thoughts and assumptions was potentially flawed because it occurred towards the end of data collection and therefore it possibly captured how the material had influenced my thinking, not necessarily how I influenced the material:

\begin{abstract}
"Do you think ISB differs from other forms of behaviour?" $\mathrm{Um}$ (.) I think it does. Um (..) I think, oh (.) I mean I've been the recipient of aggressive behaviours before (..) and it's not that they're acceptable (.) now you see I've got to be careful that I'm not picking up things that I've been reading in my research cause I have thought about this" (Interview).
\end{abstract}

However, I found the process extremely beneficial. In particular, being interviewed allowed me to appreciate the process as experienced by participants; the interview identified some of my own experiences and assumptions and where they differed or overlapped; lastly the interview supported me in elaborating my thoughts regarding the data.

\footnotetext{
H+ Bold italics denotes my academic supervisor
} 
"I suppose the question of how do you feel about having (.) responded to those questions as opposed to asking them? I think it's quite interesting to sit in the other chair, um (..) yeah, um, I think they make you think...they do make you think quite hard about where you position yourself. And they also throw up a heck of a lot in terms of where you've worked mm the teams that you've worked with. Um, what you think is sexual. I'm aware that I, in, in my mind, you know, I've got another lady who (.) stripped quite a lot but actually do I think that's sexual? Um, and I'm, I'm presuming that these are some of the issues that people are grappling with while they are sitting with me. Um (..) and in fact in just, whatever, thirty-forty minutes there's still so much, it's brought a lot of, it's made me think quite a lot I think" (Interview)

"And do you (..) sense any differences between ISB exhibited by someone who's in early onset (.) dementia versus someone who's in later stage? Mm. I think that's a really interesting question (.) and I think, er, that is something that has come (.) is coming out of the research and I've wondered where $\underline{I}$ stand on that. I suppose my two examples are quite interesting because the first client, um, with the frontal lobe dementia was probably further on in his dementia..." (Interview).

Regarding my own assumptions, I anticipated that participants would generally find ISB difficult to tolerate because of the client's age. However, with exception of a small 
minority, this was not the case. I also thought that participants would find discussing sex and sexuality challenging. However, on the whole I found that staff were very open to discussing their experiences of ISB and quick to recognise and normalise patient sexuality.

From a process point of view I found recollecting past experience difficult at times. Rather than vivid details I was reconstructing a sense of what occurred, which as discussed is a limitation of interviews.

\section{My Position as an External Researcher}

Dispassion and a lack of knowledge about the service being researched/evaluated are two facets of being an external researcher/evaluator (Barker, Pistrang \& Elliot, 2002). Regarding the former, I felt highly attached to the Hospital. My investment in the project and participants and efforts to become familiar with the Hospital facilitated positive working relationships. However, learning about the organisation and remaining in touch with new developments (e.g., moving from mixed gender to single gender wards) was difficult at times. Thankfully, my field supervisor was supportive and kept me updated accordingly.

\section{Supervision}

Regular supervision ensured that the research process was monitored, my analysis remained grounded and conversations about the emerging data encouraged new reflections that continued immersion in the analysis. It was useful to have access to 
significant clinical expertise in the area of older adult working and both supervisors remained curious and questioning throughout, which aided my thinking.

\section{My Learning}

“...I think that's something, again, that I've been thinking about because I think initially, who, who are staff? I'm staff. And trying to put myself into (.) into that context and actually rather than being critical, which perhaps I maybe did do (.) initially with my initial interests, I feel respect" (Interview).

I found being with participants and subsequently analysing their transcripts incredibly engaging. I was struck by the openness and honesty offered by staff in relation to what had the potential to be a very personal experience and was so humbled by their willingness to think together that after my fourth interview I began to send thank you letters to everyone who took part.

I also learned to own my own prejudices about staff working in inpatient settings. Based on previous experience, I had anticipated that generally staff would be pejorative towards people with a dementia, undermining person-centred care, which was erroneous. Furthermore, I learnt to appreciate the 'realities' of staff who, for instance, work hard to foster unilateral relationships with people who are unable to reciprocate. My own 'distance' through Clinical Psychology training and little access to inpatient acute settings for this client group possibly narrowed my vision, meaning that I lost touch with 
what it was like to work with this client group with a closed environment, that is, until conducting the research. This awareness had been beyond my construing.

\section{Personal Impact}

Sadly, my husband's Granddad was diagnosed with Alzheimer's disease during the research process. How my family related to him and the diagnosis put me in touch with the grief people experience when their father, granddad, husband and loved one mentally deteriorate. I began to realise the importance of recognising people's grief and sorrow (Davis, 2004), which resonated with the category 'Holding the Whole Person in Mind'. Some staff regarded themselves as the only family patients had and emphasised the importance of understanding people. Perceiving patients as diminishing and fracturing off the ISB could be seen as undermining personhood (Kitwood, 1997). However, staff held onto the individual by reminding themselves of their history and being in touch with their own sadness.

\section{Participant Wellbeing}

I was constantly mindful that discussing the psychological impact of ISB could be emotionally affecting and in addition to debriefing, time was spent at the end of the interview bringing the interaction back to general conversation.

As previously mentioned, several participants commented that the interview had raised thoughts and ideas that they had never considered before. One participant was left feeling uncomfortable because she felt that she had emphasised the role of age and was concerned that she may have portrayed herself as ageist: 
"And how did you find the experience of the interview? It was okay. It's quite (.) you know when you talk, start talking and, you know, I'm talking, I was very conscious that I'm talking about age quite a lot and I'm (.) almost ageist. I'm not ageist but I'm just very aware I guess that you know, I'm comparing, I'm not old by any means but I'm comparing sort of young school leavers with perhaps, you know, a mother of three, um and I don't know, I feel a little bit uncomfortable that I've done that in a respect. Um, but it's certainly not been intentional $\mathbf{m m}$ and just, and I guess the only reason I've related to that is because, you know, years ago I felt very differently and as time as gone on and I've matured and I've sort of you know had my experience, my whole way of dealing with matters is, is changed so..." (Kate, p75-76, 1853-1872).

I informed Kate that age had been raised in other interviews, which comforted her somewhat. This also reminded me that interviews, like therapy, are powerful tools and have the potential to facilitate ill-feeling as well as positive insight.

\section{My own Views towards Sexuality}

"Intimacy, affection and flirtation are positive and meaningful aspects of communication that may support and cement relationships with and between people with dementia" (Ward, Vaas, Aggarwal, Garfield \& Cybyk, 2005, p58). 
As a consequence of the research I have become more aware of sex in discourse and society, which has also been influenced by a programme I completed regarding personality development and psychodynamic thinking. Reading controversial works by early thinkers such as Sigmund Freud highlighted how deeply entrenched these discourses are within present-day society and also how sex and intimacy are often confused, which was one area that I, like many of the participants I spoke with, grappled with (e.g., is a stroking of the hand inappropriate?).

The differences in perception between male and female sexual expression was hugely fascinating and also poignant. Discussing this in supervision led to conversations regarding 'men don't cry' and the restrictions surrounding male intimacy. As Ward et al (2005) noted, positive sexual expression is often subsumed by problematic sexual behaviour. In addition to being more alert to sex and sexuality in dementia care, this research has heightened my awareness regarding the potential differences and marginalization of male sexual expression, an awareness and responsibility that I will take forward into my clinical practice.

\section{Concluding Thoughts}

I have often likened my research journey to climbing in the Lake District. With its many unanticipated and often arduous undulations, completing this piece of qualitative research has not always been 'a walk in the park'. From mapping my method to deliberating epistemologies, to setting out and encountering various avenues and horizons that I had not envisaged. The journey, however, has been engaging and liberating. Similarly, these findings will hopefully shape perspectives within the healthcare community about the 
different ways ISB can affect staff members and clients and will hopefully create new possibilities for support and research including attending to familial caregivers. 


\section{References}

Algaiakrishnan, D. L., Brahim, A., Wong, A., Wood, A., Senthilselvan, A., Chimich, W.T., \& Kagan, L. (2005). Sexually inappropriate behaviour in demented elderly people. Postgraduate Medical Journal, 81, 463-466.

Barker, C., Pistrang, N., \& Elliot, R. (2002). Research Methods in Clinical Psychology. $2^{\text {nd }}$ Eds. Wiley. Sussex.

Charmaz, K. (2006). Constructing Grounded Theory. A Practical Guide through Qualitative Analysis. Sage. London.

Davis, D. H. J. (2004). Dementia: sociological and philosophical constructions. Social Science \& Medicine, 58, 369-378.

Denzin, N. K, \& Lincoln, Y. S. (2000). Handbook of Qualitative Research. $2^{\text {nd }}$ Ed. Sage. London.

Department of Health. (2005). Elimination of Mixed-Sex Hospital Accommodation. Retrieved from the Web $26^{\text {th }}$ February 2009 from: http://www.dh.gov.uk/en/Publicationsandstatistics/Publications/PublicationsStatisti cs/DH_4112140

Edberg, A., K., Bird, M., Richards, D. A., Woods. R., Keeley. P., \& Davis-Quarrell, V. (2008). Strain in nursing care of people with dementia: Nurses' experience in Australia, Sweden and United Kingdom. Ageing and Mental Health, 12(2), 236243.

Fransella, F. (2005). The Essential Practitioner's Handbook of Personal Construct Psychology. Wiley. West Sussex. 
Grbich, C. (1999). Qualitative Research in Health - an Introduction. Sage. London.

Henwood, K., \& Pidgeon, N. (2003). In P. M. Camic, J. E. Rhodes \& L. Yardley (Eds). Qualitative Research in Psychology. Expanding Perspectives in Methodology and Design. American Psychological Association. London.

Holstein, J. A., \& Gubrium, J. F. (1995). The Active Interview. Qualitative Research Methods Series, 37. Sage. London.

Johnson, C., Knight, C., \& Alderman, N. (2006). Challenges associated with the definition and assessment of inappropriate sexual behaviour amongst individuals with an acquired neurological impairment. Brain Injury, 20, $687-693$.

Kitwood, T. (1997). Dementia Reconsidered: The Person Comes First. Open University Press. Buckingham.

Knight, C., Alderman, N., Johnson, C., Green, S., Birkett-Swan, L., \& Yorstan, G. (2008). The St Andrews Sexual Behaviour Assessment (SASBA): Development of a standardised recording instrument for the measurement and assessment of challenging sexual behaviour in people with progressive and acquired neurological impairment. Neuropsychological Rehabilitation, 18, 129-159.

Madill, A., Jordan, A., \& Shirley, C. (2000). Objectivity and reliability in qualitative analysis: Realist, contextualist and radical constructionist epistemologies. British Journal of Psychology, 91, 1-20.

Smith, J. A., \& Osborn, M. (2008). In J. A. Smith (Ed). Qualitative Psychology: a Practical Guide to Research Methods. Sage, London.

Strauss, A. L., \& Corbin, J. (1998). Basics of Qualitative Research: Techniques and Procedures for Developing Grounded Theory. $2^{\text {nd }}$ Ed. Sage. London. 
Ward, R., Vaas, A. A., Aggarwal, N., Garfield. C., \& Cybyk, B. (2005). A kiss is still a kiss? The construction of sexuality in dementia care. Dementia, 4(1), 49-72.

Yardley, L. (2000). Dilemmas in qualitative health research. Psychology and Health, 15, $215-228$. 
Appendix 1

Notes to Contributors: Aging and Mental Health 


\section{Aging \& Mental Health ${ }^{\S \S \S \S}$}

\section{Instructions for Authors}

Aging \& Mental Health welcomes original contributions from all parts of the world on the understanding that their contents have not previously been published nor submitted elsewhere for publication. We encourage the submission of timely review articles that summarize emerging trends in an area of mental health and aging, or which address issues which have been overlooked in the field. Reviews should be conceptual and address theory and methodology as appropriate. All submissions will be sent anonymously to independent referees. It is a condition of acceptance that papers become the copyright of the publisher.

\section{Manuscripts}

All submissions should be made online at Aging \& Mental Health's Manuscript Central site. New users should first create an account. Once a user is logged onto the site submissions should be made via the Author Centre.

Authors should prepare and upload two versions of their manuscript. One should be a complete text, while in the second all document information identifying the author should be removed from files to allow them to be sent anonymously to referees. When uploading files authors will then be able to define the non-anonymous version as "File not for review".

Books for review should be sent to Professor Murna Downs, Bradford Dementia Group, School of Health Studies, University of Bradford, Bradford BD5 0BB, UK.

All submissions should be in the style of the Publication Manual of the American Psychological Association (4th edition, 1994). Papers should be double spaced throughout (including the references), with margins of at least $2.5 \mathrm{~cm}$ (1 inch). All pages must be numbered.

The first page should include the title of the paper, first name, middle initial(s) and last name of the author(s), and for each author a short institutional address, and an abbreviated title (for running headlines within the article). At the bottom of the page give the full name and address (including telephone and fax numbers and e-mail address if possible) of the author to whom all correspondence (including proofs) should be sent. The second page should repeat the title and contain an abstract of not more than 250 words. The third page should repeat the title as a heading to the main body of the text.

Structured abstracts: The main text should be preceded by a short structured abstract, accompanied by a list of keywords. The abstract should be arranged as follows: Title of manuscript; name of journal; abstract text containing the following headings: Objectives, Method, Results, and Conclusion.

${ }^{\S \S \S}$ Retrieved from http://www.tandf.co.uk/journals/journal.asp?issn=1360-7863\&linktype $=44$ 
Key words: A list of 3-5 keywords should be provided. Words already used in the title should be avoided if possible

The text should normally be divided into sections with the headings Introduction, Methods, Results, and Discussion. Long articles may need subheadings within some sections to clarify their content. Within the text section headings and subheadings should be typed on a separate line without numbering, indentation or bold or italic typeface.

\section{Style guidelines}

Description of the Journal's article style

Description of the Journal's reference style, Quick guide

Any consistent spelling style is acceptable. Use single quotation marks with double within if needed.

If you have any questions about references or formatting your article, please contact authorqueries@tandf.co.uk (please mention the journal title in your email).

\section{Illustrations}

All illustrations (including photographs, graphs and diagrams) should be referred to as Figures and their position indicated in the text (e.g. Fig. 3). Each should be submitted numbered on the back with Figure number (Arabic numerals) and the title of the paper. The captions of all figures should be submitted on a separate page, should include keys to symbols, and should make interpretation possible without reference to the text.

Figures should ideally be professionally drawn and designed with the format of the journal (A4 portrait, $297 \times 210 \mathrm{~mm}$ ) in mind and should be capable of reduction.

\section{Tables}

Tables should be submitted on separate pages, numbered in Arabic numerals, and their position indicated in the text (e.g. Table 1). Each table should have a short, selfexplanatory title. Vertical rules should not be used to separate columns. Units should appear in parentheses in the column heading but not in the body of the table. Any explanatory notes should be given as a footnote at the bottom of the table.

\section{Proofs}

Proofs will be sent to the author nominated for correspondence. Proofs are supplied for checking and making essential typographical corrections, not for general revision or alteration. Proofs must be returned within 72 hours of receipt.

\section{Free article access}

Corresponding authors will receive free online access to their article through our website (www.informaworld.com) and a complimentary copy of the issue containing their article. Reprints of articles published in this journal can be purchased through Rightslink ${ }^{\circledR}$ when proofs are received. If you have any queries, please contact our reprints department at reprints@tandf.co.ulk 


\section{Copyright}

It is a condition of publication that authors assign copyright or licence the publication rights in their articles, including abstracts, to Taylor \& Francis. This enables us to ensure full copyright protection and to disseminate the article, and the journal, to the widest possible readership in print and electronic formats as appropriate. Authors retain many rights under the Taylor \& Francis rights policies, which can be found at www.informaworld.com/authors journals_copyright position. Authors are themselves responsible for obtaining permission to reproduce copyright material from other sources.

Aging \& Mental Health has a new editorial e-mail address: amh@ucl.ac.ulk. General enquires can be sent to m.orrell@ucl.ac.uk. 
Appendix 2

Overview of Qualitative Methods 
Attention to qualitative methods in psychology developed following the recognition that quantitative methods had failed to address the inherent subjectivity, dynamism and language of its subject: human beings (Parker, 1994). Some researchers argued that abstracting general principles/concepts and applying them across contexts forced data into pre-conceived boxes lacking depth and relevance (Charmaz, 2006). It is beyond the remit of this thesis to enter into a history of the debates surrounding quantitative and qualitative approaches (see Denzin \& Lincoln, 2000). Also, as Glaser and Strauss suggested (1967), rather than interpreting quantitative and qualitative approaches as separate paradigms, both are often necessary to address the area of interest.

According to Charmaz (2006) the advantage of qualitative methods is the ability for researchers to 'dispense with sensitising concepts' should they transpire to be of little ongoing relevance to the research question. This flexibility and responsiveness towards exploring the phenomena under investigation means that researchers do not become 'locked in' to pre-conceived boxes, a characteristic of many quantitative approaches. Grounded theory (GT) is one method that allows assumptions to be tested, not reproduced (Charmaz, 2006).

\section{Grounded Theory}

Grounded theory was developed by the sociologists, Glaser and Strauss (1967), in response to what they perceived as an over-emphasis on verification rather than "discovering what concepts and hypotheses are relevant for the area that one wishes to research “ ( $(\mathrm{p} 2)$. Grounded theorists seek patterns and variation within patterns to illuminate social and psychological processes, often to research previously unexplored 
areas (Heath \& Cowley, 2004; Henwood \& Pidgeon, 2003). Charmaz (2006) states that GT produces 'useful analytic frameworks' that enhance formal understandings across multiple substantive areas:

“...the logic of grounded theory can reach across substantive areas and into the realm of formal theory, which means generating abstract concepts and specifying relationships between them to understand problems in multiple substantive areas..." (p 8).

Grounded theory, like most qualitative methods, is not a 'unitary' approach (Henwood \& Pidgeon, 2003; Parker, 1994); it can be considered from a range of positions, the corpus of which is based in pragmatism or epistemology (Grbich, 1999). Kathy Charmaz (2006) presents the differences between objectivist and constructivist GT. Objectivist GT assumes that there is a free-floating reality 'out there' to be harnessed, written about and bestowed within the scientific community. In contrast a constructivist GT views theory production as an interpretation between the researcher and researched, both of which are situated within a context.

\section{Researcher's Epistemology ${ }^{* * * * * *}$}

A social constructivist GT was used for two reasons. Firstly, rather than explanation and prediction, as synonymous with an objectivist GT, the aims of this research sought to understand the phenomena of ISB by abstracting a theoretical framework. Secondly, this

\footnotetext{
${ }^{* * * * * *}$ Further details about this author's epistemological standpoint are provided in the Critical Appraisal.
} 
author believed that our 'realities' are essentially created and interpreted in interaction. No meaning is static, nor do we exist in a social vacuum (Charmaz, 2006; Cutliffe, 2000). Generalizability was regarded as a potential benefit of using GT but primarily the study hoped to invite conversations regarding ISB and to inform further research plus clinical practice. As generalisation was not the main aim of this study and because one cannot predict the direction theoretical sampling might take, a broad initial criteria was adopted and a diverse sample were invited to take part.

\section{Researcher's Relationship to GT}

This author had no prior experience of GT and after researching Interpretative Phenomenological Analysis (IPA) and compiling an 'advantages-disadvantages' list for each method this author felt positive that GT would allow her to respond to the aims of the study meaningfully and confidently. 


\section{Appendix 3}

Chronology of the Major Milestones in the Research Process 
June 2007

Research proposal reviewed by university panel

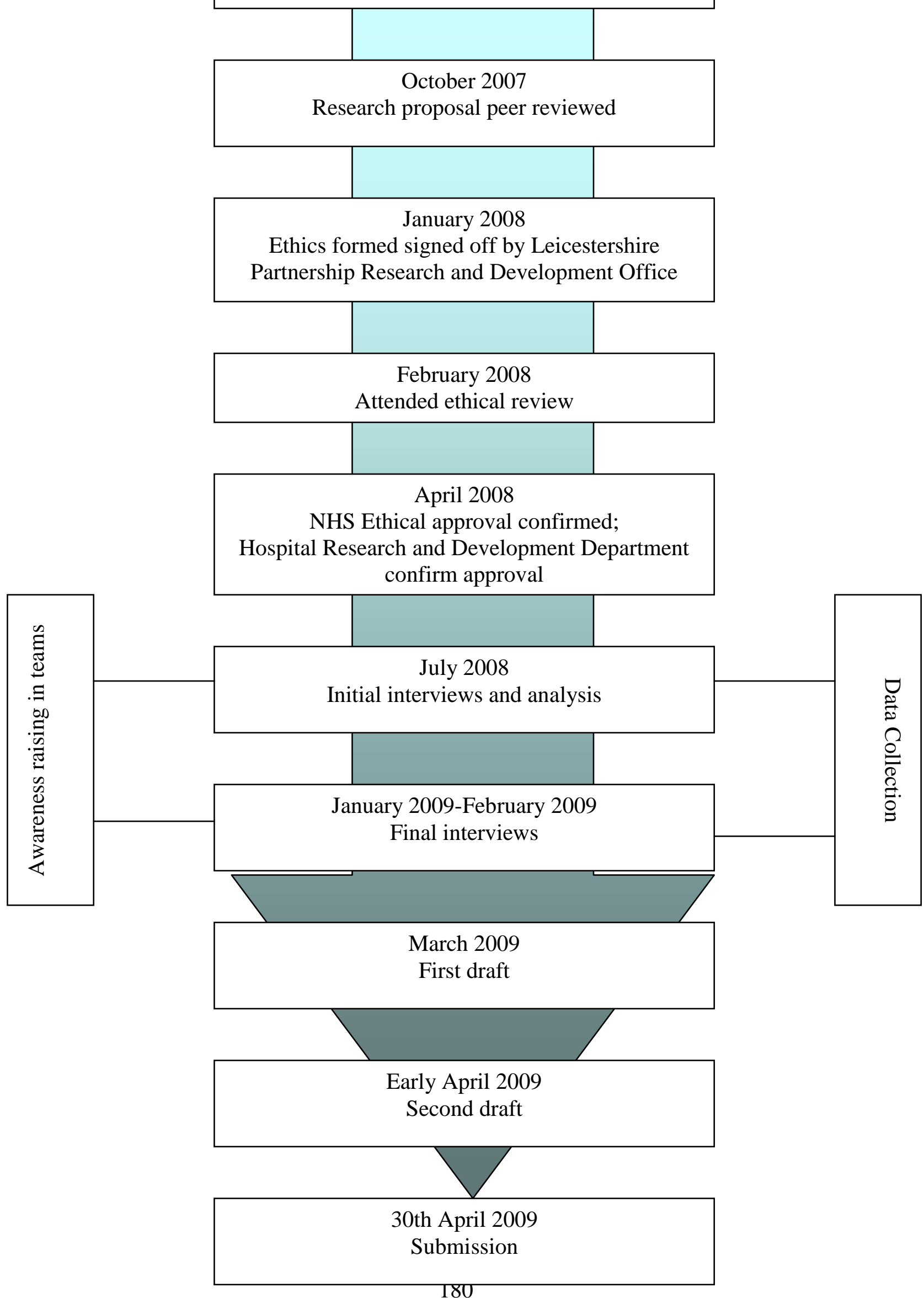


Appendix 4

Ethics Approval 


\section{Leicestershire, Northamptonshire \& Rutland Research Ethics Committee 2}

1 Standard Court Park Row Nottingham NG1 6GN

09 April 2008

Mrs Laura E Hayward

Clinical Psychology Trainee

Leicester University

School of Psychology Clinical Section

104 Regent Road

Leicester

LE1 7LT

Dear Mrs Hayward,

Full title of study: Inappropriate Sexualised Behaviour and Dementia; the

REC reference number: $\quad 08 / \mathrm{H0402/14}$ Impact on Staff in an In-Patient Setting

Thank you for your letter of 07 April 2008, responding to the Committee's request for further information on the above research and submitting revised documentation.

The further information has been considered on behalf of the Committee by the Chair.

\section{Confirmation of ethical opinion}

On behalf of the Committee, I am pleased to confirm a favourable ethical opinion for the above research on the basis described in the application form, protocol and supporting documentation as revised.

\section{Ethical review of research sites}

The Committee has designated this study as exempt from site-specific assessment (SSA). There is no requirement for [other] Local Research Ethics Committees to be informed or for site-specific assessment to be carried out at each site.

\section{Conditions of approval}

The favourable opinion is given provided that you comply with the conditions set out in the attached document. You are advised to study the conditions carefully. 


\section{Approved documents}

The final list of documents reviewed and approved by the Committee is as follows:

\begin{tabular}{|l|l|l|}
\hline Document & Version & Date \\
\hline Application & AB/122503/1 & 17 January 2008 \\
\hline Investigator CV: Supervisor & & 01 September 2007 \\
\hline Investigator CV & & 17 January 2008 \\
\hline Protocol & 4.1 & 08 April 2008 \\
\hline Summary/Synopsis: Abstract & 4.1 & 08 April 2008 \\
\hline Peer Review & & 24 September 2007 \\
\hline Interview Schedules/Topic Guides & 2 & 10 January 2008 \\
\hline Questionnaire: Demographics & 4.1 & 08 April 2008 \\
\hline Letter of invitation to participant & 4.1 & 08 April 2008 \\
\hline Participant Information Sheet & 4.1 & 08 April 2008 \\
\hline Participant Consent Form: To participate & 4.1 & 08 April 2008 \\
\hline Participant Consent Form: To be approached & 4.1 & 08 April 2008 \\
\hline Response to Request for Further Information & & 07 April 2008 \\
\hline
\end{tabular}

\section{R\&D approval}

All researchers and research collaborators who will be participating in the research at NHS sites should apply for R\&D approval from the relevant care organisation, if they have not yet done so. R\&D approval is required, whether or not the study is exempt from SSA. You should advise researchers and local collaborators accordingly.

Guidance on applying for $R \& D$ approval is available from http://www.rdforum.nhs.uk/rdform.htm.

\section{Statement of compliance}

The Committee is constituted in accordance with the Governance Arrangements for Research Ethics Committees (July 2001) and complies fully with the Standard Operating Procedures for Research Ethics Committees in the UK.

\section{After ethical review}

Now that you have completed the application process please visit the National Research Ethics Website > After Review

Here you will find links to the following

a) Providing feedback. You are invited to give your view of the service that you have received from the National Research Ethics Service on the application procedure. If you wish to make your views known please use the feedback form available on the website. 
b) Progress Reports. Please refer to the attached Standard conditions of approval by Research Ethics Committees.

c) Safety Reports. Please refer to the attached Standard conditions of approval by Research Ethics Committees.

d) Amendments. Please refer to the attached Standard conditions of approval by Research Ethics Committees.

e) End of Study/Project. Please refer to the attached Standard conditions of approval by Research Ethics Committees.

We would also like to inform you that we consult regularly with stakeholders to improve our service. If you would like to join our Reference Group please email referencegroup@nationalres.org.uk.

08/H0402/14

Please quote this number on all correspondence

With the Committee's best wishes for the success of this project

Yours sincerely,

\section{Mr Ken Willis/Miss Jeannie McKie \\ Chair/Committee Coordinator}

Email: jeannie.mckie@nottspct.nhs.uk

Enclosures: $\quad$ Standard approval conditions

Copy to: $\quad$ R\&D office for NHS care organisation at lead site - LPT 
Appendix 5

Themes Generated from the Pilot Interviews 


\section{Pilot Interview $1^{\dagger \dagger \dagger \dagger \dagger}$}

Job role

Experience of ISB

Themes
Pilot Interview 2

Assistant Psychologist (Hospital)

Various incidents. Previous role in forensic services

Palliative care; less hope of change increases people's sympathy and therefore staff are less likely to challenge ISB

Different ward ethos.

ISB different to other challenging behaviours; heightens anxiety
Trying to manage ISB in context of promoting normalisation principles (e.g., taking patients into the community)

Gender; males seen as more risky and of more personal significance.

Verbal comments most difficult to deal with as patient holding sexual ideas about you.

$\overline{\Pi \Pi \dagger}$ The schedule was not delivered in full as the interviewee had to take an important phone call part way through the interview. 
Appendix 6

Introduction Letter 
Date

Hello

I would like to invite you to take part in a research study. Before you decide whether or not to take part, you need to understand what the research is about and what it could mean for you. Please take your time to read the Participant Information Sheet that you will find enclosed with this letter. Also, feel free to talk to others about it if you wish. If you have any questions about the research please contact me by email or by phone.

You do not have to take part in the research if you do not want to.

If you would like to learn more about the study and are happy for me to contact you then I will need your consent to be approached. If this is the case please read, sign and date two copies of the Consent to be Approached form. Return one copy to me, Laura Hayward, using the internal mail system at _. Keep the other copy for your own records.

Once you have been approached and if you decide to participate then I will need your consent to take part in the study. A Consent to Participate from will be provided at that point for you to sign.

Thank you for taking the time to read this proposal.

Yours sincerely

Laura Hayward

Clinical Psychology Trainee

University of Leicester

DClinPsy 


\section{Appendix 7}

\section{Information Sheet}




\section{University of \\ Leicester}

\section{Participant Information Sheet}

I would like to invite you to take part in a research study that I am doing as part of my clinical psychology training. Before you decide whether or not to take part, it is important that you understand what the research is about and what it could mean for you. Please read the following information carefully. If you have any questions about the research please contact me by email or by phone. Please take your time to decide whether or not you want to participate and feel free to talk to others about the study.

\section{Title of study}

'Inappropriate Sexual Behaviour and Dementia; the Impact on Staff in an

In-Patient Setting'.

\section{Principal Investigator}

Laura Hayward, Clinical Psychology Trainee, University of Leicester.

\section{Co-Researchers}

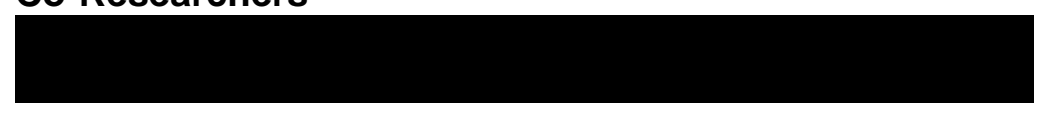

What is the purpose of the study?

Inappropriate Sexual Behaviour exhibited by older adults with a dementia is reported less frequently than other challenging behaviours, such as aggression. The impact of Inappropriate Sexual Behaviour (ISB) on staff who work with this client group is currently unknown. The purpose of this study is to explore staff experiences of ISB and the impact this might have on staff members.

\section{What is inappropriate sexual behaviour?}

Inappropriate Sexual Behaviour (ISB) has been defined as "a verbal or physical act of an explicit, or perceived, sexual nature, which is unacceptable within the social context in which it is carried out"

\section{Has the study been approved?}

Yes. This study has been approved by the School of Psychology at the University of Leicester, my academic and field supervisors plus the Research and Development Departments at Leicestershire Partnership Trust and

It has also been reviewed and approved by the Leicestershire, Northamptonshire and Rutland Local Ethics Committee 2 (LREC) a body appointed by the Strategic Health Authority. It consists of a number of people with various backgrounds, including health care. Their role is to consider the ethical merits of any research and whether the benefits if doing the research outweigh any disadvantages. Research cannot happen without LREC approval. 
I have only ever experienced one incident of ISB. Can I still take part?

Yes. Providing that you have experienced and can recall at least one incident of ISB exhibited by an older adult with a dementia you can take part.

\section{Do I have to take part?}

No. There is no obligation to take part in the study. Choosing not to take part will not affect you or your role in any way.

\section{What will happen to me if I decide to take part?}

If you are interested in taking part you will need to sign and date two copies of the Consent to be Approached form (attached) and return one to me at . I will then contact you by phone or meet with you in person to talk about the nature of the study. If you decide to take part in the study we will arrange an interview at which point you will be asked to sign and date a Consent to Participate form.

The interview will be held at on a date and at a time that is convenient for you. The interview will last for approximately one hour, although it can be shorter or longer if necessary. The interview will start with a brief questionnaire that will ask for basic information, such as 'how long have you worked with people with a dementia'?

The interview itself will be semi-structured and involve a number of open ended questions. The interview can be flexible and we can discuss a particular area should you feel it is important. The word 'interview' can seem quite formal; I hope that it will be more like a conversation about your experiences rather than a question and answer session. Do note that the purpose of the questions is to gain a richer understanding of your experiences; there are no right or wrong answers.

Interviews will be audio recorded with your consent so that they can be typed up and analysed by me at a later date. Once typed up the recordings will be destroyed.

Although unlikely, after analysing your transcript there is the possibility that I might recontact you for a further interview. This will be because something you have said in passing or alluded to in your initial interview becomes of interest and requires further exploration. This will only happen if I feel that your experiences are necessary to help deepen the research findings. If this occurs then I will contact you and providing you are happy to take part in a second interview, you will need to sign another Consent to Participate form.

\section{Will my contribution be confidential?}

Absolutely. Your data will be treated in accordance with the Data Protection Act. Information provided by you will be assigned a pseudonym (fictitious name) to protect your identity. Your actual details will be kept separately in a locked cabinet at

or at the University of Leicester. Details such as your age and length of work experience, for example, will be asked for in ranges (e.g., 'are you aged between 18 29; $30-39$ ' etc) to ensure anonymity. Any information that is kept on the computer will be password protected. Only I will have access to it.

There may be times during the analysis when my research supervisors read through your material (the transcripts) but they won't have access to your information. Your information and transcript will be kept in a locked place when not being studied. Once 
the research is over your transcript and accompanying information will be securely kept at the University of Leicester for a period of five years. It will be destroyed after that.

As part of my clinical psychology training it is hoped that my research will be published. Quotes from you may be used in the write-up but will be kept anonymous.

It is important to note that although all data will be treated in accordance with the Data Protection Act there may be instances when it becomes necessary to break confidentiality. For example, if you tell me anything that causes me concern regarding patient care then I have a duty to report this to a line manager. In the unlikely event of this occurring I will discuss my concerns with you as appropriate.

\section{What are the benefits of taking part?}

You may not experience any direct benefits of taking part in this study. However, taking part will help clinicians understand the impact of ISB on staff working with older adults with a dementia within an in-patient setting. It is hard to predict at this stage but your participation might help to develop training packages in relation to ISB and/or supervision practices, initiating support for staff working at__ and possibly in other settings. There could also be benefits for patients.

\section{What are the potential risks?}

Although at $\quad$ staff manage a range of difficult behaviours routinely, having the opportunity to reflect on some of these experiences in depth, in particular ISB, may provoke discomfort or upset. Should this happen during interview, it is important that you make me aware so that we can either break or if necessary, stop the interview.

I will be available for the duration of my training (up to September 2009) should you need to contact me about taking part. (Consultant Clinical Psychologist) will also be available should you need to discuss any aspects of the research, especially anything that you are unhappy with. In addition, the Care First Employee Assistance Programme is available to you for independent support.

\section{What happens if something goes wrong?}

If you have reason to complain about any aspect of the study, the 1 and NHS complaints mechanisms are available to you. You may also contact my Academic Supervisor, , at the University on 0116223

In the event that something goes wrong and you are harmed during the research because of someone's negligence then you may have grounds for legal action for compensation against Leicestershire Partnership Trust. Please note that you may have to pay legal costs.

\section{What happens if I change my mind and don't want to participate?}

Your participation is voluntary and you are free to withdraw your contributions prior to data analysis and publication. Your material will be removed and destroyed on your request. You do not have to justify your decision. Deciding to withdraw will not affect you or your role in any way. 


\section{What will happen with the results of the study?}

The results will form my thesis that will be submitted as part of my doctorate in clinical psychology. Following this it is hoped that the study will be published in a journal and be presented at a conference.

\section{I am already taking part in a research project. Does this matter? \\ Deciding to take part in more than one study is your choice. However, being involved in multiple research projects can be physically and emotionally tiring. If you are involved in other research and still want to participate in this study then perhaps this is something we can discuss on our first contact.}

\section{I would like to take part. What do I do now?}

Sign and date the two copies of the Consent to be Approached form and return one to me at , keeping the other copy for your reference. I will then ring you to discuss the study in more detail, which could be done on the telephone or face-to-face, whichever you prefer. Agreeing to be approached does not mean that you have to take part in the study and following our conversation you will be required to sign and date a Consent to Participate form if you decide to take part.

\section{Contact Details}

Phone: 07967136271

Email: $\quad \underline{\text { leh22@le.ac.uk }}$

Address: Laura Hayward, Clinical Psychology Trainee, School of Psychology, Clinical Section, 104 Regent Road, Leicester, LE1 7LT

Thank you for taking the time to think about taking part in my study. 


\section{Appendix 8}

Consent to be Approached Form 


\section{S. University of \\ Leicester}

\section{Consent to be Approached}

\section{Title of study}

'Inappropriate Sexual Behaviour and Dementia; the Impact on Staff in an In-Patient Setting'.

\section{Name of Principal Investigator}

Laura Hayward, Clinical Psychology Trainee, University of Leicester

I have read and understood the Participant Information Sheet and am interested in taking part in the study.

I know that I can withdraw my participation at any time.

I am happy for you to contact me so that we can discuss the research.

My preferred contact details are:

Name:

Signature:

Date:

Please let me know if you have any preferences regarding when I can contact you: 
Appendix 9

Consent to Participate Form 


\section{University of Leicester}

\section{Consent to Participate}

Please make sure you have read and fully understand the Participant Information Sheet before deciding whether or not to take part in this study. If you have further questions about the study please do not hesitate to contact me.

\section{Title of study}

'Inappropriate Sexual Behaviour and Dementia; the Impact on Staff in an In-Patient Setting'.

\section{Name of Principal Investigator}

Laura Hayward, Clinical Psychology Trainee, University of Leicester

\section{Contact details}

Phone: $07967136271 \quad$ Email: leh22@le.ac.uk

Address: $\quad$ Laura Hayward, Clinical Psychology Trainee, School of Psychology, Clinical Section, 104 Regent Road, Leicester, LE1 7LT

\begin{tabular}{|l|l|}
\multicolumn{2}{|c|}{ Please Circle } \\
$\begin{array}{l}\text { I confirm that I have read and understand the Participant Information Sheet for the } \\
\text { above study. }\end{array}$ & Yes No \\
\hline $\begin{array}{l}\text { I have been given the opportunity to consider the information, ask questions and } \\
\text { have had these answered satisfactorily. }\end{array}$ & Yes No \\
\hline $\begin{array}{l}\text { I understand that my participation is voluntary and that I am free to withdraw prior to } \\
\text { analysis without justification and without my role at being affected. }\end{array}$ & Yes No \\
\hline $\begin{array}{l}\text { I consent to my interview being audio taped with possible use of verbatim } \\
\text { quotations in the write-up of the research. }\end{array}$ & Yes No \\
\hline $\begin{array}{l}\text { I understand that transcripts collected during the study will be anonymised and may } \\
\text { be looked at by supervisors from the University of Leicester and } \\
\text { permission for these individuals to have access to my transcripts. }\end{array}$ & Yes No \\
\hline \begin{tabular}{l} 
I agree to take part in the above study \\
\hline
\end{tabular}
\end{tabular}

Participant Name (please print): Researcher Name (please print):

Participant Signature: Researcher Signature:

Date:

Date:

Once completed please return this form to Laura Hayward. Thank you 
Appendix 10

Initial Interview Schedule 


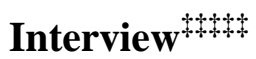

\section{Experience}

1. Tell me about your experience/s of Inappropriate Sexual Behaviour (ISB) exhibited by a person with a dementia?

2. Tell me about your reactions when you first encountered ISB.

3. Have your reactions to ISB changed over time? If so, what are your reactions now?

\section{Making Sense}

4. How do you make sense of ISB exhibited by someone with a dementia?

5. How (if at all) has this changed over time?

6. What do you think causes someone with a dementia to behave this way?

\section{Patient Group}

7. Do you think ISB exhibited by people with a dementia is different to ISB exhibited by other groups of people?

\section{Impact}

8. How does ISB exhibited by a person with a dementia affect you?

9. How does ISB exhibited by a person with a dementia affect the way you work?

10. What aspects of ISB do you find most difficult (if any)?

11. Do you think these behaviours differ from other forms of inappropriate behaviours? If so, how?

\section{Responding}

12. How do you feel about responding to ISB?

13. How able do you feel in responding to ISB?

14. How does this compare to how others respond to ISB?

\section{Reporting}

15. Tell me about how you report ISB.

16. What are your thoughts about reporting ISB?

\section{Support}

17. What kind of support do you get in managing ISB on a day-to-day basis?

18. Is there anything you would like to change regarding the type/frequency of support you receive in relation to ISB?

\footnotetext{
\$+स Probes have been removed due to word constraints and can be provided on request.
} 
Appendix 11

Example of Coding 
Appendix 12

Supporting Quotes 


\section{Main Category: Beyond My Construing}

*1 “... I wasn't sort of scared but I was sort of (.) 'what do I do'? You know, do I pretpretend I hadn't noticed?” (Beth, p9, 213-215).

*2 "...I think aggression, most people expect if you like whereas sexualised behaviour not, not as frequently certainly and it's not something, it's not something you're prepared for really even through your training. It's just something you have to learn to deal with", (Kate, p65, 1588-1593).

*3 'I don't know why but you wouldn't necessarily expect that sort of behaviour from somebody with dementia” (Rachel, p7, 165-167).

*4 “I didn't think it would happen. No, no, course not [laughs]. No don't be silly. An, an older gentleman would never say an inappropriate comment like that" (Sam, p49, 1443-1446).

* 5 "... an older adult sort of saying things to me like, sort of, just felt a bit strange cause I've never ever experienced that before. Um, you know, it'd always been younger people" (Grace, p6, 137-141).

*6"...he just turned round and looked at me and says, 'give me a wank'... What was that like for you? Well it was a shock because I'd never (.) you know, see him do anything like that before" (Eileen, p45, 1087-1095).

\section{Main Category: Contextualising}

*7 "...it would be the way that I feel when it's said to me that I would feel it's sexual or I'd feel that, I'd feel it's not sexual" (Grace, p.25, 609-611).

*8 “...I suppose instinctively aggression is potentially more (..) physically (..) dangerous... a lot of sexual inhibition very often doesn't physically affect you” (Julie, p27, 654-658).

*9 “...I just think if you understand something it helps you process it much more easily and helps you deal with it happening than if you have no understanding of it and you just see it at face value" (Grace, p42, 1038-1042).

*10 "...it depends if I see it as inappropriate sexual behaviour, because depending, I usually (.) tend to look at the history of the patient..." (Christopher, p4, 92-94).

*11 “...if they've got a history of, of sexual abuse before they became, you know, before they suffered from dementia, um (.) then obviously there-there would pro (.) more than probably be a link (.)... between their past behaviour and, and their behaviour now. Um 
but if not (.) I mean I suppose I, I would perhaps just, it was a misfiring of the brain" (Steve, p18, 429-438).

*12 “...sexually disinhibited behaviour maybe isn't the norm but (..) you kind of get (...) I think cause we have patients in for quite some time you kind of get to know (.) who's going to display what...So you prepare for it in a way I suppose" (Rachel, p48, 11621168).

*13 “...I'm aware that in other wards, forensic wards where patients, some of them have dementia (.) their history is what determines staff to record it. It's not about the dementia because although they've got dementia, or they, they, are in early stages of dementia they are still capable of probably doing whatever they want to do. But their past, their past is still shadowing them..." (Christopher, p34, 823-831).

*14 “...they've all obviously still got the same urges as everybody else whether they're ill or not $\mathbf{m m}$ you know so I mean they probably haven't had a loving relationship for a long, long time so they still get these urges now and again, which you have to try and understand even though they're ill' (Eileen, p10, 224-232).

*15 “...you look at their history and there's photos of them in their younger days with their wife and their (.) children, how they were. And then you look at em and like, you think 'oh you know, what a shame. They're shells of people, you know. They're minds have gone" (Helen, p33-34, 814-820).

*16 “...sometimes it's a bit borderline and you're not really sure if it is really sexually inappropriate or they're (female patients) just being friendly. ”(Mike, p8, 189-191).

*17 “... I've not worked with a great many females that have had sort of sexually inappropriate behaviour, um, apart from disrobing perhaps, um, going in and sitting on somebody's lap. A gentleman's lap, for example. Um (.) I've never come across a lady sort of masturbating as I would with a man quite regularly..." (Kate, p31, 749-756).

*18 “I don't have many [experiences of ISB] because I'm a man it's [laugh] usually, er, and most of the clients we've got here are (..) are men, they tend not to do that...I don't see myself as a target as much as if I was a woman" (Christopher, p9-10, 223-232).

*19 “...I think if you are a female working in an all male environment it's something .hhh you can almost sort of anticipate, um, and you're probably more observant of it... er, whereas when you're working with older females there might be things that happen that you might just dismiss as not being (.) sexually inappropriate or you might not pick up (Kate, p32, 771-781).

\section{Main Category: Interpreting}

*20 “...I do think that people with later stages of dementia are considered to be more unaware. It's not always the case but I think it's how people perceive almost not (.) 
almost not in- they can't help their actions...I've worked with people with earlier onset if you like and early stages of the journey of dementia, um (.) and I think people think it's a bit more intentional because they come across as more able. They're able to communicate properly with you, they're able to express a lot of their needs whereas somebody who's perhaps older and, and further sort of, um, more severe dementia can 't do that" (Kate, p25-26, 602-624)

*21 “Intention as opposed to awareness in a sick patient. I don't know...From the sort of background he came from it may have been the sort of thing he said all the time, if you know what I mean. I mean it might have been quite a, an appropriate, not appropriate, it might have been (..) within his, the sort of thing that he would (..) say to a women" (Julie, p34, 809-826).

*22 “...it's not the intention behind the behaviour, it's the behaviour itself, which might be a problem so." (Grace, p27, 669-671).

*23 “Words come out. They're pretty meaningless in terms of (..) how they affect me. They don't affect-they don't affect me like that. I'm dealing with patients whose minds are not right." (Julie, p29, 690-693)

*24 "So I may feel (..) shocked. I may feel alarmed. I may feel, um, worried or anxious. But it wouldn't be to a degree that would impact (.) or, or last to be honest. That, that's how I, I (.) again as I say, my, my experiences are relatively limited in sort of, terms of, of actually witnessing or experiencing and of those things they haven't been high or severe and they're not regular either" (Neil, p70, 1708-1717).

*25 “...when you're caring for someone as well and they just come out with a comment I just find it very distressing” (Sam, p7, 171-173).

*26 “I found it quite [laughs] quite er, quite disturbing really because we, we don't get any (.) $\mathbf{m m}$ on $X$ [ward] and it had been a long time since (.) since I've experienced before" (Steve,p4, 84-90).

*27 “...I felt quite angry and the staff were as well. Um, and also the patients. He'd had an impact on those as well..." (Helen, p44, 1074-1075).

*28 “...I suppose initially I was a bit cross” (Mike, p7, 156-157)

*29 “...it's still a taboo isn't it? People don't want to talk about sexual behaviour and, because it's very much (...) to the interpretation of who saw it or who experienced it and, and sometimes people feel scared to talk about it..." (Christopher, p55, 1356-1361).

*30 “...it's quite helpful to discuss it in ward round $\mathbf{m m}$ because of colleagues and just to see hear their experiences, um, just try and help rationalise it and put it into perspective really" (Mike, p39, 932-937) 
*31 “...if it weren't for your team, people who you work with and people just talking about general, you know, situations about what's happened, um (..) I think you would feel quite isolated that you think it was only happening to you..." (Anna, p50, 1230-1235).

*32 “"...I don't think here people have the understanding, I don't think it's talked about enough...that's one of the reasons why I, I came forward to $\underline{\mathbf{m m}}$ do this" (Anna, p6, 132139).

\section{Main Category: Dealing With}

*33 “... you do become desensitised and what probably someone outside the profession might look on as sexual we just look on it in our days work” (Beth, p2, 45-48).

*34 "I'm a lot more sort of calm and collected about it now and less phased by it. Which I don't know if it's a good thing or a bad thing really. Mm. In wh-in what way? Um, well, because I think its, like with, with violence... you get .hhh more tolerant and more comfortable then, you know, it could happen and you're less risk aware that it could happen. You know again and put yourself in more vulnerable positions" (Mike, p16, 375-394).

*35 "I'm not saying it's acceptable but I (.) I do accept that it, it could happen potentially" (Kate, p4, 78-79).

*36 “I think younger people are more open to, um, speaking about, um (.) people's needs perhaps in the bedroom..." (Kate, p60-61, 1485-1488).

*37 "What about the one in ten? How do you handle those situations um where you can't maybe distract or? I would probably say um, 'that's inappropriate', or, you know, 'you can stop that I'm old enough to be your daughter', you know, that sort of thing" (Eileen, p26, 623-630).

*38 "...I mean this was a young (.) you know, strong, male and I just (.) I, I think I, perhaps I even seem like a rabbit in the headlights. I was just, it really, really upset me. And because I could choose where I worked I didn't go there again" (Beth, p24, 567572).

*39 "I'll say something along the lines of, 'that's not appropriate'. Mm. Or, you know, 'pl-please don't say anything like that..." (Sam, p8, 175-180).

*40 "...we are a dementia unit and I think that is, um (..) you know, taken into consideration...I do think other wards deal with it in different, well, I do think (.) they deal with it in a different way (..) but I think you still feel the same in any aspect" (Anna, p59, 1445-1456). 
*41 “They don't see it as a risk so, the only recordings they do is obvious sexual behaviour like masturbating or (.) taking clothes off in a public area of the ward, that's the only recordings they tend to do" (Christopher, p36, 877-881). 